$\frac{135}{9.24} F$ Renetore $a+B$ fournal

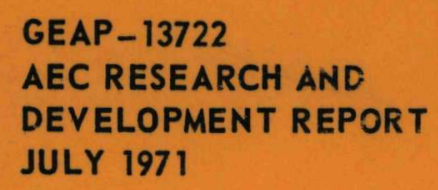

\title{
PERFORMANCE TESTS OF SODIUM-FILLED POWDER AND PELLET OXIDE FUEL UNDER TRANSIENT OVERPOWER
}

T. HIKIDO

J. H. FIELD

U.S. ATOMIC ENERGY COMAISSION

CONTRACT AT $(04-3)-189$

PROJECT AGREEMENT 10

\section{GENERAL ELECTRIC}




\section{NOTICE}

This report was prepared as an account of work sponsored by the United States Government. Neither the United States nor the United States Atomic Energy Commission, nor any of their employees, nor any of their contractors, subcontractors, or their employees, makes any warranty, express or implied, or assumes any legal liability or responsibility for the accuracy, completeness or usefulness of any information, apparatus, product or process disclosed, or represents that its use would not infringe privately owned rights. 


\section{DISCLAIMER}

This report was prepared as an account of work sponsored by an agency of the United States Government. Neither the United States Government nor any agency Thereof, nor any of their employees, makes any warranty, express or implied, or assumes any legal liability or responsibility for the accuracy, completeness, or usefulness of any information, apparatus, product, or process disclosed, or represents that its use would not infringe privately owned rights. Reference herein to any specific commercial product, process, or service by trade name, trademark, manufacturer, or otherwise does not necessarily constitute or imply its endorsement, recommendation, or favoring by the United States Government or any agency thereof. The views and opinions of authors expressed herein do not necessarily state or reflect those of the United States Government or any agency thereof. 


\section{DISCLAIMER}

Portions of this document may be illegible in electronic image products. Images are produced from the best available original document. 
AEC Research and Development Report

July 1971

This report was prepared as an account of work sponsored by the United States Government. Neither the United States nor the United States Atomic Energv Commission, nor any of their employees, nor any of their contractors, subcontractors, or their employees, makes any warranty, express or implied, or assumes any legal liability or responsibility for the accuracy, completeness or usefulness of any information, apparatus, product or process disclosed, or represents that its use would not infringe privately owned rights.

\title{
PERFORMANCE TESTS OF SODIUM-FILLED POWDER AND PELLET OXIDE FUEL UNDER TRANSIENT OVERPOWER
}

\author{
T. Hikido
}

J. H. Field

Approved:

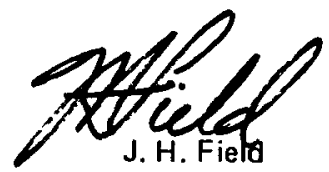

Principal Project Engineer
Approved:

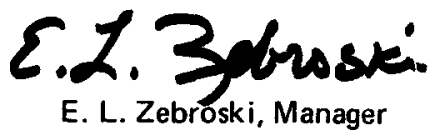

Development Engineering

Prepared for the

United States Atomic Energy Commission

Under Contract No. AT(04-3)-189

Project Agreement No. 10 


\section{TABLE OF CONTENTS}

ABSTRACT . . . . . . . . . . . . . . . . . . . . . . . . . . . . 1

1. INTRODUCTION . . . . . . . . . . . . . . . . . . . . . . . . . . . . . 1

2. SUMMARY AND CONCLUSIONS . . . . . . . . . . . . . . . . . . . . . . . . . . 3

2.1 Summary . . . . . . . . . . . . . . . . . . . . . . . . . . . . . . 3

2.2 Conclusions . . . . . . . . . . . . . . . . . . . . . . . . . . . . . 3

3. PROCEDURE AND RESULTS . . . . . . . . . . . . . . . . . . . . . . . . . . . . . 3

3.1 Transient Irradiation . . . . . . . . . . . . . . . . . . . . . . . . . . 4

3.2 Post-Irradiation Examination . . . . . . . . . . . . . . . . . . . . . . . . . . . . . . . . . .99

3.3 Discussion of Results . . . . . . . . . . . . . . . . . . . . . . . . . . 31

REFERENCES . . . . . . . . . . . . . . . . . . . . . . . . . . . . . . . 34

APPENDICES

A EQUIPMENT DESCRIPTION . . . . . . . . . . . . . . . . . . . . . . . 35

B SERIES 6 HEAT TRANSFER ANALYSIS MOdEL . . . . . . . . . . . . . . . . . . . . . . . . . 43

C SODIUM VAPOR FORMATION AND EXPANSION CALCULATIONS . . . . . . . . . . . . . . . . . . 49

ACKNOWLEDGMENTS . . . . . . . . . . . . . . . . . . . . . . . . . . . . 51

DISTRIBUTION . . . . . . . . . . . . . . . . . . . . . . . . . . . . 53 
$\bullet$

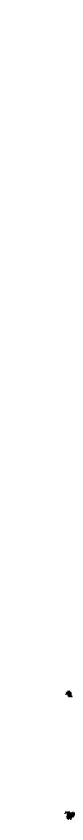




\section{LIST OF ILLUSTRATIONS}

Figure

Title

1.1 Series C6 Capsule Assembly Schematic . . . . . . . . . . . . . . . . . . . . . . . . . . . . . 2

3.1 Calculated and Measured Sodium Coolant Temperatures Versus Time, Capsule C6B, TT 1308-442 MW-sec 6

3.2 Calculated Fuel Temperature Versus Radius and Time, Capsule C6B, TT 1308-442 MW-sec . . . . . 7

3.3 Transient Energy Study, Specimen C6B-3 (Gas-Bonded Pellet), TT 1308-442 MW-sec . . . . . . . . . . 8

3.4 Calculated and Measured Sodium Coolant Temperatures Versus Time, Capsule C6A, TT $1312-485$ MW-sec 10

3.5 Calculated Fuel Temperature Versus Radius and Time, Capsule C6A, TT 1312-485 MW-sec . . . . . 11

3.6 Transient Energy Study Capsule C6A - Specimen C6A-3 (Gas-Bonded Pellet), Specimen C6A-1 (Sodium-Filled Pellet) TT 1312-485 MW-sec . . . . . . . . . . . . . . . . . . . . 12

3.7 Neutron Radiograph of C6B Inner Capsules Following Transient Irradiation, TT 1308-442 MW-sec . . . 13

3.8 Specimen C6B-1 (Sodium-Filled Pellet) Transverse Sample Showing Fuel Microstructure at the Fuel Column Midplane . . . . . . . . . . . . . . . . . . . . . . . . . . . . . 14

3.9 Specimen C6B-1 (Sodium.Filled Pellet) Longitudinal Sample Showing Molten Fuel Movement Into Space Between Pellets. . . . . . . . . . . . . . . . . . . . . . . . . . . . . . 15

3.10 Specimen C6B-2 (Sodium-Filled Powder) Transverse Sample Showing Fuel Microstructure at the Fuel Column Midplane . . . . . . . . . . . . . . . . . . . . . . . . . . . . . . 16

3.11 Specimen C6B-2 (Sodium-Filled Powder) Longitudinal Samples . . . . . . . . . . . . . . 17

3.12 Specimen C6B-3 (Gas-Bonded Pellet) Transverse Sample Showing Fuel Microstructure at the Fuel Column Midplane . . . . . . . . . . . . . . . . . . . . . . . . . . 19

3.13 Specimen C6B-3 (Gas-Bonded Pellet) Longitudinal Sample . . . . . . . . . . . . . . . . . 20

3.14 Specimen C6B-3 (Gas-Bonded Pellet) Longitudinal Sample . . . . . . . . . . . . . . . . . . 21

3.15 Specimen C6B-3 (Gas-Bonded Pellet) Longitudinal Sample . . . . . . . . . . . . . . . . 22

3.16 Neutron Radiograph of C6A Inner Capsules Following Transient Irradiation, TT 1312-485 MW-sec . . 23

3.17 Specimen C6A-1 (Sodium-Filled Pellet) Transverse Sample Showing Fuel Microstructure at the Fuel Column Midplane . . . . . . . . . . . . . . . . . . . . . . . . . . . . . . . . 24

3.18 Specimen C6A-1 (Sodium-Filled Pellet) Longitudinal Sample Showing Once-Molten Fuel in Space between Fuel Pellets . . . . . . . . . . . . . . . . . . . . . . . . . . . . . . . 25

3.19 Specimen C6A-2 (Sodium-Filled Powder) Transverse Sample Showing Fuel Microstructure at the Fuel Column Midplane . . . . . . . . . . . . . . . . . . . . . . . . . . . . . 26 


\section{LIST OF ILLUSTRATIONS (Continued)}

3.20 Specimen C6A-2 (Sodium-Filled Powder) Longitudinal Sample . . . . . . . . . . . . . . . . . 27

3.21 Specimen C6A-3 (Gas-Bonded Pellet) Transverse Sample Showing Fuel Microstructure at the

Fuel Column Midplane . . . . . . . . . . . . . . . . . . . . . . . . . . . . . . . . . 28

3.22 Specimen C6A-3 (Gas-Conded Pellet) Longitudinal Sample . . . . . . . . . . . . . . . . . . 29

3.23 Specimen C6A-3 (Gas-Bonded Pellet) Longitudinal Sample . . . . . . . . . . . . . . . . . 30

3.24 Capsule C6B Transverse Fuel Sections Illustrating the Effects of Sodium Within the Fuel Pin

TT 1308-442 MW-sec . . . . . . . . . . . . . . . . . . . . . . . . . . . . . . . 32

3.25 Capsule C6A Transverse Fuel Sections Illustrating the Effects of Sodium Within the Fuel Pin,

$\mathrm{TT} 1312.485 \mathrm{MW}$-sec . . . . . . . . . . . . . . . . . . . . . . . . . . 33

A.1 Series 6 Fuel Pin Assembly, Sodium-Filled Specimens . . . . . . . . . . . . . . . . . . . . . . . . 37

A.2 Series 6 Fuel Pin Assembly, Gas-Bonded Specimens . . . . . . . . . . . . . . . . . . . . . 38

A.3 Series 6 TREAT Capsule Assembly . . . . . . . . . . . . . . . . . . . . . . . . . . . . . . . . . . 39

A.4 High Pressure Sodium Filling System, Schematic . . . . . . . . . . . . . . . . . . . . 40

A.5 System for Filling Fuel Pins with Sodium . . . . . . . . . . . . . . . . . . . . . . . . 41

B.1 Series 6 Heat Transfer Analysis Model Schematic . . . . . . . . . . . . . . . . . . . . . . 44

B.2 Instantaneous and Integrated Power Versus Time for TT 1308 and TT 1312 . . . . . . . . . . . 45

B.3 Calculated Fuel Melt Radius, Fuel Melt Fraction, and Fuel Temperature Versus Time, C6B-3

(Gas-Bonded Pellet), TT 1308-442 MW-sec . . . . . . . . . . . . . . . . . . . . . . . . . . . . . . . . . 46

B.4 Calculated Fuel Melt Radius, Fuel Melt Fraction, and Fuel Temperature Versus Time, C6A-3

(Gas-Bonded Pellet), TT 1312-485 MW-sec . . . . . . . . . . . . . . . . . . . . . . . . . 47

B.5 Calculated Fuel Melt Radius, Fuel Melt Fraction, and Fuel Temperature Versus Time, C6A-1

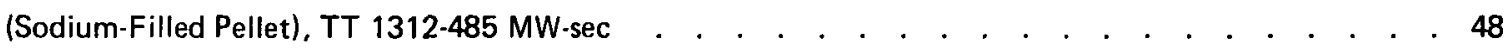


GEAP-13722

\section{LIST OF TABLES}

Table

Title

Page

3.1 Treat Parameters for Series VI Transients . . . . . . . . . . . . . . . . . . . . . . . . . . 4

3.2 Summary of Transient Test Results, Computed . . . . . . . . . . . . . . . . . . . . . . . . . 5

A.1 Series VI Fuel Pin Parameters . . . . . . . . . . . . . . . . . . . . . . . . . . . 36

A.2 Fill System Operating Parameters and Sodium Volumes . . . . . . . . . . . . . . . . . 36

$\mathrm{vii/viii}$ 



\begin{abstract}
The behavior of sodium-filled fuel pins in power transients was investigated using two experimental capsules in the TREAT (transient) facility. Each capsule contained three slightly enriched 0.250-inch 0.d., stainless steel clad $\mathrm{UO}_{2}$ fuel specimens. The three specimens (reference gas-bonded pellet, sodium-filled pellet, and sodium-filled powder) arranged side-by-side, were compared with regard to fuel temperatures, mechanical deformations, and post-irradiation appearance. There were no failures even though over fifty area percent of the gas-bonded pellet fuel specimen melted. The increased heat transfer afforded by the sodium resulted in significantly lower fuel temperatures in those two fuel pins.
\end{abstract}

\title{
1. INTRODUCTION
}

The dynamic and neutronic response of large fast ceramic reactor cores to sudden reactivity additions or rises in power are among the central problems in the analysis and design for the safety of such reactors. Of particular importance is the response and performance of the fuel, cladding, and coolant, during conceivable accidental power excursions. Realistic experimental information on the behavior of LMFBR fuel and cladding, with particular emphasis on failure limits and mechanisms, is required for the orderly design, safety analysis, and licensability of this reactor concept.

This report covers one of a continuing series of experiments aimed at defining the failure limits and mechanisms of LMFBR fuel under severe overpower conditions.

The purpose of this current series (Series VI) of tests was to evaluate the transient performance of defected or sodium-filled fuel. The experiments included both pellet and powder fuel to determine relative performance limits and failure mechanisms under transient overpower conditions. The tests were not intended to provide detailed answers, but were designed as scoping experiments to indicate whether or not there is a significant safety penalty associated with defected fuel or sodium-filled fuel.

The tests were performed with 24-inch length, 0.250 -inch o.d. oxide $\left(\mathrm{UO}_{2}, 10 \% \mathrm{U}-235\right)$ fuel specimens in the Transient Reactor Test Facility (TREAT). Each capsule assembly, C6A and C6B, contained three separate inner capsule assemblies installed side-by-side in a triangular array. Two of the inner capsules contained a pellet fuel pin, one of which was sodium filled; and the third capsule contained a sodium-filled powder fuel pin. Figure 1.1 shows a schematic view of the major components of the capsule.

Data obtained from the Series VI tests complement information obtained from the following ongoing or completed experiments conducted under this program:

Series $I^{1}$ was primarily directed toward fuel development for the Experimental Fast Ceramic Reactor which is now known as SEFOR.

Series II irradiations ${ }^{2}$ were concerned with the investigation of the fuel and cladding transient performance of 0.250-inch diameter mixed-oxide fuel with zero burnup.

Series III irradiations ${ }^{3,4}$ were designed to investigate the added effects of short and long term steady-state irradiation on fuel and cladding transient performance.

The purpose of the Series IV irradiations ${ }^{5}$ is to evaluate the effects of axial restraint, density, composition, and burnup.

Series $V$ irradiations $^{6}$ investigated the effects of molten fuel movement, fission product gases, and fuel and blanket lengths, on transient failure thresholds and mechanisms.

Series VI experiments compared the performance of sodium-filled (or defected) fuel pins, both pellet and powder, with that of a reference gas-bonded pellet fuel pin under severe transient power excursions.

This report presents the results and conclusions obtained from the initial experiment performed under Series VI of the test program. 

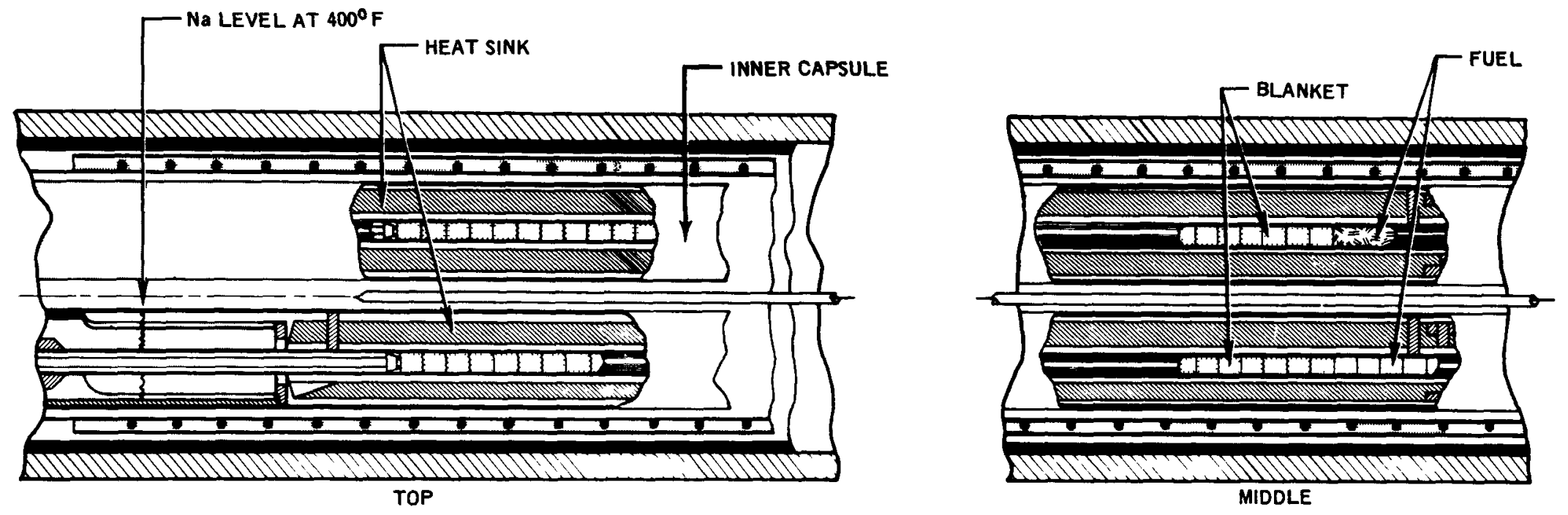

$\dot{\sim}$
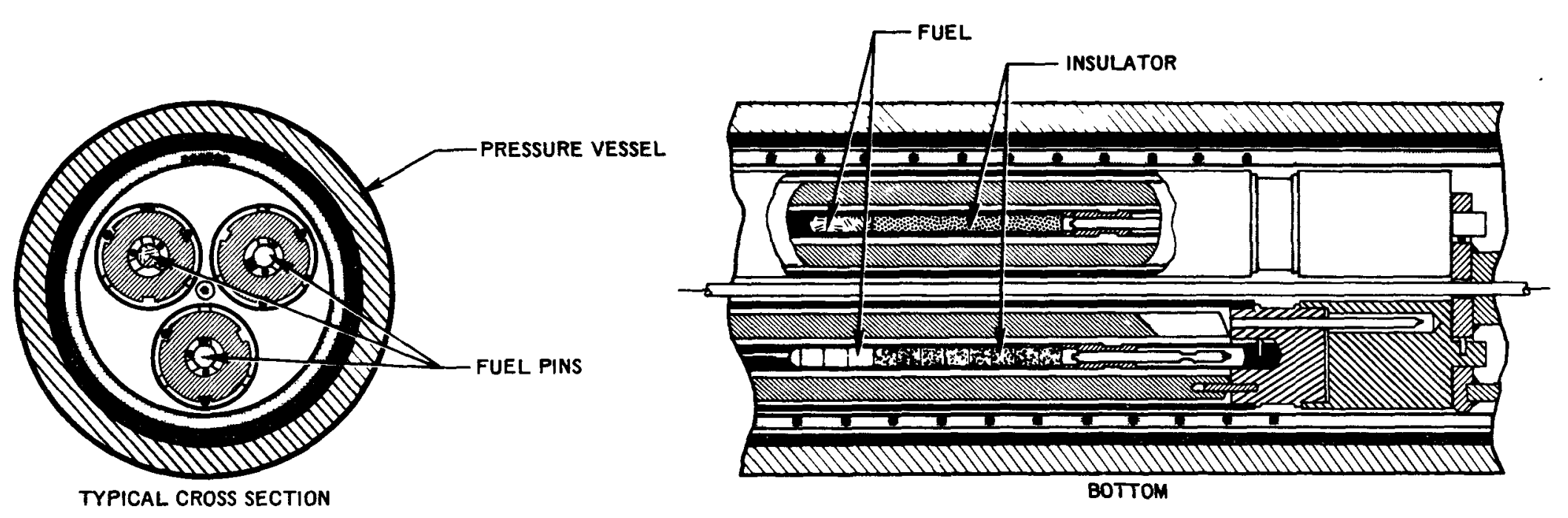

FCR TREAT CAPSULE

Figure 1.1 Series C6 Capsule Assembly Schematic 


\section{SUMMARY AND CONCLUSIONS}

\subsection{SUMMARY}

Transient irradiations of two capsule assemblies (each containing two sodium-filled specimens, one pellet and one powder, and one gas-bonded pellet specimen), designated C6A and C6B, were conducted in the TREAT facility at the National Reactor Testing Station (NRTS) in Idaho. The sodium-filled specimens simulated a failed fuel pin condition. The simultaneous exposure of the gas-bonded and sodium-filled specimens provided direct comparison of behavior under identical transient conditions. Prior steady-state irradiation was not a prerequisite for the initial tests of this series. Peak specimen power during the transient was equivalent to $\sim 232 \mathrm{~kW} / \mathrm{ft}$ for $\mathrm{C} 6 \mathrm{~A}$. Total specimen transient energies of $\sim 338 \mathrm{cal} / \mathrm{gm}$ for $\mathrm{C} 6 \mathrm{~B}$ and $\sim 371 \mathrm{cal} / \mathrm{gm}$ for $\mathrm{C} 6 \mathrm{~A}$, resulted in molten fuel volumes (gas-bonded specimens) of $\sim 47 \%$ for $\mathrm{C} 6 \mathrm{~B}$ and $\sim 60 \%$ for $\mathrm{C} 6 \mathrm{~A}$.

The fuel specimens were composed of $\mathrm{UO}_{2}$ pellets or powder $(10 \% \mathrm{U}-235$ enrichment). Smeared density was $\sim 82 \%$ for all specimens. The fuel was contained in a 0.250 -inch o.d., 0.015 -inch wall, Type-316 stainless steel tube with a total active fuel length of 24 inches. A 15 -inch long natural $\mathrm{UO}_{2}$ blanket was located between the top end of the fuel and the plenum. The two capsule assemblies were identical.

None of the specimens experienced failure during the transients. Post-test observations from the two capsule tests were similar, differing only in fuel melt volumes. The gas-bonded pellet specimens contained irregularly shaped voids with evidence of fuel movement in both axial directions; sodium-filled powder specimens exhibited central voids and a fuel column extension of up to 2 inches; and the sodium-filled pellet specimens were observed to have some pellet separations and small central voids.

\subsection{CONCLUSIONS}

Interpretation and analysis of these transient overpower test results for zero burnup, slightly enriched $\mathrm{UO}_{2}$, sodium-filled pellet and powder and gas-bonded pellet fuel pins have led to the following conclusions:

- There is no apparent safety penalty associated with sodium-filled or failed fuel pins in a hypothetical overpower accident.

- Overpower conditions equivalent to a $\$ 1.50$ reactivity excursion on a $\$ 15 / \mathrm{sec}$ ramp did cause some damage but no failure of the sodium-filled fuel pins. The transient limits reached in these experiments correspond to extreme accident conditions in an LMFBR and are considered very unlikely or "terminal accidents." The transient input amounted to a total energy insertion of $\cong 1500$ watt-sec/gm of fuel.

- The presence of sodium in the fuel pin significantly reduced transient fuel center temperatures.

- The driving force exerted by the expansion of the gas in the fuel voids was sufficient to cause relocation of melted fuel axially in both directions.

The reduced fuel center temperatures and potential increase in safety margin support observations of previous short-term tests ${ }^{8}, 9$ with sodium-filled or failed fuel pins. The presence of sodium resulted in an apparent improvement in the effective fuel thermal conductivity as well as improved gap conductance. It should be noted, however, that long-term irradiation tests ${ }^{10}$ of sodium-filled mixed-oxide fuel pins have indicated fuel center temperatures higher than, or comparable to, gas-bonded fuel pins. In this case, the formation of fuel/sodium reaction products apparently negated any initial improvement in fuel thermal conductivity and gap conductance. Additional tests with pre-irradiated mixed oxide pins filled with sodium are desirable.

\section{PROCEDURE AND RESULTS}

The construction of the pins and capsules is described in Appendix A (Section A.1). The transient irradiation was performed at TREAT.

During each transient the temperatures of the sodium in two annuli were measured. These were (1) between clad and heat sink and (2) between heat sink and capsule. The location of the seven chromel-alumel thermocouples is shown in Figure A.3 in Appendix A.

A computer model using the THTD code (see Appendix B) accepted the energy input values and computed temperatures within the pin and in the two annuli. The parameters of the model (primarily conductances) were adjusted until the computed temperatures at the locations of the thermocouples matched the measured values. This is shown in Figures 3.1 and 3.4 . 


\subsection{TRANSIENT IRRADIATION}

The Series VI transient irradiation experiments involved a total of three transients (one calibration and two tests) on the two capsules. The TREAT reactor parameters for each transient are given in Table 3.1 and a compilation of pertinent specimen performance data is given in Table 3.2 .

\subsubsection{Capsule C6B}

Capsule C6B containing specimens C6B-1 (sodium-filled pellet), C6B-2 (sodium-filled powder), and C6B-3 (gas-bonded pellet) was subjected to two transients. The first was a calibration transient designed to verify physics and heat transfer calculations. Based upon the calibration test data, a test transient was designed to result in a molten fuel volume of $40-50 \%$ for the gas-bonded pellet pin (the expected failure threshold for zero burnup gas-bonded pellet pins. $)^{5}$ The results of the test transient are shown in Figures 3.1 and 3.2 . The steep rise of the coolant temperature traces for the sodium-filled pins compared to the gas-bonded pin should be noted. The sodium provided a path for increased heat transfer to the fuel pin surroundings (coolant channels and heat sink) resulting in lower fuel temperatures and initially higher coolant temperatures. reached.

In Figure 3.2 (and in 3.5) the time for the uppermost curve was chosen to show the maximum center temperature

The calculated coolant temperatures agreed very well with actual test data (thermocouples located at the fuel column midplane). The two inner coolant thermocouples are located 180 degrees apart. Differences between the two traces are due primarily to variations in the location and volume of sodium within the pin at this plane. The model used for this analysis is described in Appendix B. An effective fuel conductivity higher than for the fuel itself, and a larger fuel-clad gap conductance were employed to simulate the effects of sodium on the heat transfer characteristics.

Since a substantial amount of the energy is transferred to the capsule (the coolant channels and heat sink simulate the heat removal capability of the reactor system), the energy retained in the fuel, rather than the total energy deposited, is a more significant parameter in defining the threshold of failure for this fuel. The total energy deposited in the fuel pin (C6B-3, gas-bonded pellet) and the energy retained in the fuel are shown together as a function of time in Figure 3.3. Note the substantial difference between the two curves at the peak energy levels. Utilizing temperature data from previous calculations (coolant temperature correlations) and enthalpy tables for the capsule component materials, the energy retained in the fuel was calculated. Knowing the total energy deposited and enthalpy for each material at any temperature, a simple summation process gives the energy retained in the fuel.

Table 3.1

TREAT PARAMETERS FOR SERIES VI TRANSIENTS

$\begin{array}{cccccr}\text { Capsule } & \begin{array}{c}\text { Treat } \\ \text { Transient } \\ \text { number/date }\end{array} & \begin{array}{c}\text { Initial } \\ \text { Period* } \\ \text { (sec) }\end{array} & \begin{array}{c}\text { Reactivity } \\ \text { Addition* } \\ \text { (\%) }\end{array} & \begin{array}{c}\text { Integrated } \\ \text { Power* } \\ \text { (MW-sec) }\end{array} & \begin{array}{r}\text { Peak } \\ \text { Power** } \\ \text { (MW) }\end{array} \\ \text { C6B } & 13053-25.70 & 0.60 & 0.76 & 95 & 31 \\ \text { C6B } & 13084-14-70 & 0.088 & 1.71 & 442 & 900 \\ \text { C6A } & 13125-14-70 & 0.083 & 1.78 & 485 & 1064\end{array}$

* As reported from TREAT instrumentation

* $\quad$ Calculated from integrated power (TREAT data); estimated accuracy $\pm 5 \%$ 
Table 3.2

SUMMARY OF TRANSIENT TEST RESULTS, COMPUTED

\begin{tabular}{|c|c|c|c|c|c|c|}
\hline Specimen & $\begin{array}{c}\text { C6B-1 } \\
\text { Sodium } \\
\text { Filled } \\
\text { Pellet }\end{array}$ & $\begin{array}{c}\text { C6B-2 } \\
\text { Sodium } \\
\text { Filled } \\
\text { Powder }\end{array}$ & $\begin{array}{c}\text { C6B-3 } \\
\text { Gas } \\
\text { Bonded } \\
\text { Pellet }\end{array}$ & $\begin{array}{c}\text { C6A-1 } \\
\text { Sodium } \\
\text { Filled } \\
\text { Pellet }\end{array}$ & $\begin{array}{c}\text { C6A-2 } \\
\text { Sodium } \\
\text { Filled } \\
\text { Powder }\end{array}$ & $\begin{array}{c}\text { C6A-3 } \\
\text { Gas } \\
\text { Bonded } \\
\text { Pellet }\end{array}$ \\
\hline TREAT Transient No. & 1308 & 1308 & 1308 & 1312 & 1312 & 1312 \\
\hline Peak Specific Power (kW/ft) & $\sim 196$ & $\sim 196$ & $\sim 196$ & $\sim 232$ & $\sim 232$ & $\sim 232$ \\
\hline Total Specific Energy (cal/gm) & $\sim 338$ & $\sim 338$ & $\sim 338$ & $\sim 371$ & $\sim 371$ & $\sim 371$ \\
\hline Peak Fuel Temperature ( ${ }^{\circ} \mathrm{F}$ ) & 5419 & 5150 & 5620 & 5607 & 5253 & 6070 \\
\hline Peak Cladding Temperature ( ${ }^{\circ} \mathrm{F}$ ) & 1132 & 1214 & 860 & 1353 & 1350 & 960 \\
\hline Cladding Breached & No & No & No & No & No & No \\
\hline Cladding Deformation (\%) & $<0.5$ & $<0.8$ & $\sim 0.4$ & 0.5 & $\sim 1.6$ & $<0.5$ \\
\hline Molten Fuel Volume (\%) & $\sim 21$ & * & $\sim 47$ & $\sim 28$ & * & $\sim 60$ \\
\hline Fuel Movement & No & Some & Some & Some & Some & Some \\
\hline Central Void & No & Yes & Yes & Yes & Yes & Yes \\
\hline
\end{tabular}

* Molten fuel boundaries were not clearly defined 

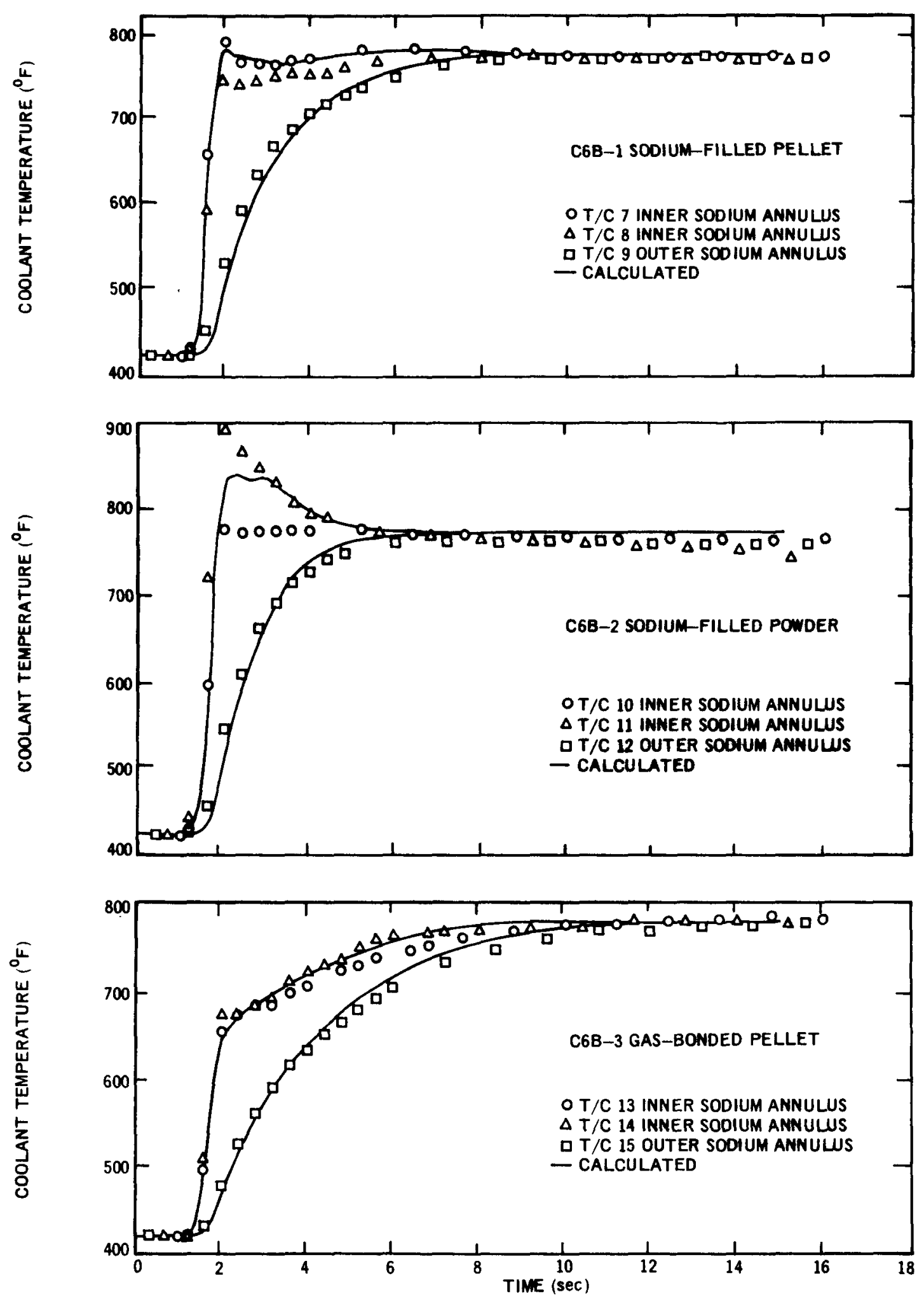

Figure 3.1 Calculated and Measured Sodium Coolant Temperatures Versus Time, Capsule C6B, TT 1308-442 MW-sec 
C6B-3 GAS-BONDED PELLET

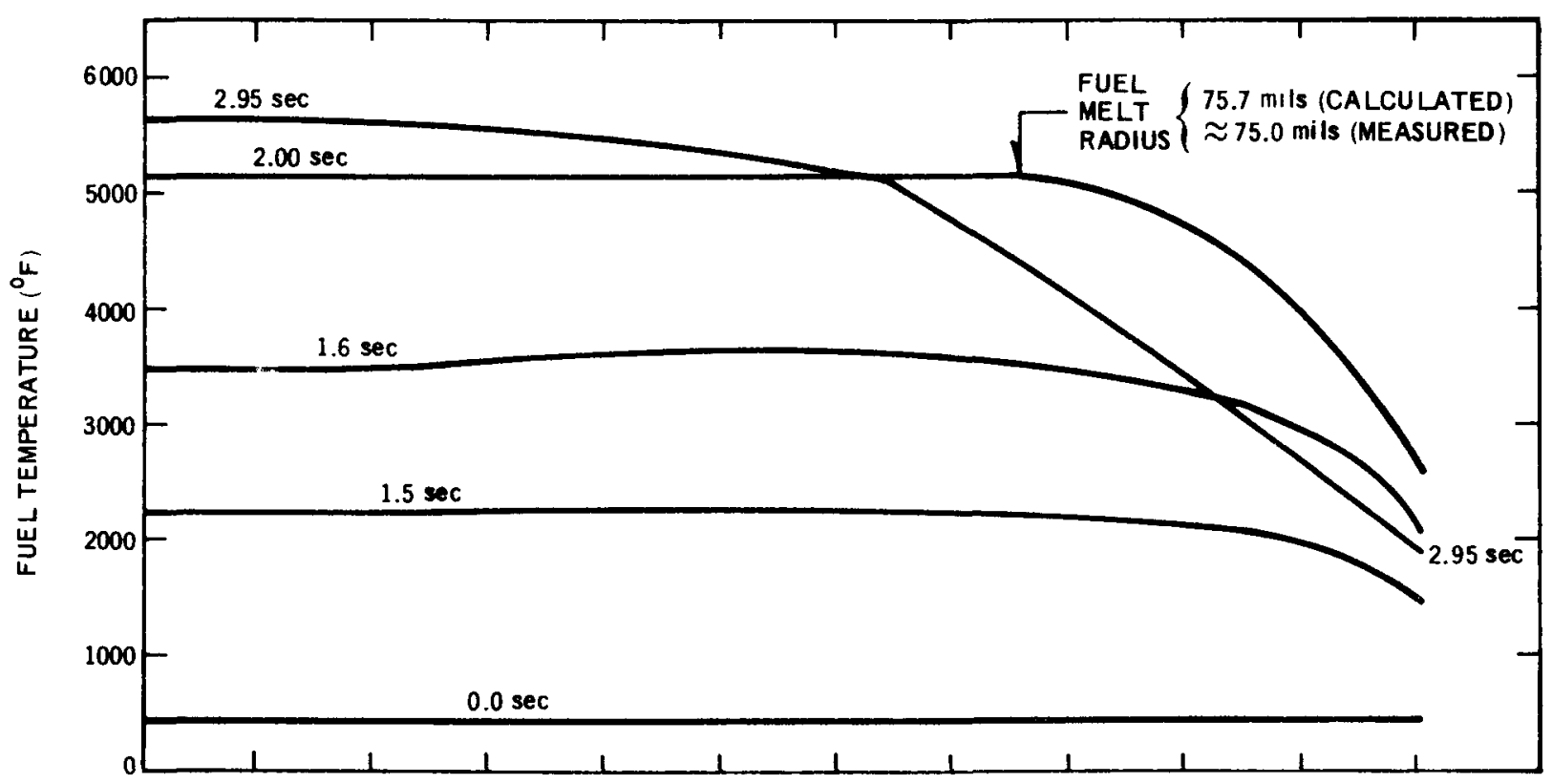

C6B-1 SODIUM-FILLED PELLET

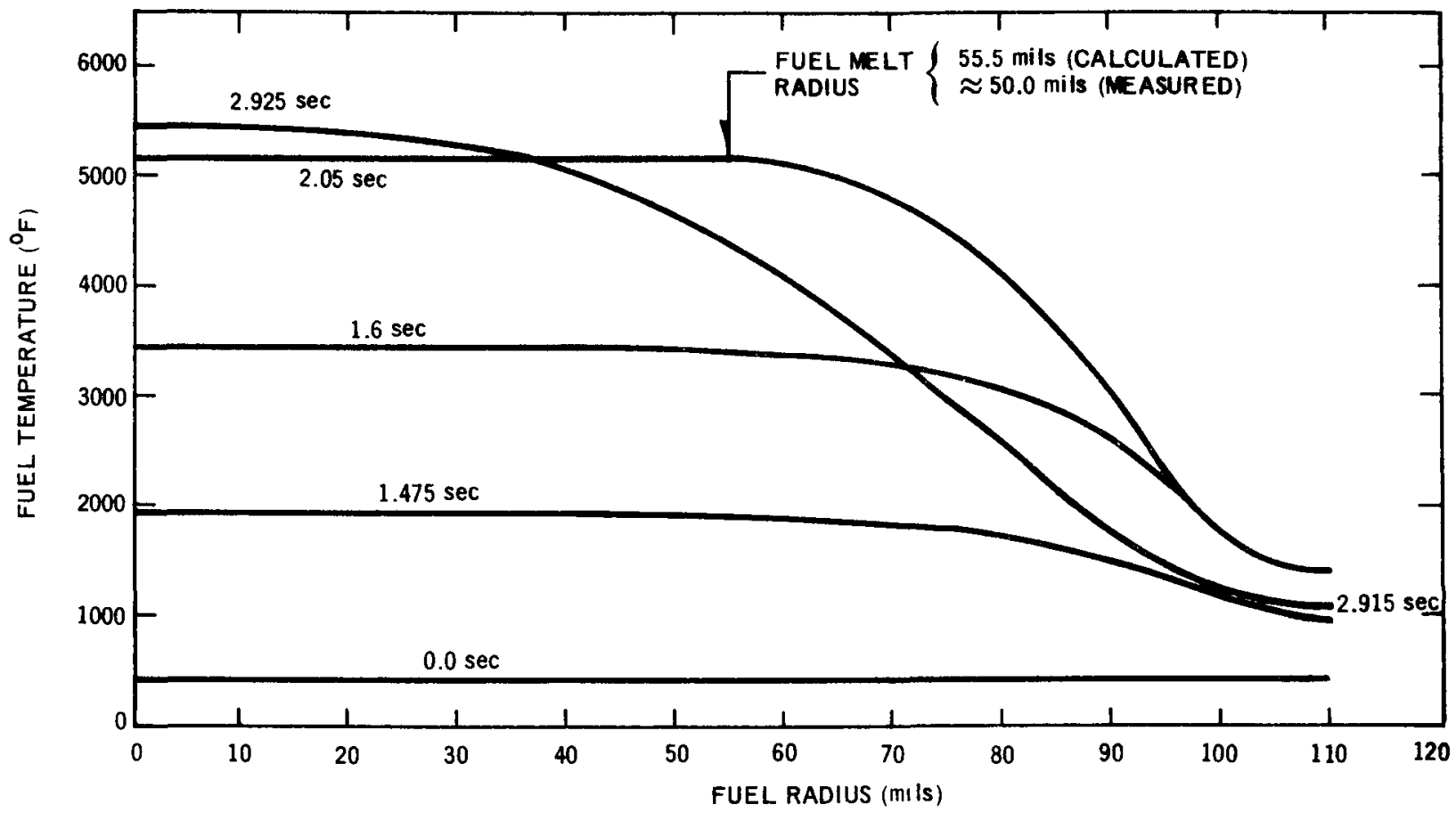

Figure 3.2 Calculated Fuel Temperature Versus Radius and Time, Capsule C6B, TT $1308-442$ MW-sec 


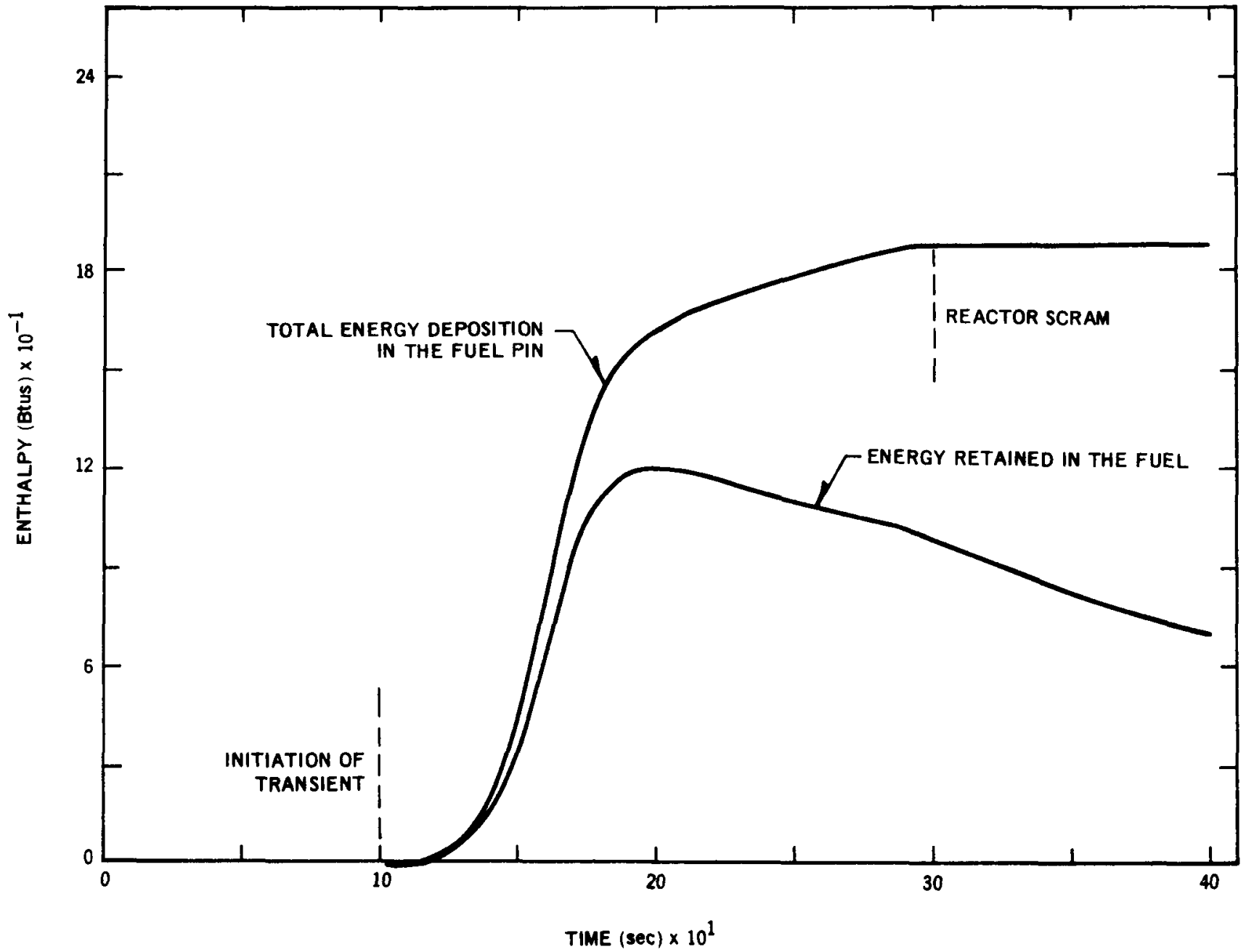

Figure 3.3 Transient Energy Study, Specimen C6B-3 (Gas-Bonded Pellet), TT 1308-442 MW-seC 


\subsubsection{Capsule C6A}

Since the two capsules were identical, a calibration transient for capsule C6A was not scheduled. The test transient design was based upon results of the two transients for C6B. In an attempt to "bracket" the failure threshold limits for the configurations tested, a transient with a total energy input approximately $10 \%$ greater than TT 1308 (C6B) was programmed.

Measured and calculated sodium coolant temperature data for the C6A specimens are shown in Figure 3.4 and 3.5. With the exception of small differences in peak temperatures (sodium-filled specimens), there was very good agreement between actual and calculated data. The trends noted in the C6B test results also occur here.

Results of the energy density study for the gas-bonded pellet specimen (C6A-3) are shown in Figure 3.6. Shown for comparison are the results for the sodium-filled pellet specimen (C6A-1). A comparison of the curves of retained energy reveals the marked effect of sodium within the fuel pin.

\subsection{POST-IRRADIATION EXAMINATION}

\subsubsection{Capsule C6B}

Although there were no indications of fuel pin failures from the test data, the complete capsule assembly was 'neutron radiographed at TREAT to verify preliminary examination results. With fuel pin integrity confirmed, the capsule was disassembled and inner capsules removed for destructive examination. The neutron radiograph of the three inner capsules (C6B-1, C6B-2, and C6B-3) is shown in Figure 3.7 (locations of figures showing detailed examination results are included for reference). Refer to Appendix $A$ for capsule details.

\subsubsection{Specimen C6B-1, Sodium-Filled Pellet}

With the exception of slight separations between pellets, there were no gross changes evident in the fuel pin as a result of the transient irradiations. The inner capsule was disassembled and the fuel pin removed. Profilometer traces did not show any significant pin deformation other than pronounced ovality. Diametral differences between the two planes, $0^{\circ}-180^{\circ}$ and $90^{\circ}-270^{\circ}$, varied up to a maximum of $\cong 0.003$ inch.

The fuel pin was sectioned for detailed examination. Sections were selected to determine the fuel melt radius and to examine pellet separations. A two-step procedure was followed in the examination of the sodium-filled samples. The samples were initially ground and polished (in the "as-tested" condition) and then examined. Exposure of the samples to the air was kept to a minimum to prevent excessive oxidation. The samples were stored in kerosene to preclude oxidation when not in use. If there were no traces of fuel-sodium reaction products (none were seen in any of the sodium-filled samples), the sample was cleaned (sodium removed) and prepared for further metallographic examination. This procedure was followed for both $\mathrm{C} 6 \mathrm{~B}$ and $\mathrm{C} 6 \mathrm{~A}$ sodium-filled specimens.

A transverse section from the fuel column midplane is shown in Figure 3.8 (the location of this and subsequent samples referred to as fuel column midplane samples correspond to the thermocouple locations for which the data is shown in Figures 3.1 and 3.41. The boundary of the porous structure in the center of sample is irregular, probably due to variations in the location and quantity of sodium at this plane. The estimated melt radius was $\cong 0.050$ inch and the calculated fuel melt volume was $\sim 21 \%$ (see Appendix $B$ for details on interpretation of fuel melt radii and melt volumes). The cladding at this plane was examined and found to be free of any defects or damage as a result of the transients.

Figure 3.9 is a longitudinal section selected to examine an area where pellet separation had occurred. Although sodium has stained the sample, central fuel melting and some fuel movement at the interface can be seen.

\subsubsection{Specimen C6B-2, Sodium-Filled Powder}

The fuel column separated in several places and a narrow central void is visible. The most noticeable result is the extension ( $\sim 1.6$ inches) of the fuel column. Clad deformation (no ovality) was less than 0.002 inch $(\sim 0.8 \%)$. There were no other discrepancies noted.

Figure 3.10 is a transverse sample from the fuel column midplane. The random fuel microstructure changes illustrate the effect of the sodium. A fuel melt radius was not readily discernible from the sample shown. Microstructural changes are apparent but whether they are due to sintering or melting was not clear. The cladding at this point did not show any effects of the transient overpower conditions.

The longitudinal sections after grinding are shown in Figure 3.11. Figure 3.11(a) is the top end of the fuel column and Figure $\mathbf{3 . 1 1 ( b )}$ is at a column separation. The light-colored areas are sodium. During polishing the fuel sample shown in 3.11(a) was destroyed. The particles of fuel were apparently held in place only by the sodium. The other sample was successfully polished and revealed a structure [Figure 3.11(c)] similar to that seen in Figure 3.10. 

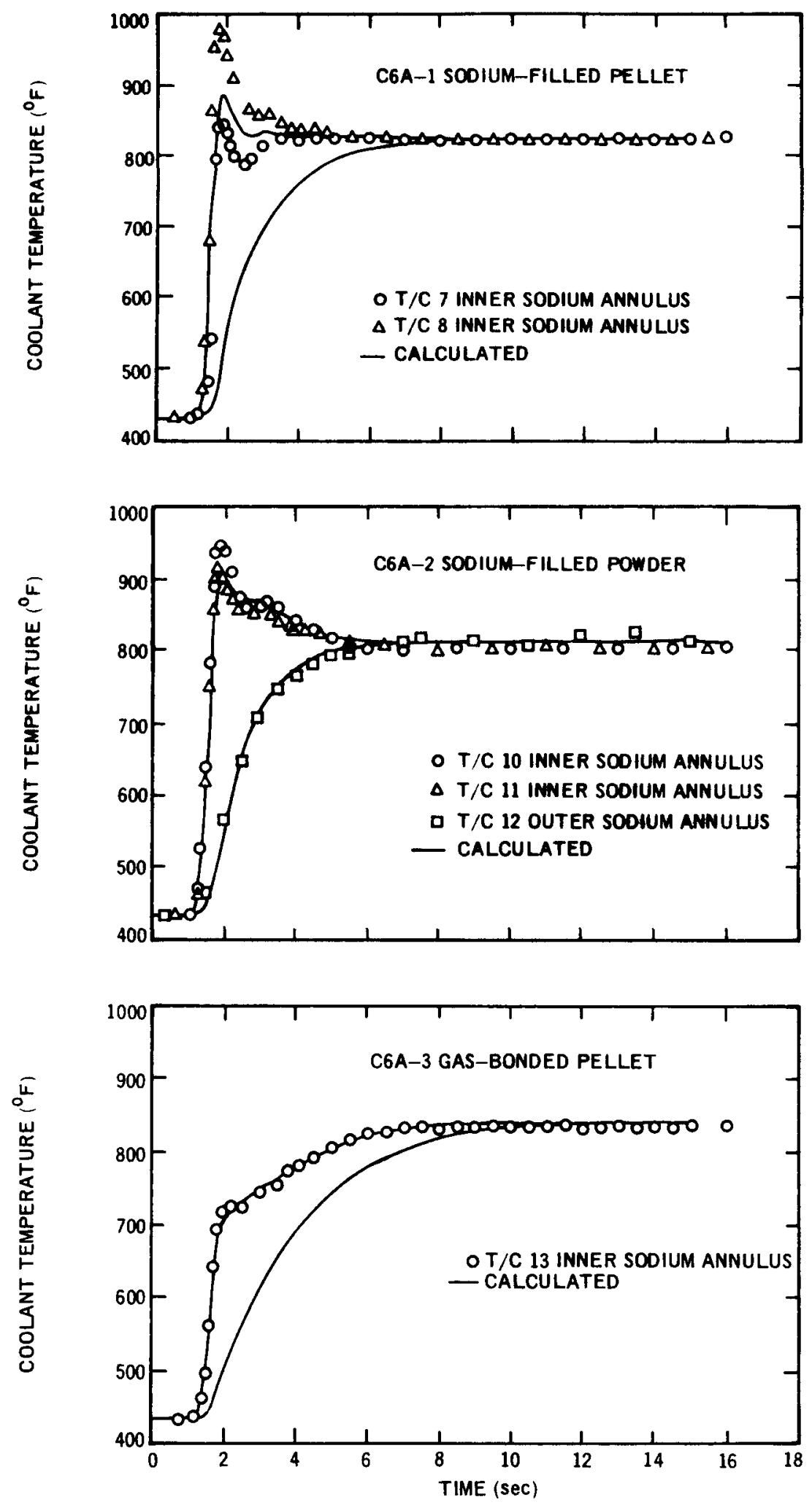

Figure 3.4 Calculated and Measured Sodium Coolant Temperatures Versus Time, Capsule C6A, TT 1312.485 MW-sec 

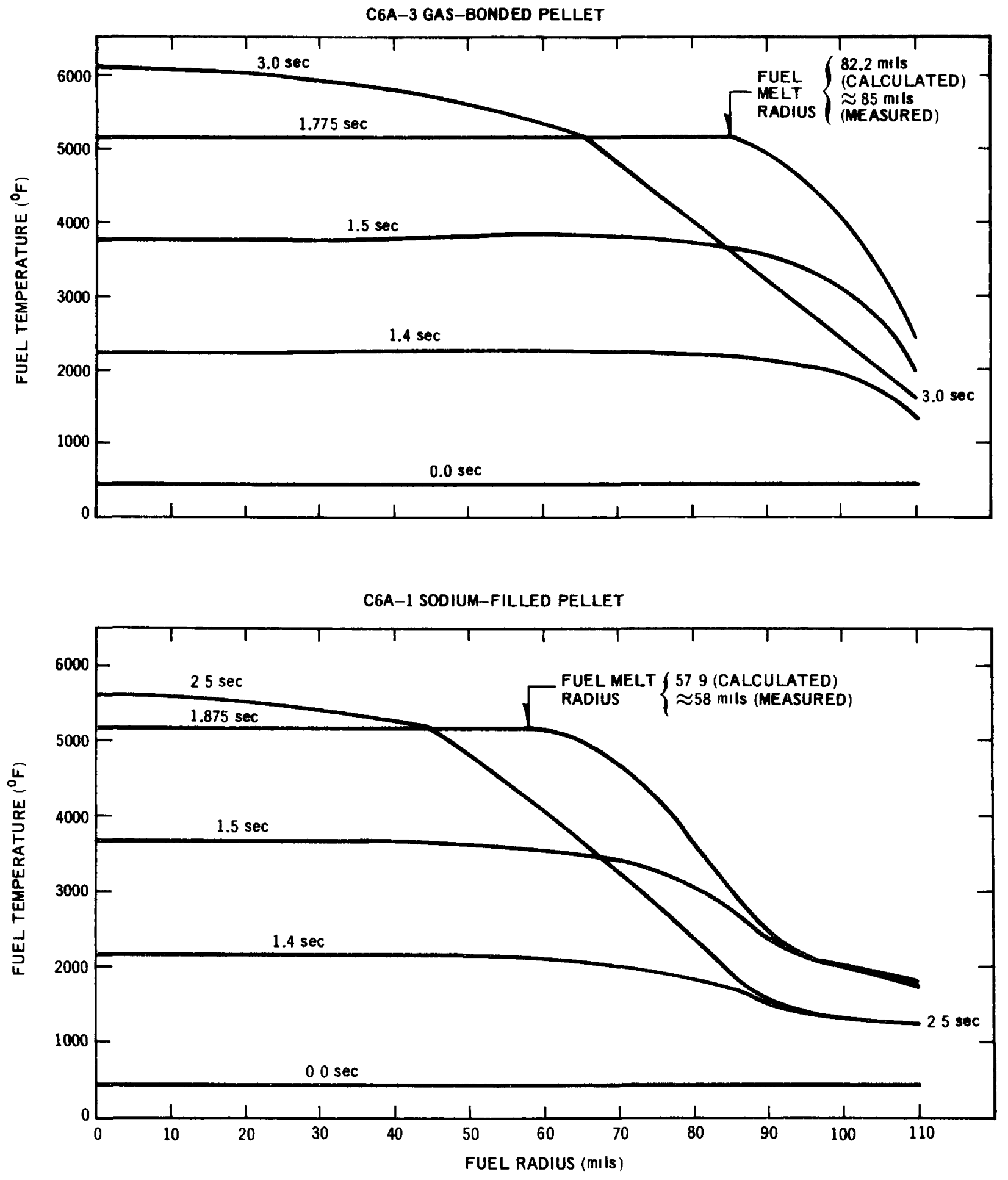

Figure 3.5 Calculated Fuel Temperature Versus Radius and Tıme, Capsule C6A, TT 1312-485 MW-sec 


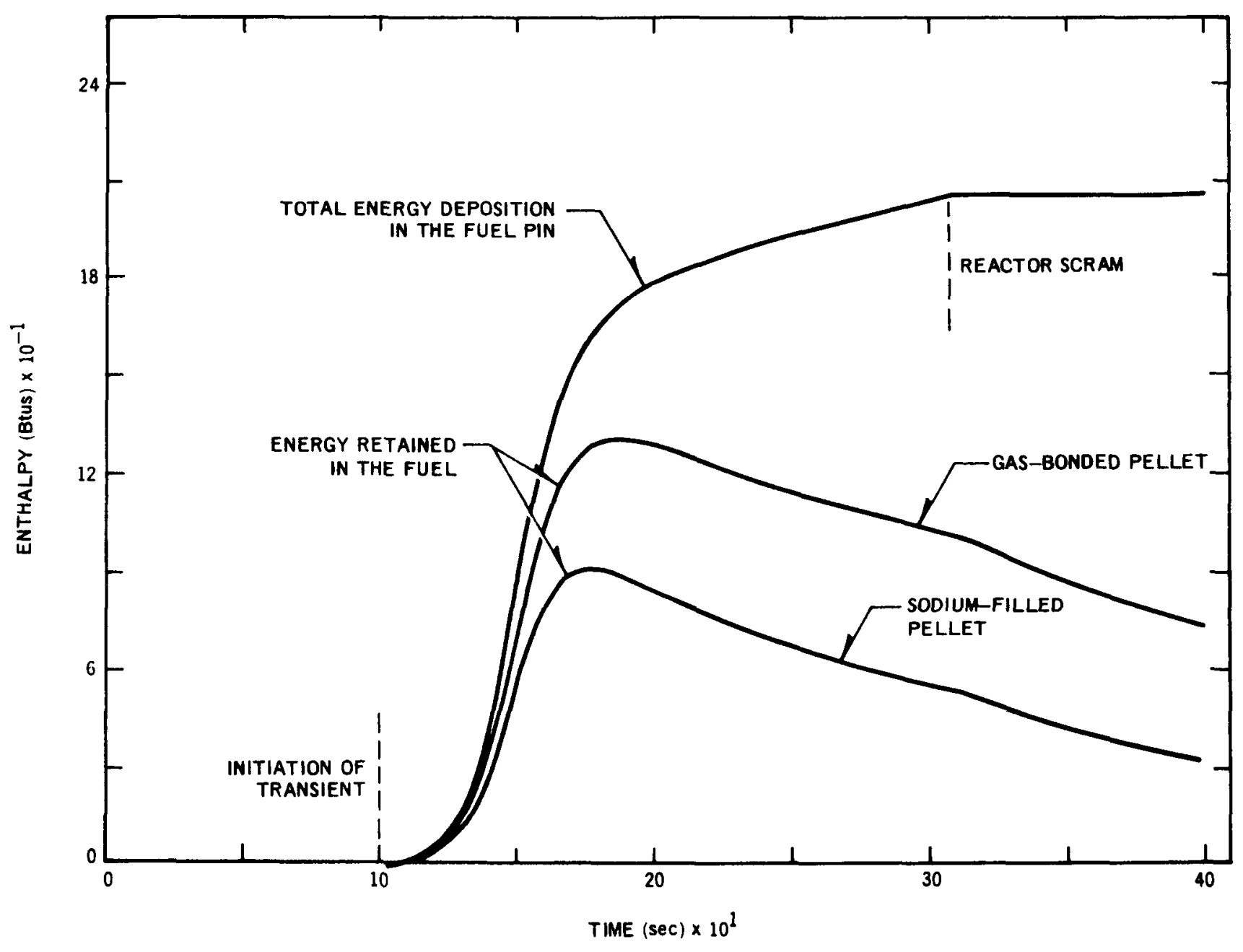

Figure 3.6 Transient Energy Study Capsule C6A - Specimen C6A-3 (Gas-Bonded Pellet), Specimen C6A-1 (Sodium-Filled Pellet) TT 1312-485 MW-sec 


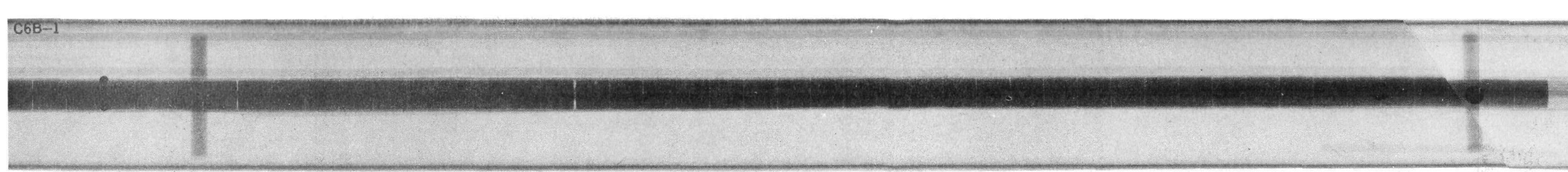

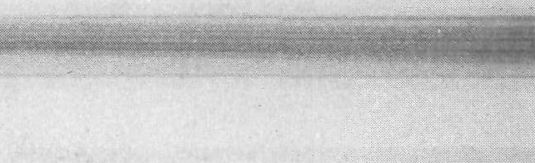
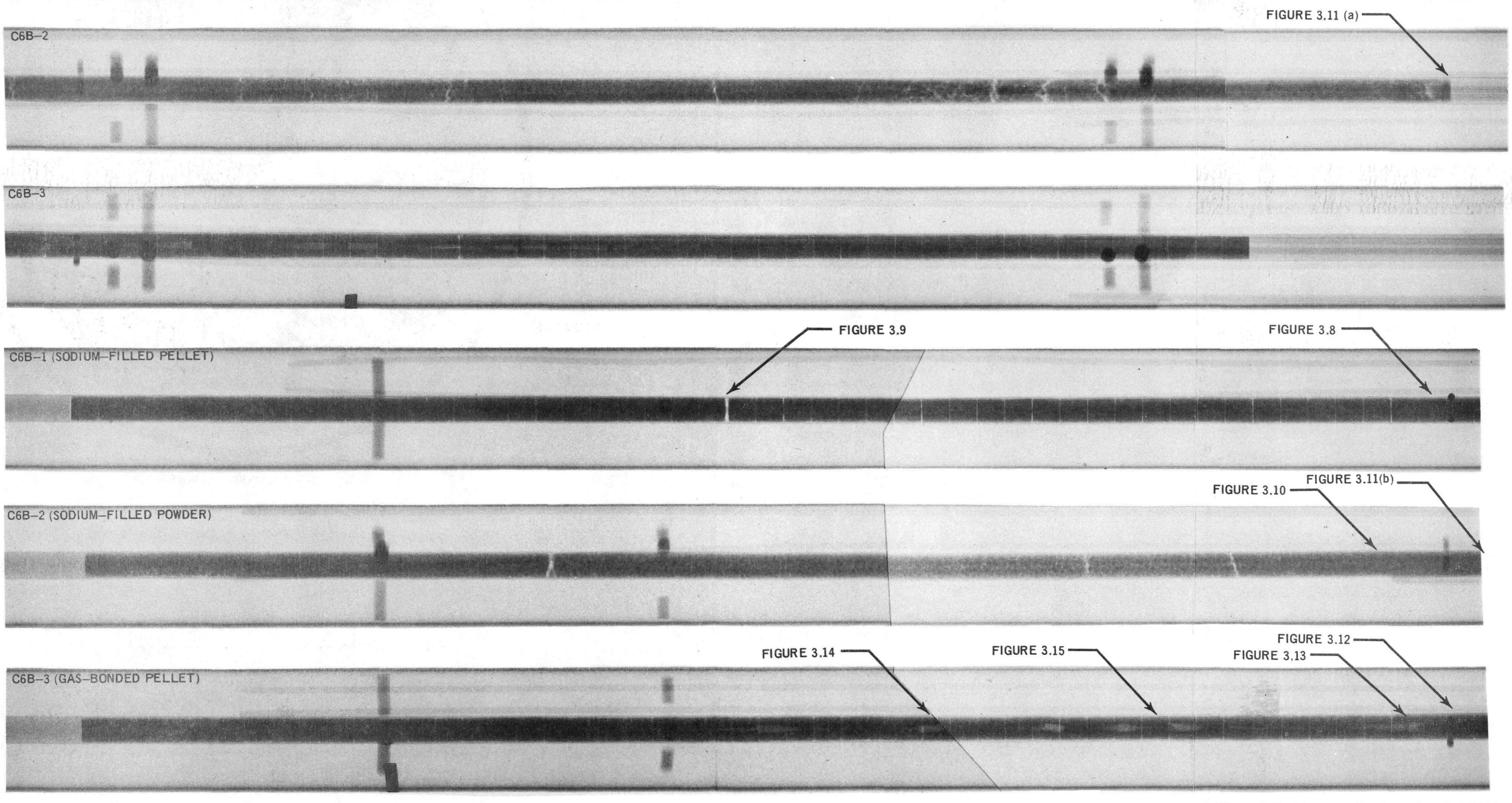

Figure 3.7 Neutron Radiograph of C6B Inner Capsules MW-sec 


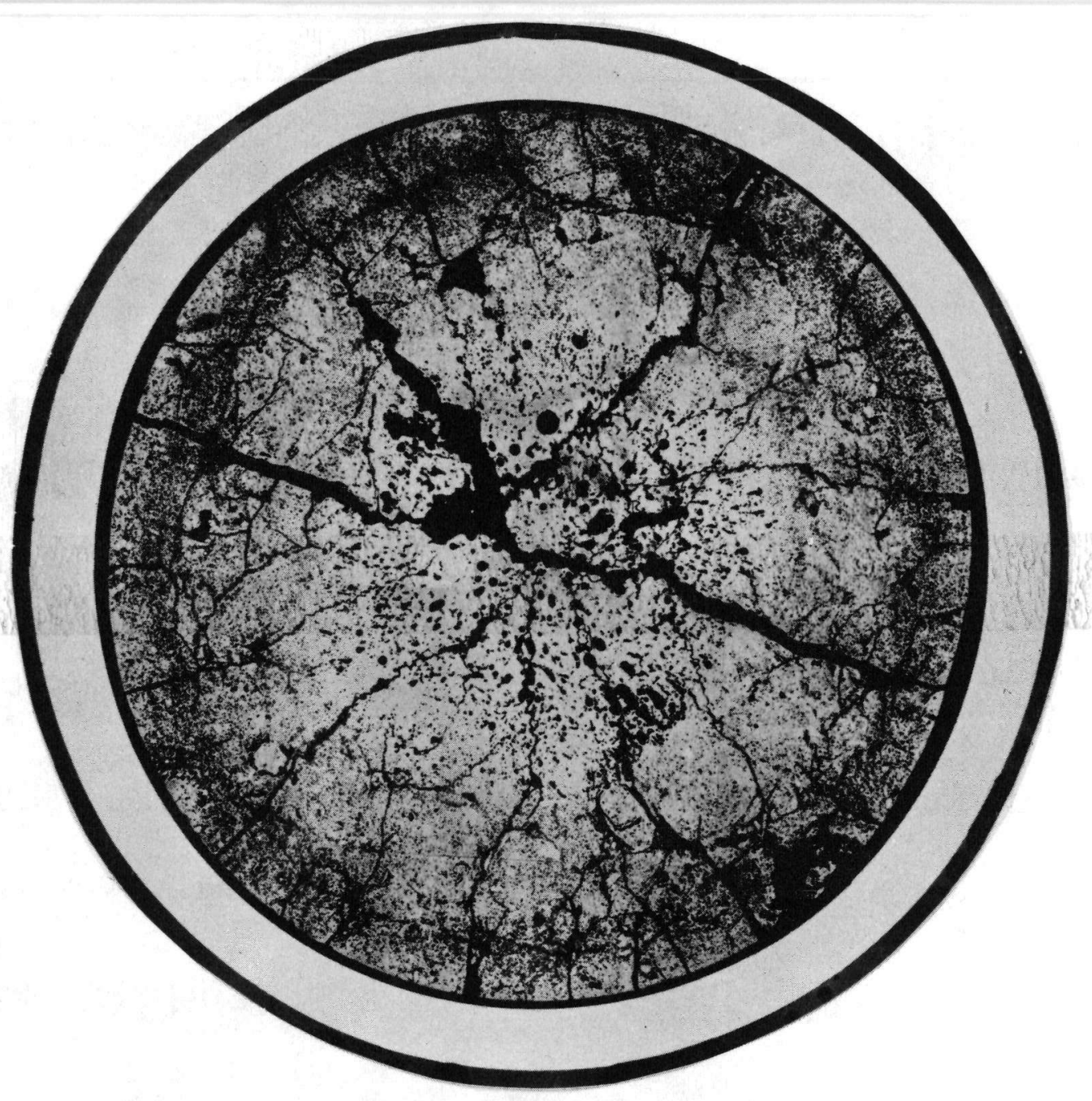

20X POLISHED A505-02

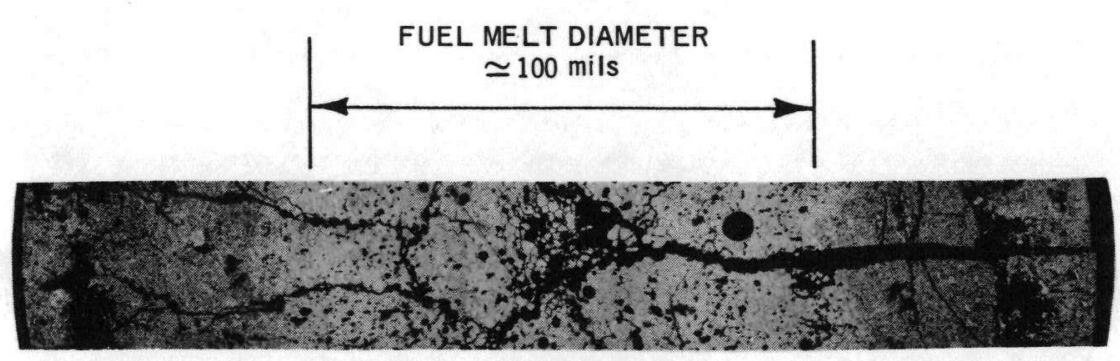

20X ETCHED A505-17

Figure 3.8 Specimen C6B-1 (Sodium-Filled Pellet) Transverse Sample Showing Fuel Microstructure at the Fuel Column Midplane 


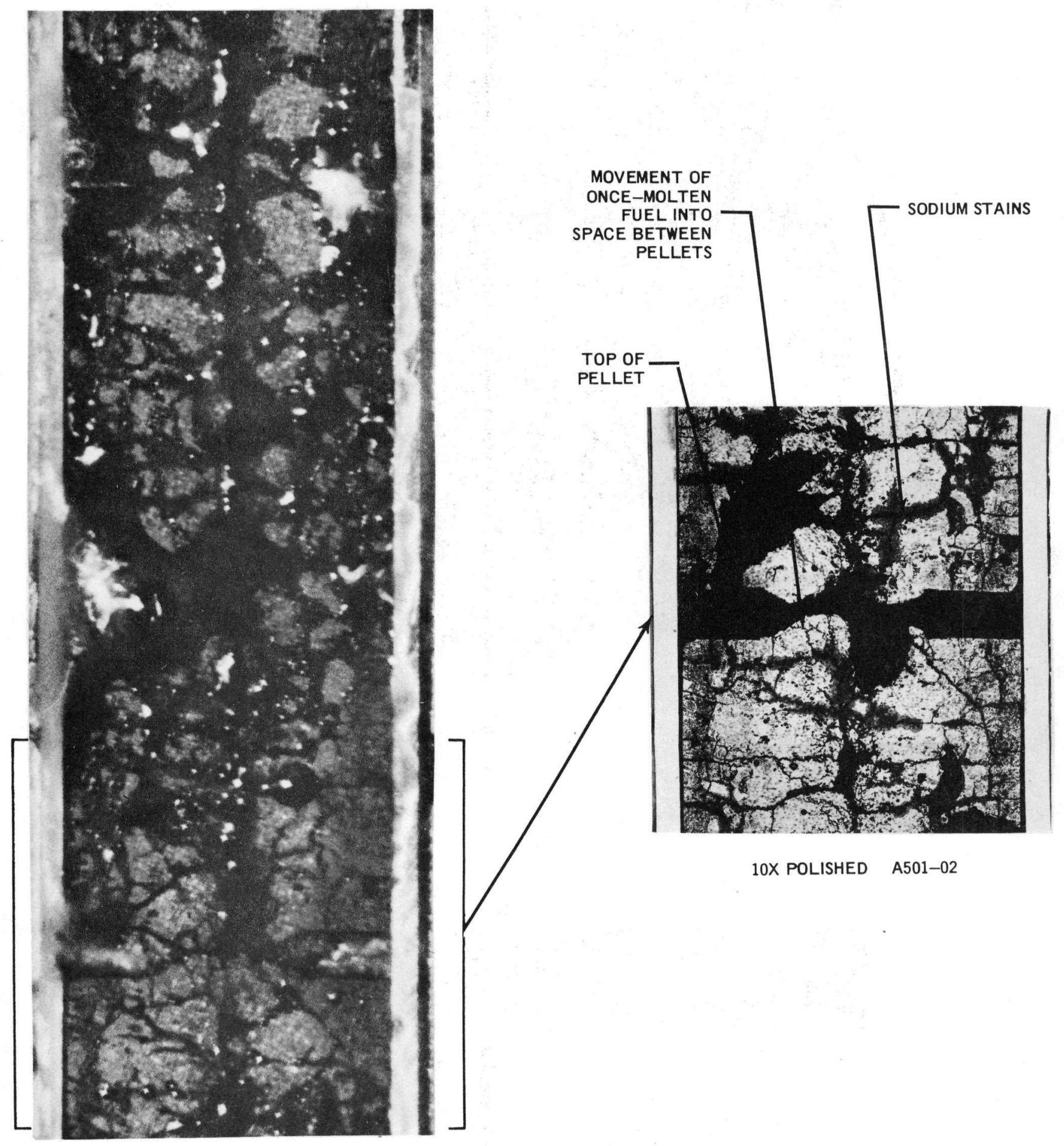

10X GROUND A501-01

Figure 3.9 Specimen C6B-1 (Sodium-Filled Pellet) Longitudinal Sample Showing Molten Fuel Movement Into Space Between Pellets 

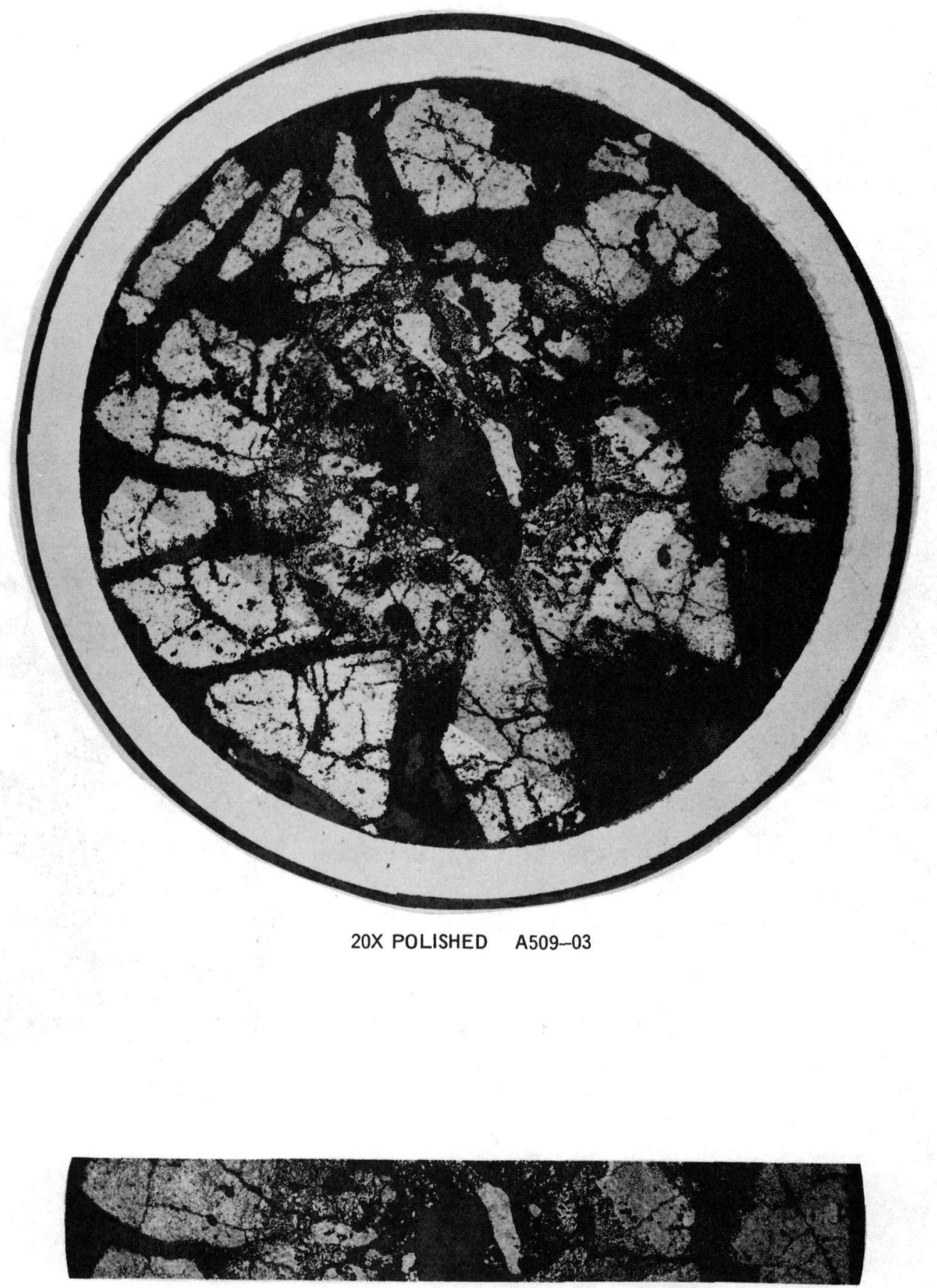

20X ETCHED A509-12

Figure 3.10 Specimen C6B-2 (Sodium-Filled Powder) Transverse Sample Showing Fuel Microstructure at the Fuel Column Midplane 


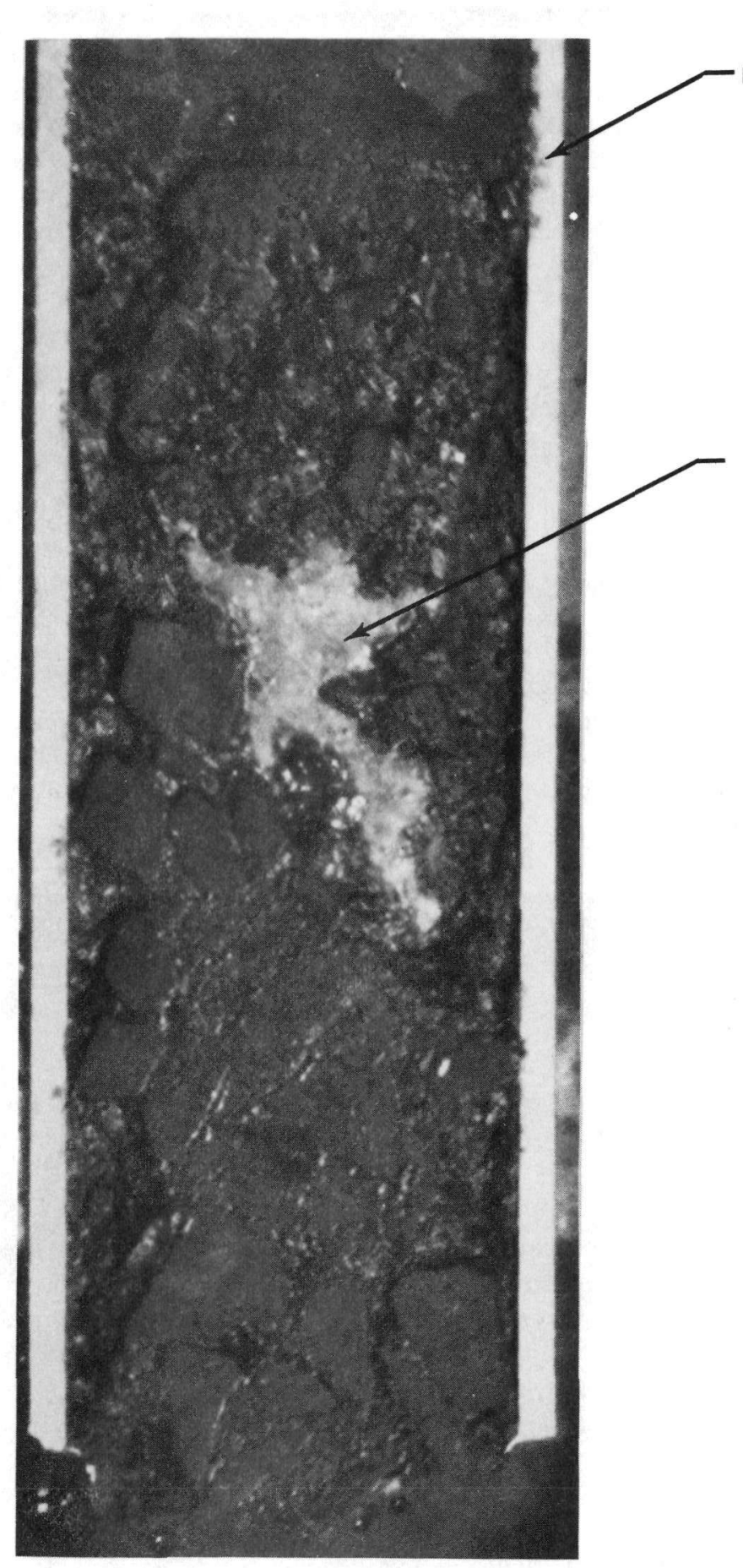

10X GROUND A512-01

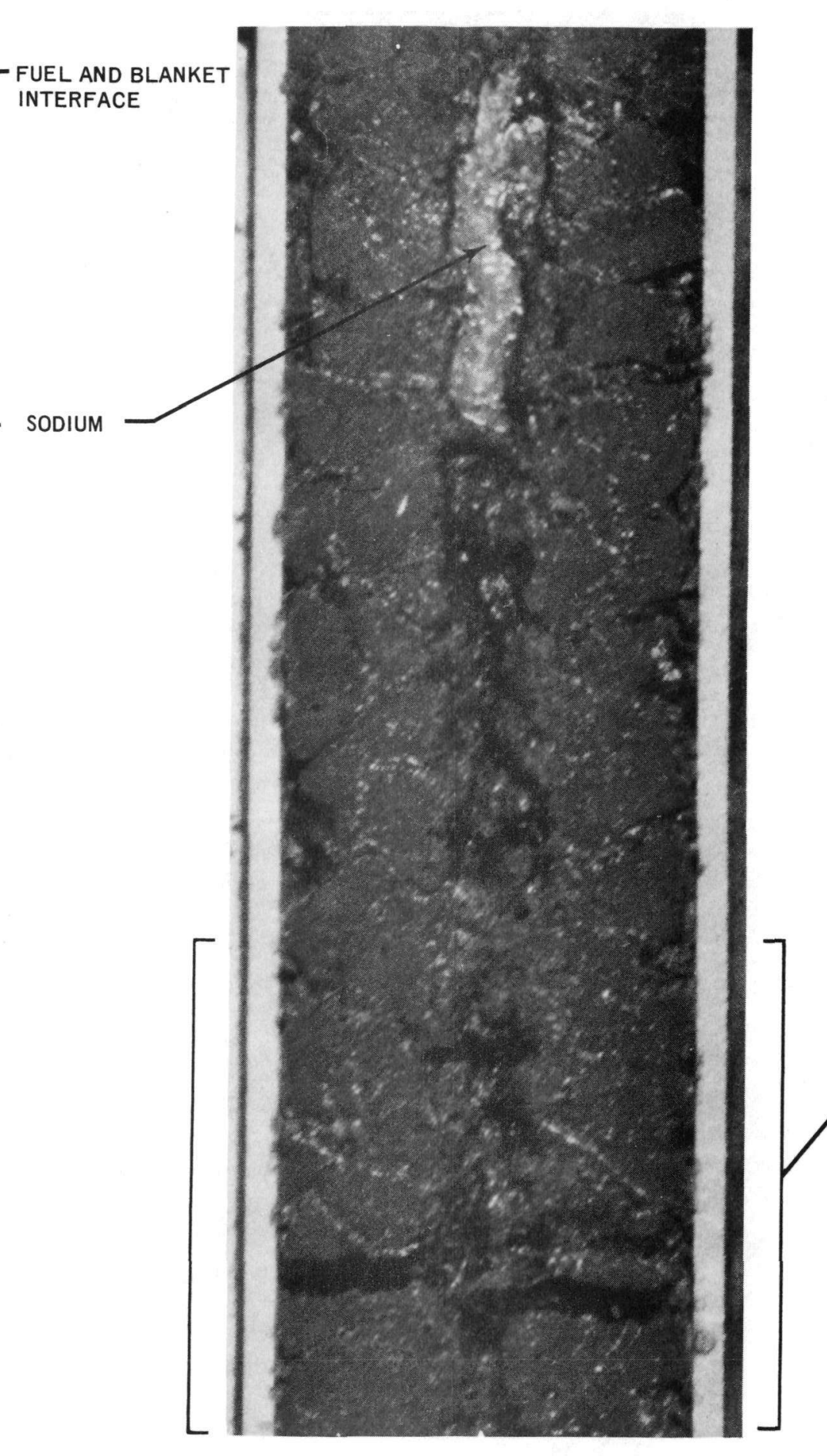

(b) $10 \mathrm{X}$ GROUND A510-01

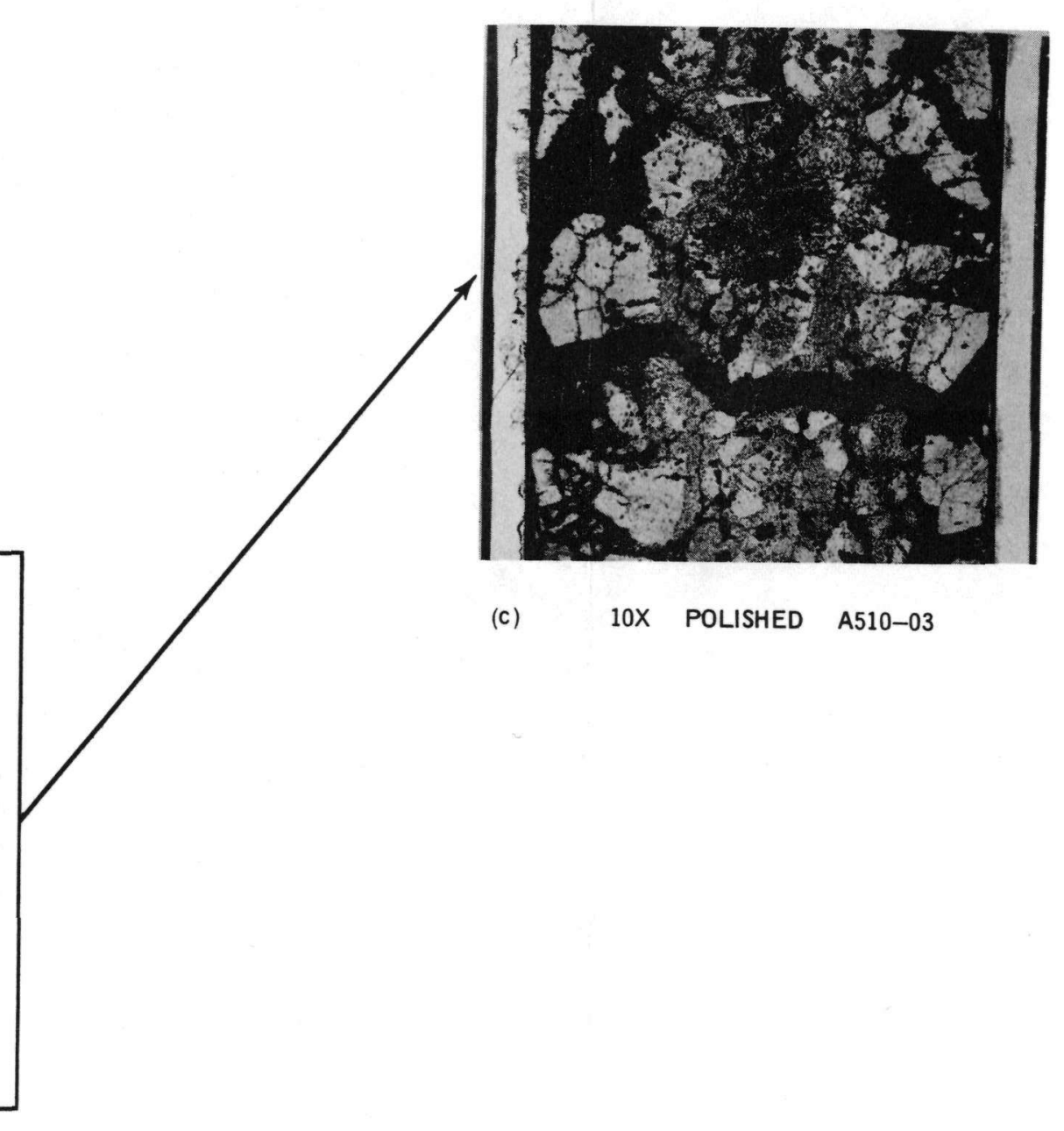

Figure 3.11 Specimen C6B-2 (Sodium-Filled Powder) Longitudinal Samples 


\subsubsection{Specimen C6B-3, Gas-Bonded Pellet}

This specimen was also found to be intact. Numerous voids of irregular shapes can be seen with no apparent pattern or trend. Fuel movement apparently occurred in both directions. Clad deformation (no ovality) was negligible, $\cong 0.001$ inch $(0.4 \%)$ in a few areas. There were no discrepancies noted during visual examination of the pins.

Figure 3.12 is a transverse sample from the fuel column midplane. The fuel radius at this point was estimated to be $\cong 0.075$ inch with a fuel melt volume of $\sim 47 \%$. The cladding was also examined at this plane and no discrepancies were noted. The longitudinal samples show various voids and areas where fuel movement had occurred. Figures 3.13 through 3.15 show the samples in the as-ground condition and with selected areas after polishing.

\subsubsection{Capsule C6A}

TREAT neutron radiographs of the complete capsule assembly following transient irradiation revealed no apparent failures. Following capsule disassembly, the inner capsules were again neutron radiographed (see Figure 3.16) to provide greater capsule and fuel pin detail. These radiographs also indicated fuel pin failure did not occur.

\subsubsection{Specimen C6A-1, Sodium-Filled Pellet}

The fuel column increased in length $\sim 1.2$ inches by spaces between pellets becoming enlarged and, in some instances, pellets cracking and expanding. A central void is also evident in Figure 3.16. Profilometry indicated ovality in some areas with up to $\cong 0.003$ inch (diametral) difference between the $0^{\circ}-180^{\circ}$ and $90^{\circ}-270^{\circ}$ planes. Diametral increases were negligible ( $\cong 0.001$ inch maximum or $0.4 \%$ ). A bow of $\sim 1$ inch (maximum near fuel and blanket interface) was also measured after removal from the inner capsule.

The pin was sectioned and samples selected to determine fuel melt radius and to examine possible areas of interest. The procedure was again hindered by the presence of sodium. Figure 3.17 shows a transverse sample from the fuel column midplane. The estimated melt radius is $\cong 0.058$ inch or a fuel melt volume of $\sim 28 \%$. The cladding was also examined at this location and found to be in good condition.

A longitudinal section with pellet interface separations is shown in Figure 3.18. Molten fuel was forced up and into the area between pellets. The molten fuel appears to have contacted the cladding, but the cladding was examined and did not show any evidence of damage due to the proximity of the once-molten fuel. Note that the fuel structure on both ends of the pellet is similar to that next to the clad. This indicates much lower temperatures, probably as a result of sodium in this area.

\subsubsection{Specimen C6A-2, Sodium-Filled Powder}

Results were similar to that for C6B-2 but reflect the increased energy input of the larger transient. The central void is larger and fuel movement is evident. The fuel column has increased axially $\sim 2$ inches. Clad deformation from $\cong 0.0025(1 \%)$ to $\cong 0.004$ inch $(1.6 \%)$ was measured. The deformation was relatively uniform with no definite peaks and no ovality.

Figure 3.19 shows the fuel microstructure at the fuel column midplane. The effect of the sodium is clearly evident in the irregular area where fuel structural changes have occurred. The sodium was evenly distributed among the fuel particles. Under these conditions (similar to C6B-2, Figure 3.10), the fuel melt radius could not be estimated, although some melting was indicated by the fuel microstructure. The center void diameter is $\cong 0.050$ inch. The cladding in this area was examined and was found to be free of any defects or damage.

Figure 3.20 shows the fuel structure directly below the previous section (Figure 3.19). The central void and a fuel plug can be seen. The light colored "object" in the central void is sodium. The difficulties (fuel fall-out) encountered during examination of the C6B sodium-filled powder specimen were also experienced.

\subsubsection{Specimen C6A-3, Gas-Bonded Pellet}

The irregularly shaped voids seen in the C6B-3 specimen (Figure 3.7) are also seen here. The central void, however, is larger and is not as intermittent. Fuel movement is also evident. Clad deformation was negligible with some ovality. A bow of $\sim 1$ inch was also measured for this pin with the maximum occurring at approximately the fuel and blanket interface.

The molten fuel radius was estimated from the sample in Figure 3.21 to be $\cong 0.085$ inch and the calculated fuel melt volume was $\sim 60 \%$. The cladding was found to be in good condition.

Figures 3.22 and 3.23 are longitudinal sections illustrating areas where fuel movement had occurred. 


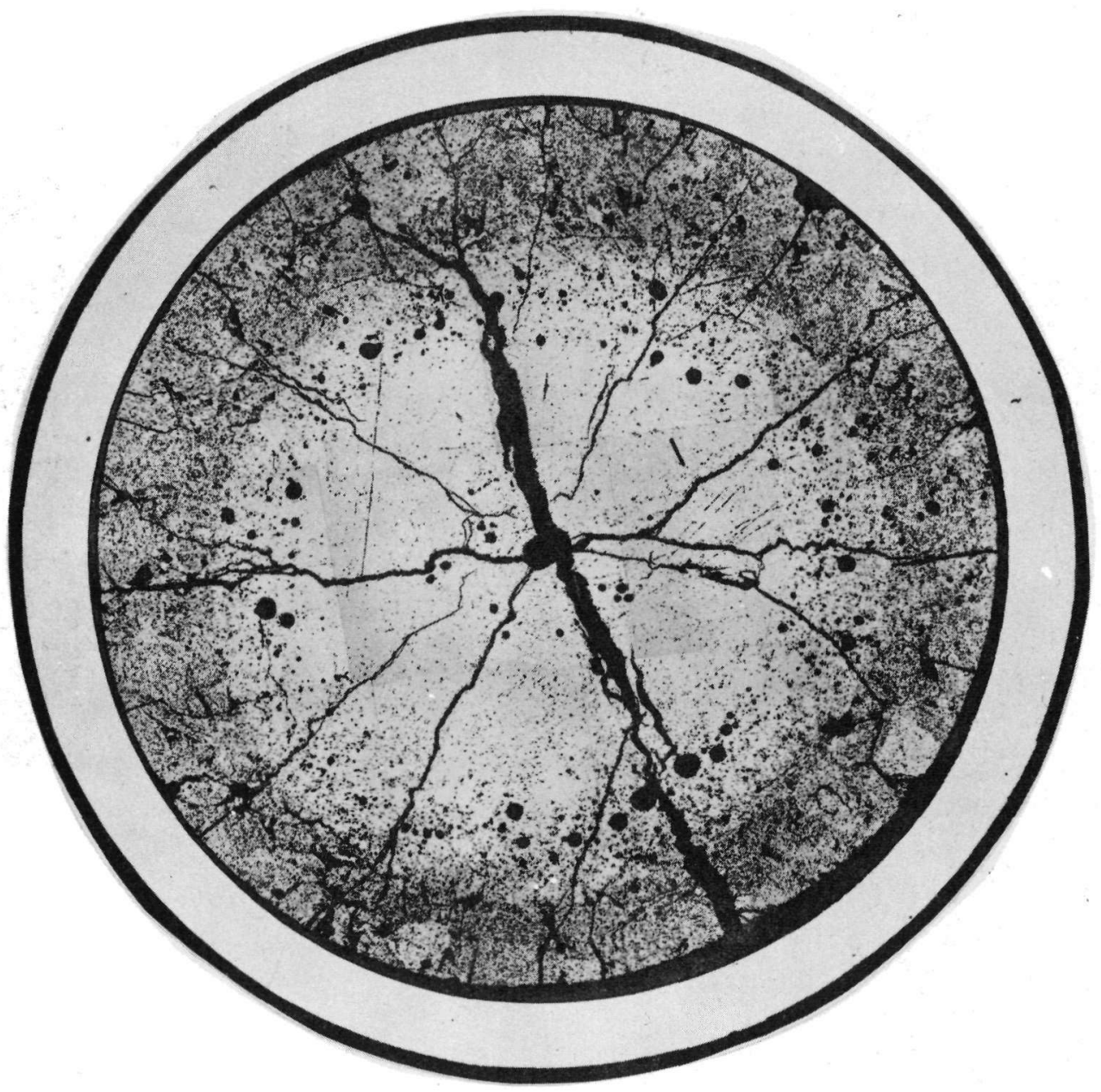

20X POLISHED A515-03

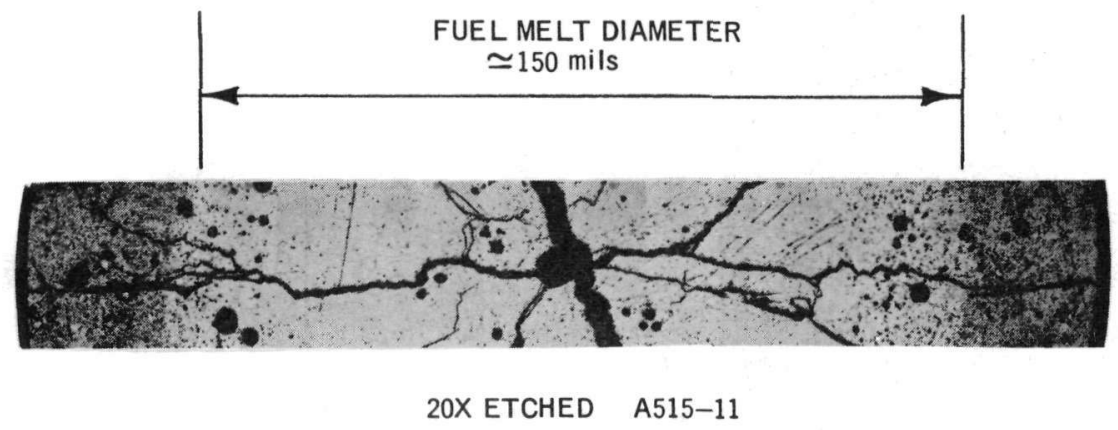

Figure 3.12 Specimen C6B-3 (Gas-Bonded Pellet) Transverse Sample Showing Fuel Microstructure at the Fuel Column Midplane 

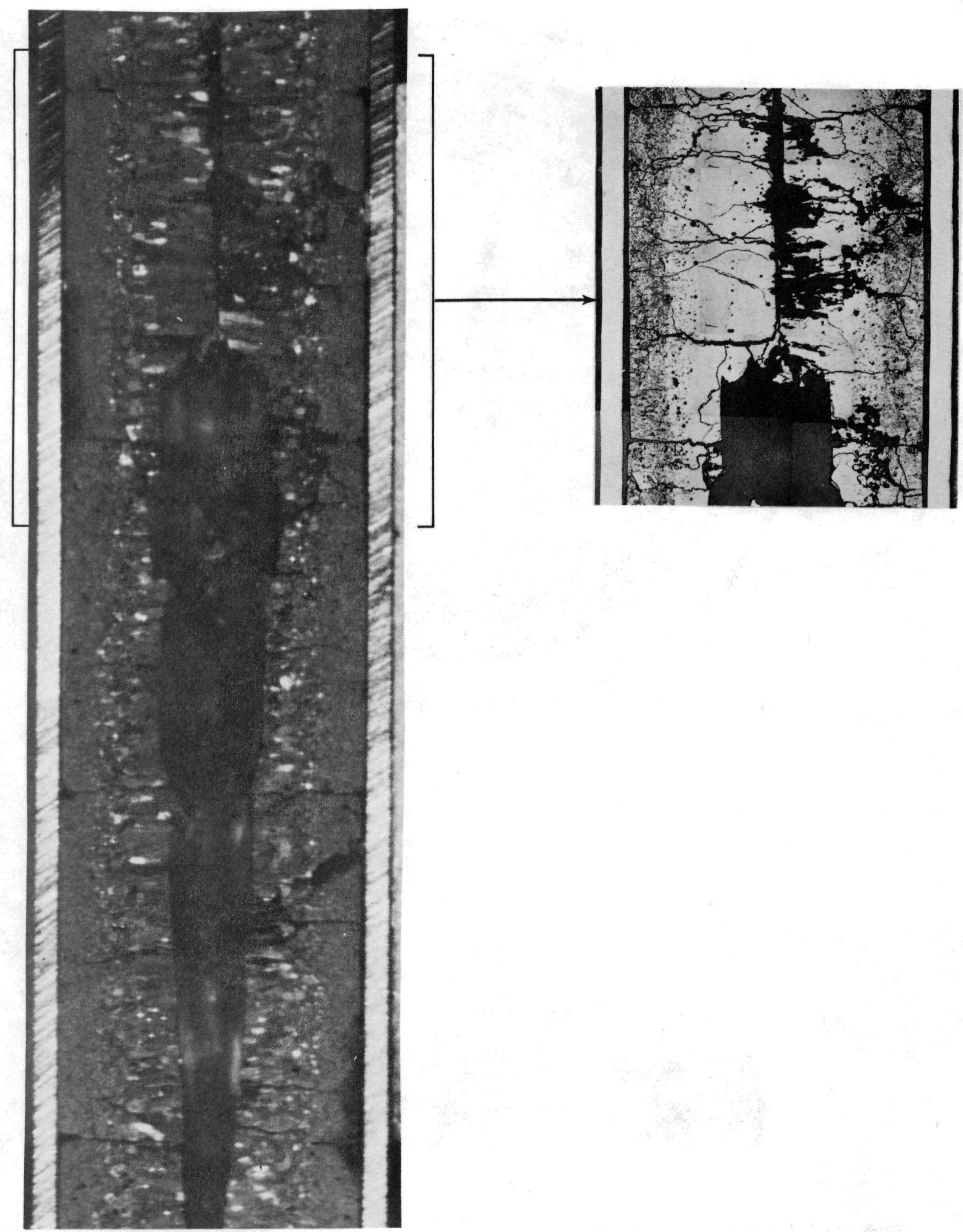

10X GROUND A517-01

Figure 3.13 Specimen C6B-3 (Gas-Bonded Pellet) Longitudinal Sample 


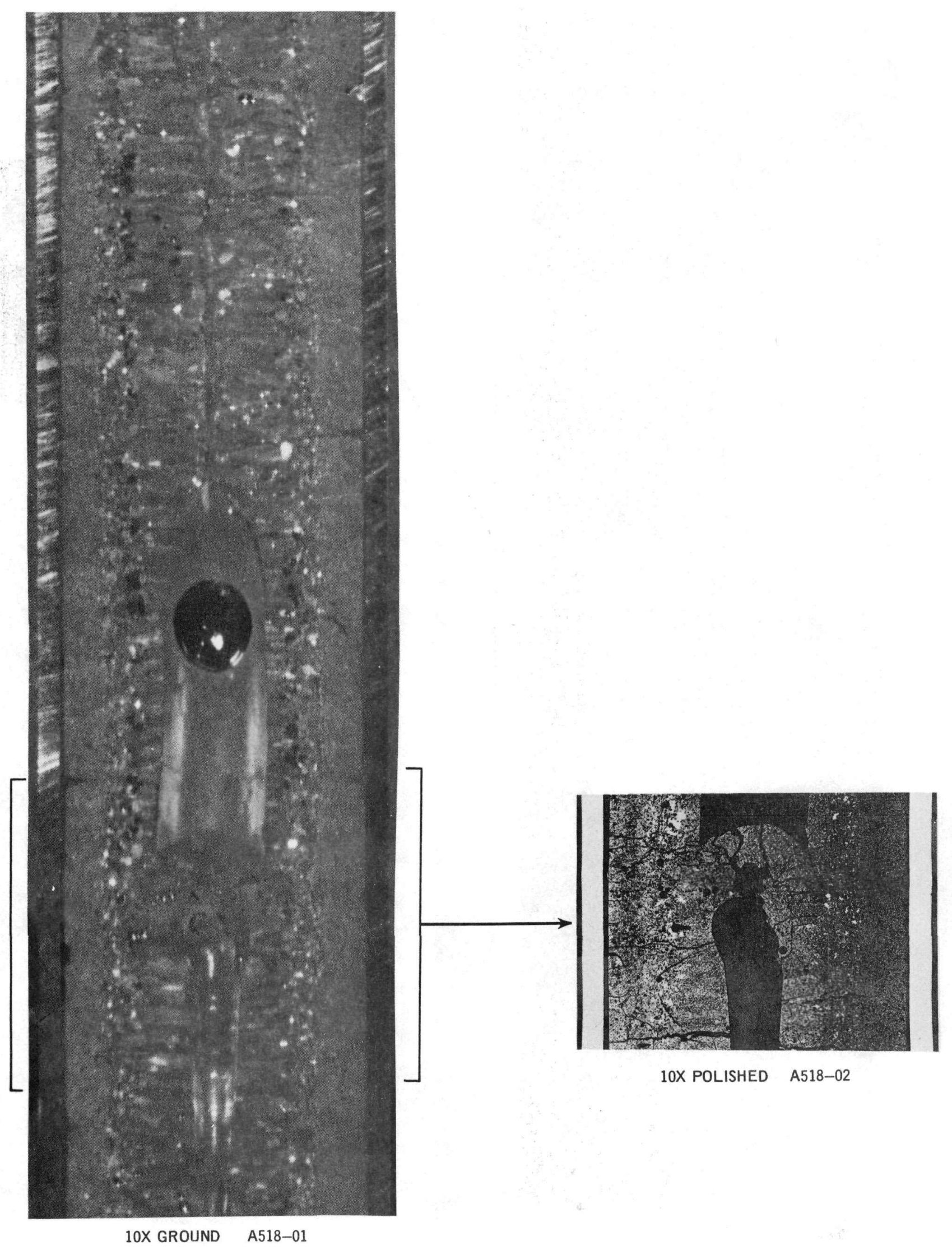

Figure 3.14 Specimen C6B-3 (Gas-Bonded Pellet) Longitudinal Sample 


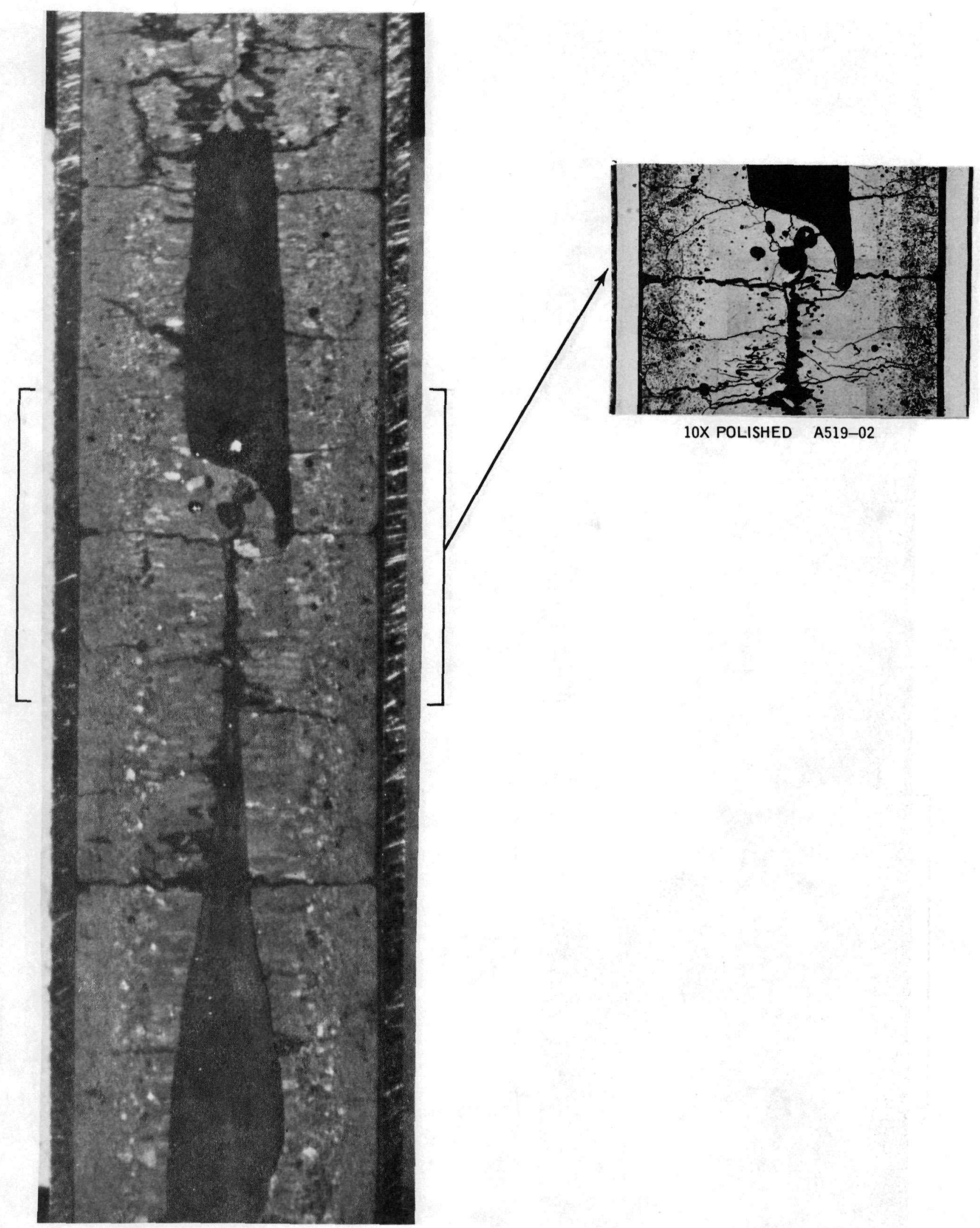

10X GROUND A519-01

Figure 3.15 Specimen C6B-3 (Gas-Bonded Pellet) Longitudinal Sample 

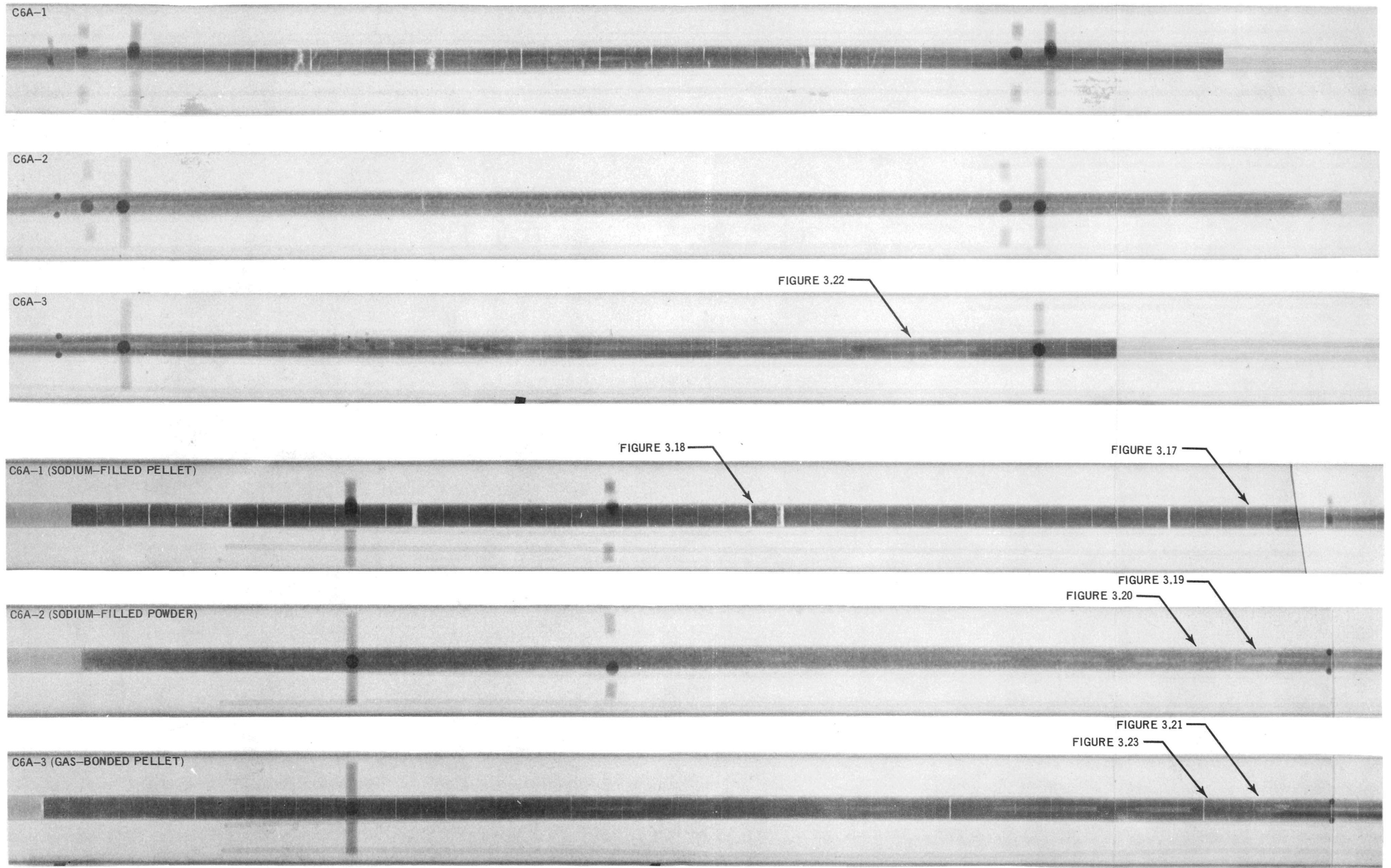

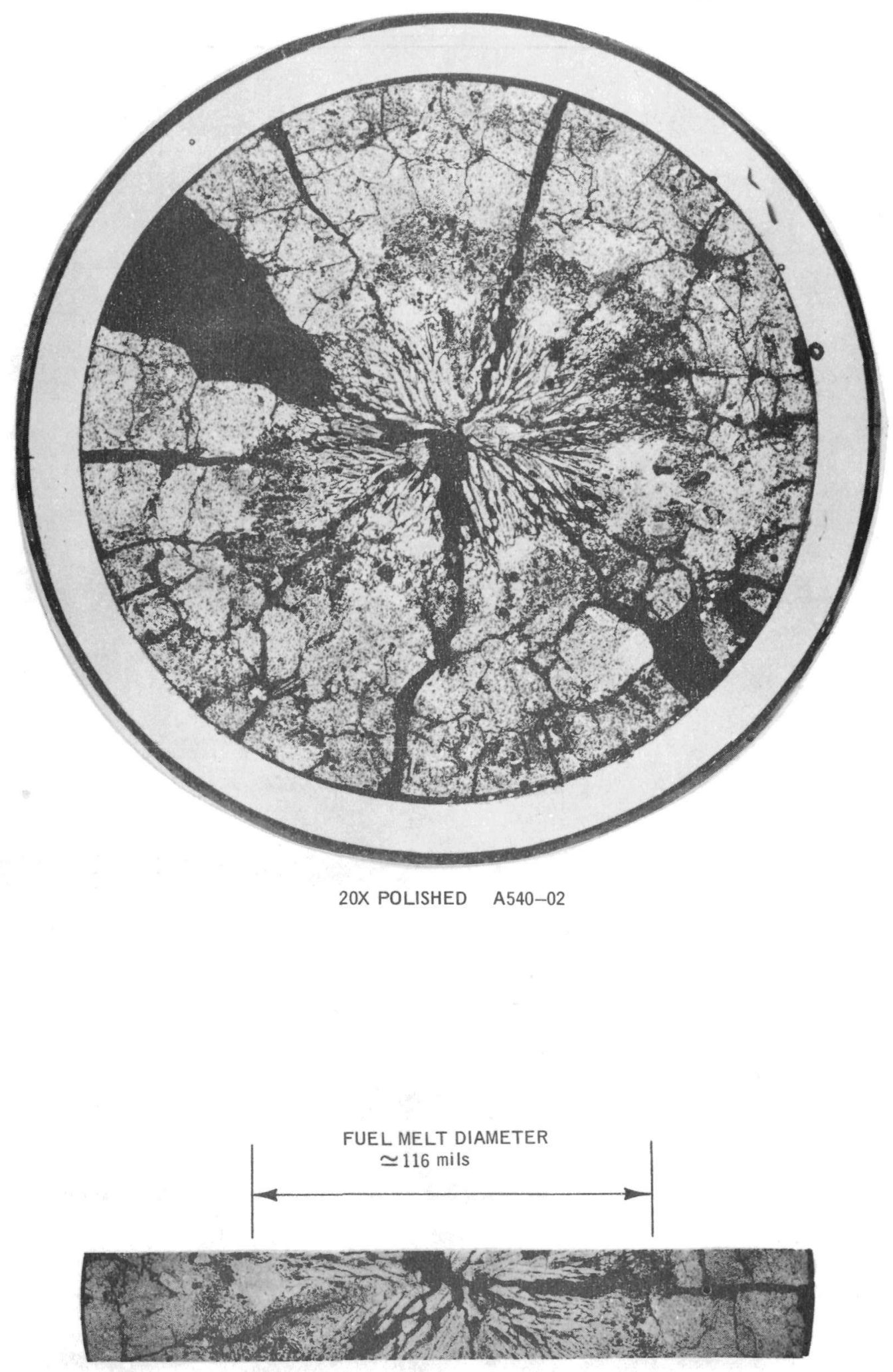

29X ETCHED A540-12

Figure 3.17 Specimen C6A-1 (Sodium-Filled Pellet) Transverse Sample Showing Fuel Microstructure at the Fuel Column Midplane 


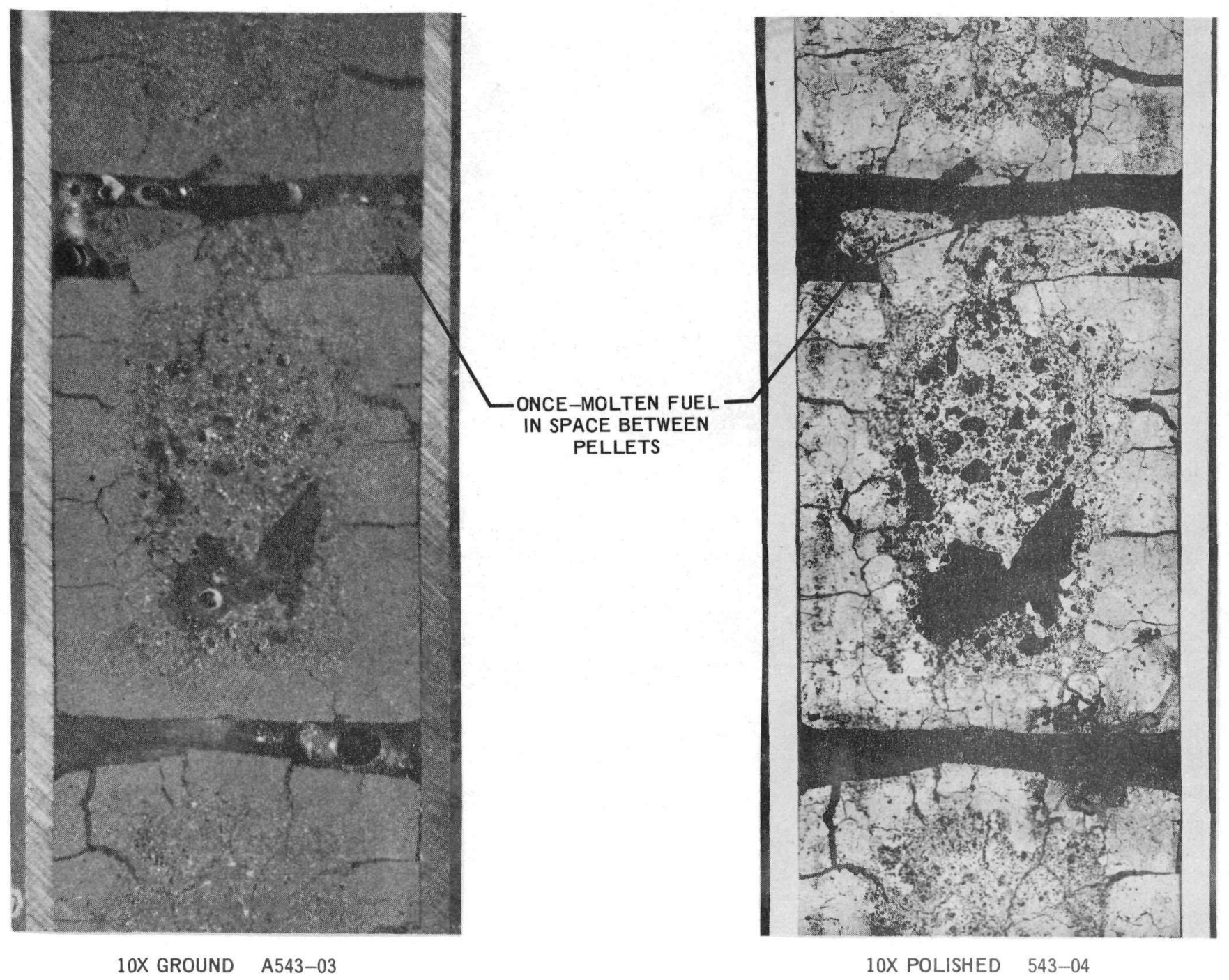

Figure 3.18 Specimen C6A-1 (Sodium-Filled Pellet) Longitudinal Sample Showing Once-Molten Fuel in Space Between Fuel Pellets 


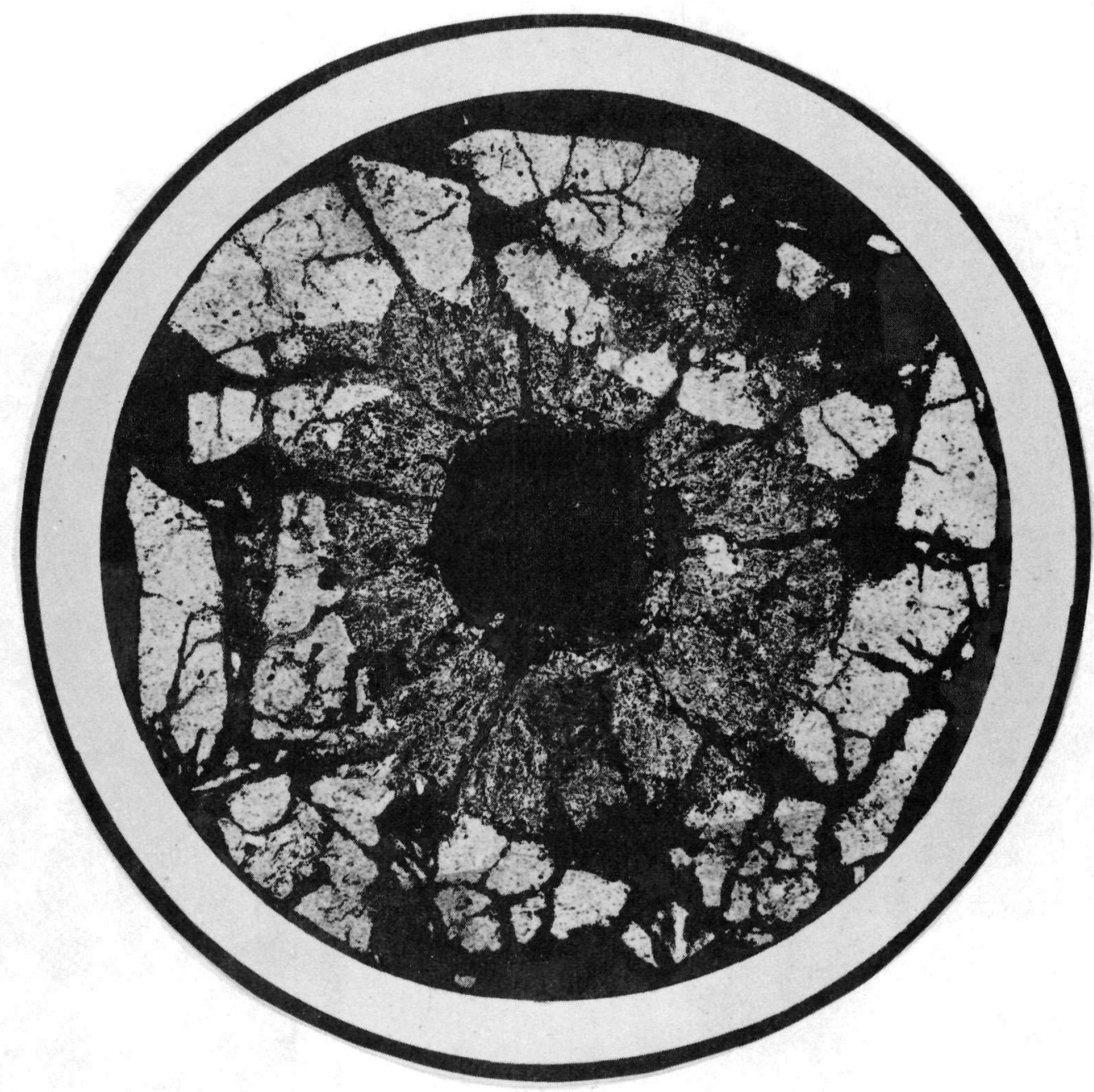

20X POLISHED A547-12

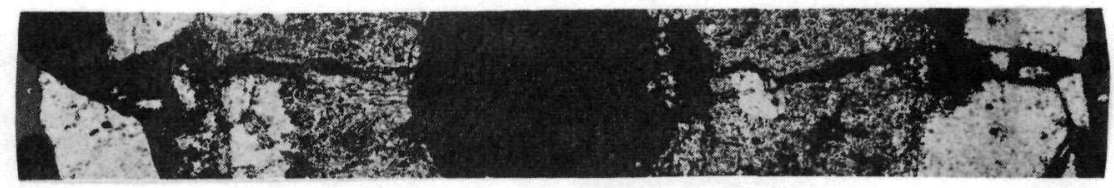

20X ETCHED A547-11

Figure 3.19 Specimen C6A-2 (Sodium-Filled Powder) Transverse Sample Showing Fuel Microstructure at the Fuel Column Midplane 


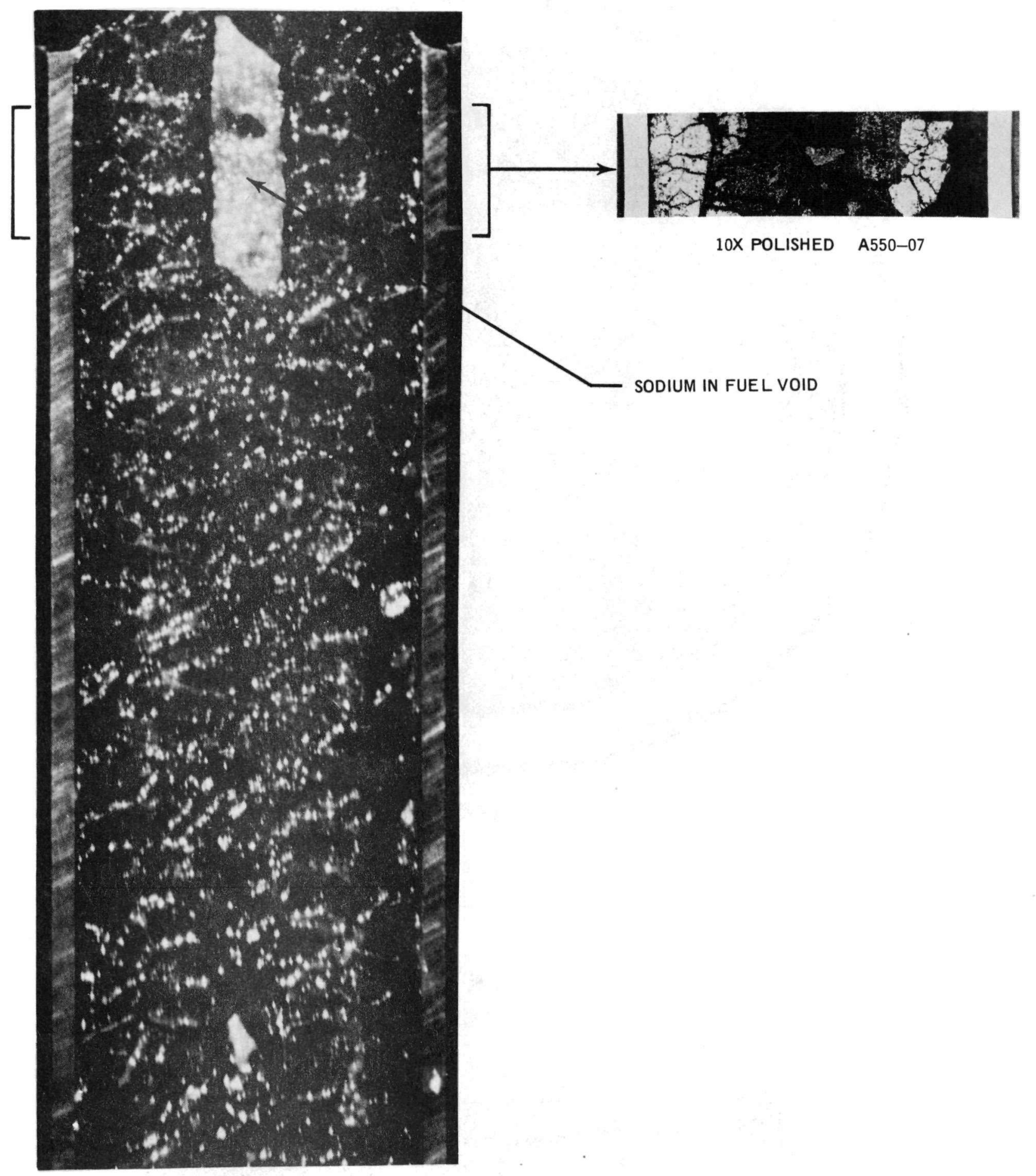

10X GROUND A550-02

Figure 3.20 Specimen C6A-2 (Sodium-Filled Powder) Longitudinal Sample 


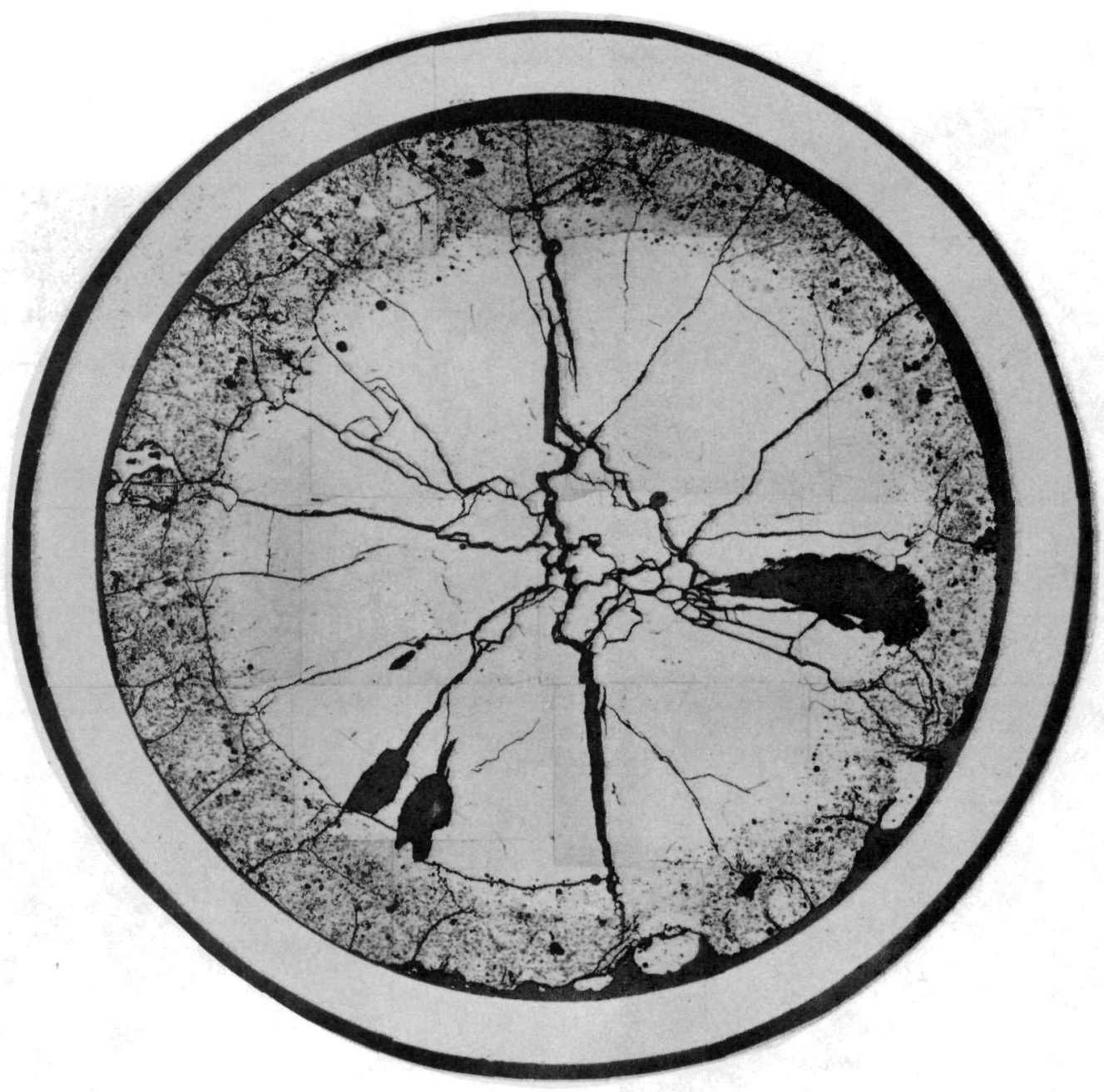

20X POLISHED A535-02

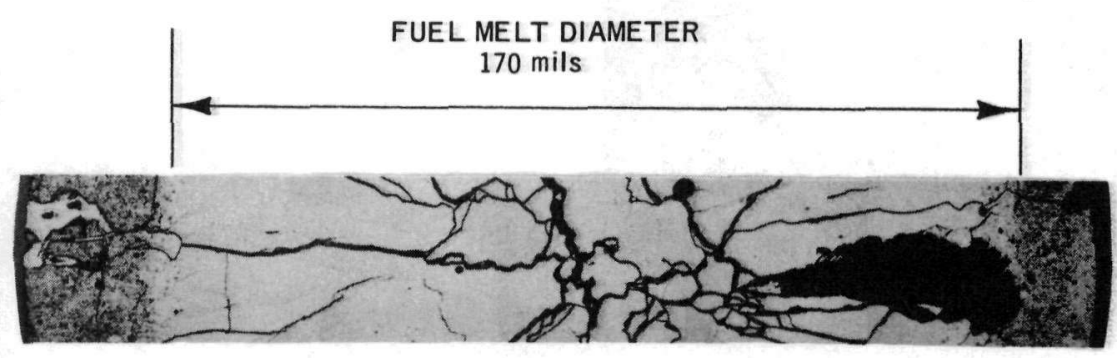

20X ETCHED A535-10

Figure 3.21 Specimen C6A-3 (Gas-Bonded Pellet) Transverse Sample Showing Fuel Microstructure at the Fuel Column Midplane 

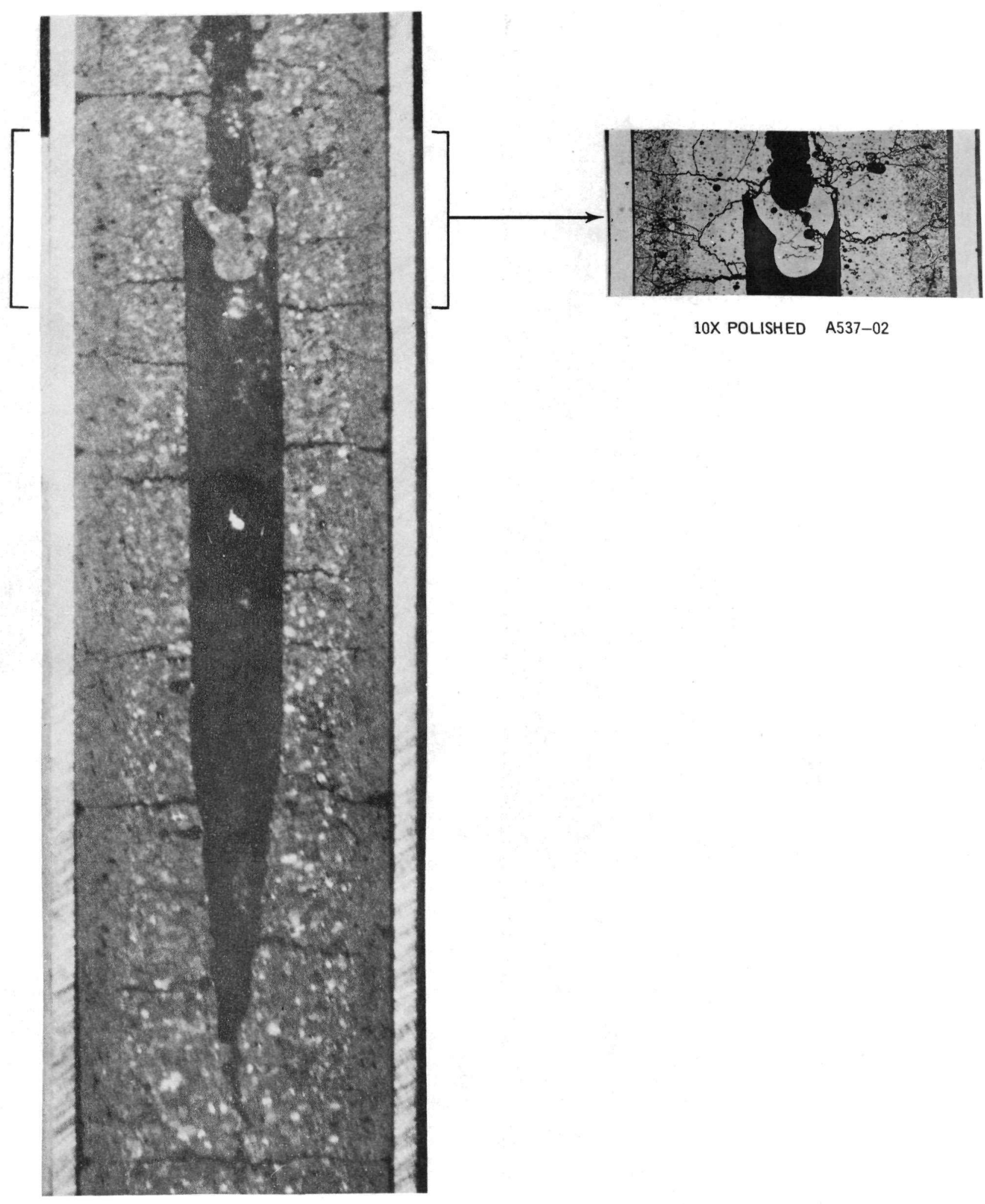

10X POLISHED A537-02

10X GROUND A537-01

Figure 3.22 Specimen C6A-3 (Gas-Bonded Pellet) Longitudinal Sample 


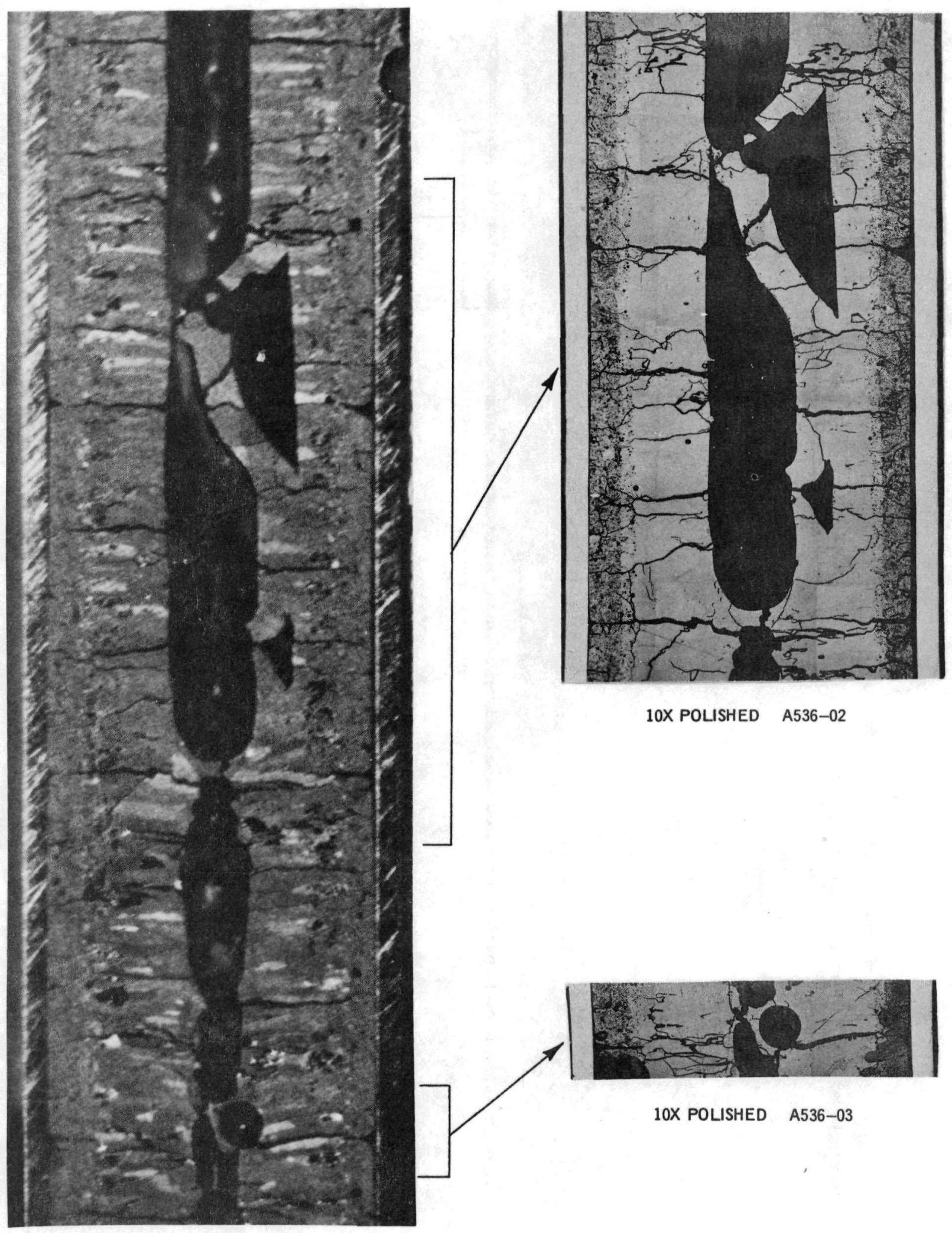

10X GROUND A536-01

Figure 3.23 Specimen C6A-3 (Gas-Bonded Pellet) Longitudinal Sample 


\subsection{DISCUSSION OF RESULTS}

The effects of sodium within the fuel pin are clearly evident in the microstructure of the fuel specimens shown in Figures 3.24 and $3.25^{*}$. The presence of sodium resulted in an apparent improvement in fuel thermal conductivity as well as improved gap conductance. Fuel temperatures and melt volumes were considerably below those observed for the gas-bonded fuel specimen.

The results tend to substantiate observations of previous experiments 8,9 with sodium-filled failed fuel pins. These were short-term and transient irradiation tests conducted in the General Electric Test Reactor (GETR) and TREAT. Fuel performance characteristics were tested to power levels which produced central fuel temperatures above the fuel melting point, yet sodium present inside the fuel rod did not create significant damaging effects. However, long-term irradiation tests ${ }^{10}$ of sodium-filled mixed-oxide fuel pins have indicated fuel center temperatures higher than or comparable to gas-bonded fuel pins. In this instance, the formation of fuel/sodium reaction products apparently negated any initial improvement in fuel thermal conductivity and gap conductance. Thus, the apparent advantages observed under accident conditions (reduced fuel temperatures and added safety margin) with sodium in zero burnup fuel may decrease with time, and conceivably become fuel performance penalties over the longer term.

The sodium-filled powder fuel specimen, which was felt to represent a "worst case" (large fuel surface area in contact with sodium), survived a transient which melted $\approx 60 \%$ of the gas-bonded pellet fuel specimen (C6A-3). Although cladding deformation (1 to $1.6 \%$ ) resulted, the fuel pin (C6A-2) remained intact.

Sodium vapor formation and expansion calculations (see Appendix $\mathrm{C}$ for details) for the sodium-filled powder pin (C6A-2) were performed to evaluate the observed deformation of the cladding. These calculations indicate that very little sodium vaporization could have occurred assuming that the active fuel portion of the pin was essentially a "closed system" during the transient. Under these conditions, the maximum pressure generated is approximately equivalent to the sodium saturated vapor pressure at the maximum volume average temperature of the fuel. This pressure was estimated to be $\cong 2900$ psi which is well below the calculated burst pressure $\left(\cong 6800\right.$ psi @ $\left.1300^{\circ} \mathrm{F}\right)$ of the cladding. Comparison of this pressure to that estimated to cause the observed cladiding deformation (approximately 3070 psi) lends credence to the "closed system" model.

The sample selected to examine the fuel column/blanket interface of the sodium-filled powder pin disintegrated during sample preparation. Consequently, the structure of the fuel at this point (fuel column extension $\cong 2$ inches) could not be determined and the sequence of events and mechanisms involved can only be surmised. Examination of the neutron radiograph (Figure 3.16) indicates the fuel structure along the entire length of the pin is similar. The fuel column probably increased proportionately along its entire length due to thermal expansion of the sodium (interspersed among the fuel particles).

The extension of the fuel column (C6A-1, sodium-filled pellet) seen in Figure 3.16 occurred primarily as a result of thermal expansion of sodium between pellets. In one instance, molten fuel was forced up and into the space between pellets (see Figure 3.18). The proximity of molten fuel, in this instance, had no adverse effects (overheating or localized deformation) upon the cladding. Molten fuel in contact with or in the proximity of the cladding has been observed in other experiments ${ }^{4,5,6}$ with no adverse effects other than localized cladding deformation. Apparently, the sodium in the coolant annulus was able to absorb and/or transfer the heat at a rate sufficient to prevent overheating.

The transient energy study results (Figures 3.3 and 3.6) indicate that specification of failure thresholds as a function of total energy deposition may not be appropriate. The fuel pin surroundings (cladding, coolant, etc.) absorb a significant percentage of the energy available during the transient. For example (Figure 3.6), at $\mathrm{t}=2$ seconds, the total energy deposited is $\cong 180$ Btu but the energy retained or remaining in the fuel is $\cong 130$ Btu (@28\% less). Had failure occurred at this point, the energy required to cause failure, if reported as total energy deposition, would be in substantial error. Failure threshold limits specified in terms of energy retention and/or fuel melt volumes would seem to be more relevant and useful to accident evaluation.

* The views shown can also be seen in Figures $3.8,3.10,3.12,3.17,3.19$, and 3.21. 
GEAP-13722

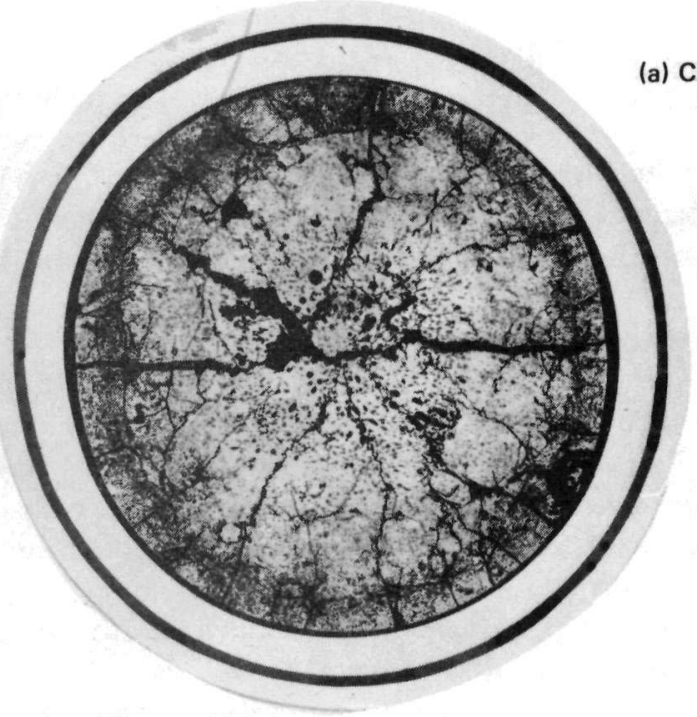

(a) C6B-1 SODIUM-FILLED PELLET

10X POLISHED A505-02

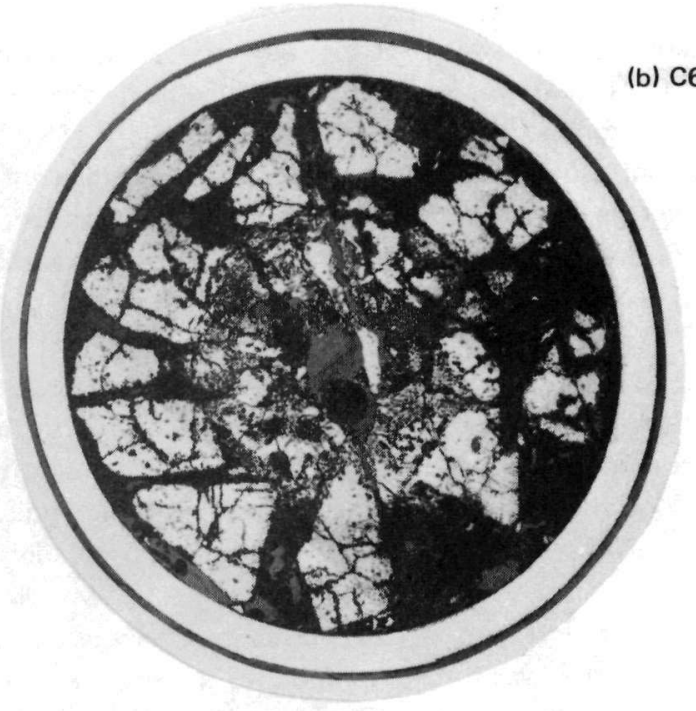

(b) C6B-2 SODIUM-FILLED POWDER

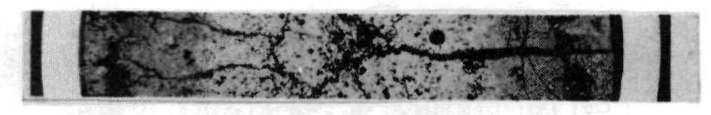

10X ETCHED A505-17

10X POLISHED A509-03

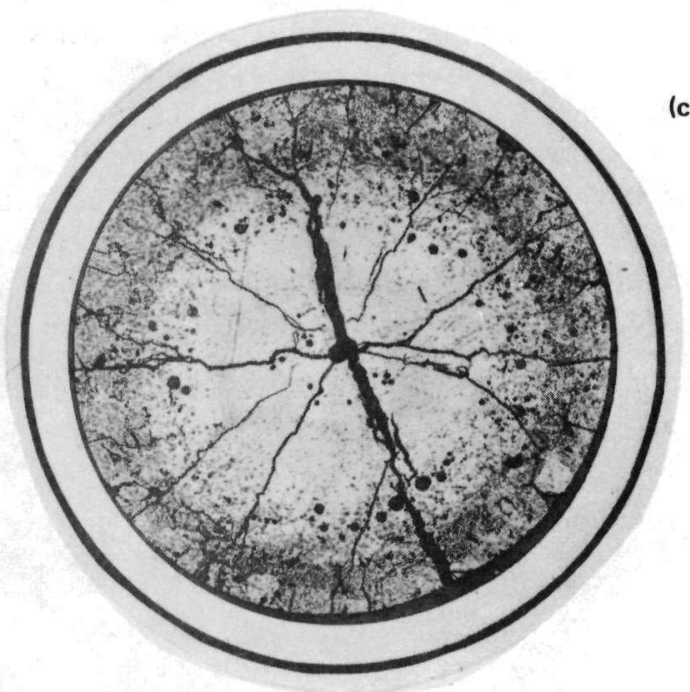

(c) C6B-3 GAS-BONDED PELLET

10X POLISHED A515-03

Figure 3.24 Capsule C6B Transverse Fuel Sections Illustrating the Effects of Sodium Within the Fuel Pin TT $1308-442$ MW-sec 
GEAP-13722

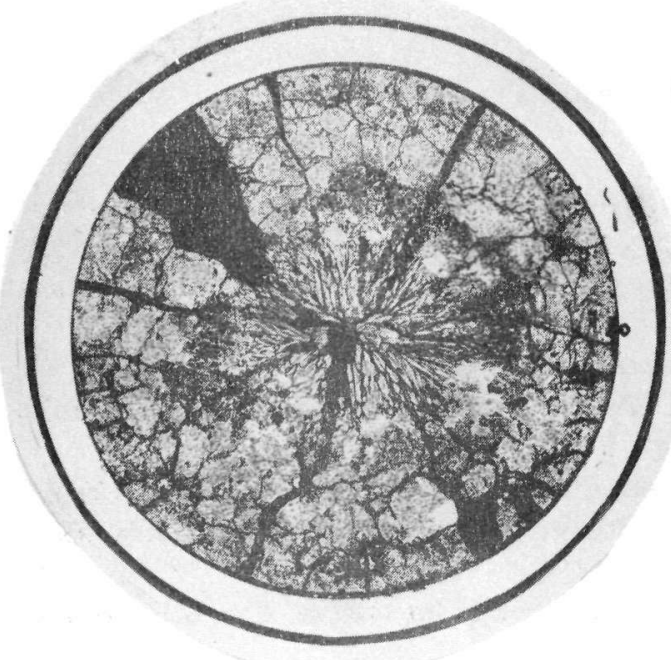

(a) C6A-1 SODIUM-FILLED PELLET
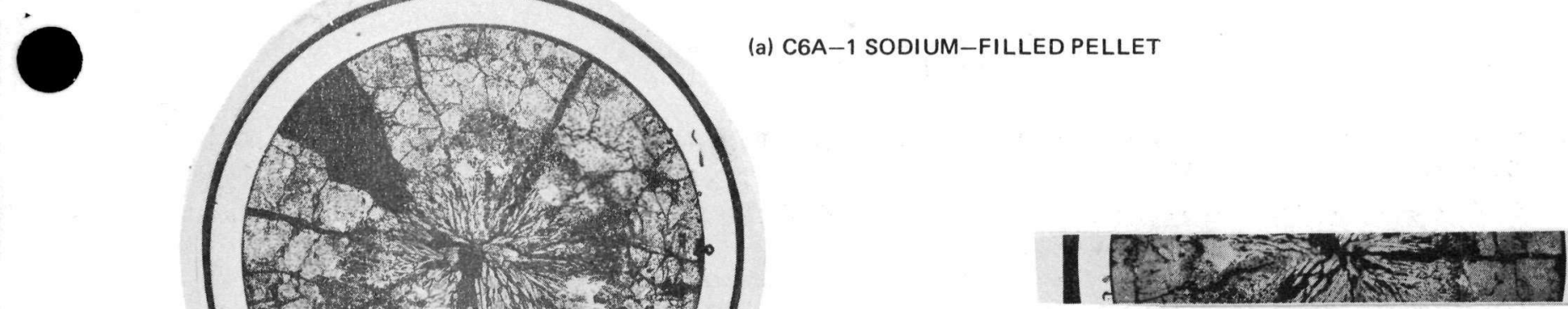

10X ETCHED A540-12

10X POLISHED A540-02

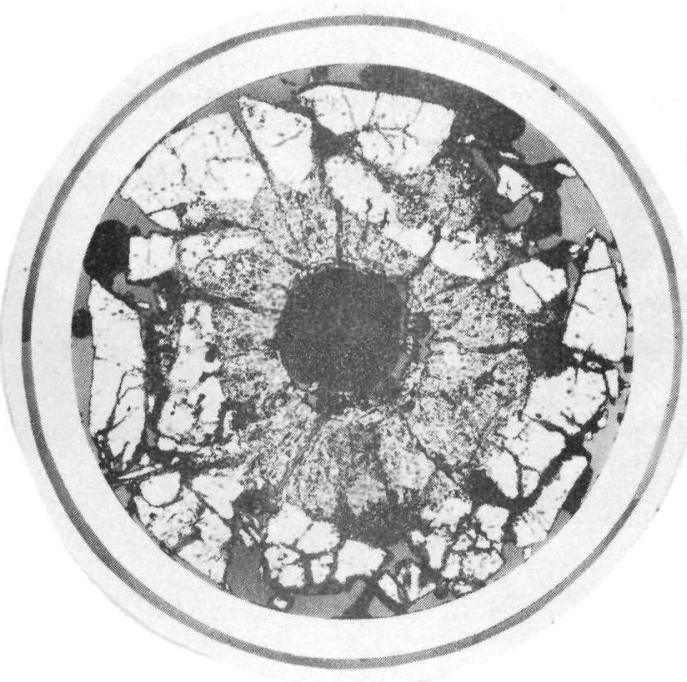

(b) C6A-2 SODIUM-FILLED POWDER

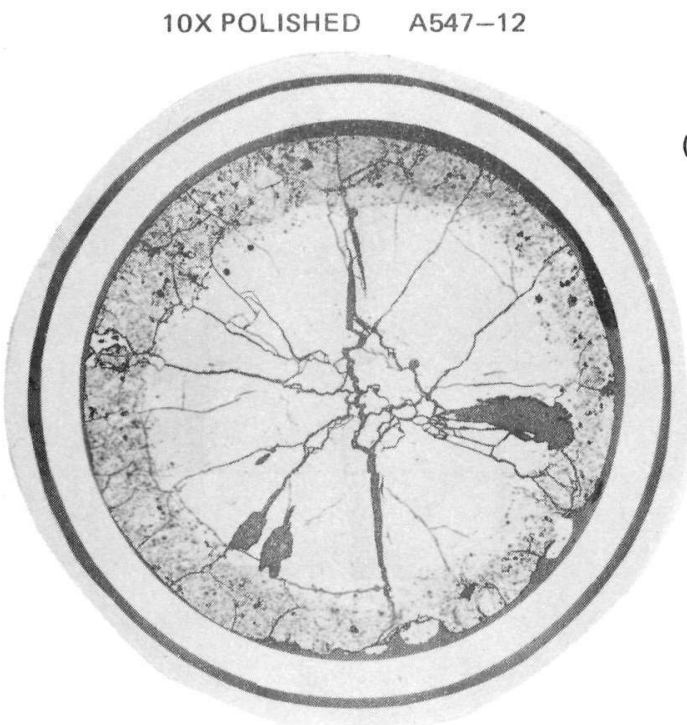

(c) C6A-3 GAS-BONDED PELLET

10X ETCHED A547-11

10X POLISHED A535-02

Figure 3.25 Capsule C6A Transverse Fuel Sections Illustrating the Effects of Sodium Within the Fuel Pin, TT 1312-485 MW-sec 


\section{REFERENCES}

1. Field, J. H., Experimental Studies of Transient Effects in Fast Reactor Fuels, Series / UO $\mathrm{U}_{2}$ Irradiations, November 1962, (GEAP-4130).

2. Hanson, J. E., Field, J. H., and Rabin, S. A., Experimental Studies of Transient Effects in Fast Reactor Fue/s, Series II, Mixed Oxide ( $\left.\mathrm{PuO}_{2}-\mathrm{UO}_{2}\right)$ Irradiations, June 1965, (GEAP-4804).

3. Hanson, J. E., and Rabin, S. A., Experimental Studies of Transient Effects in Fast Reactor Fuels, Series III, Pre-Irradiated Mixed Oxide $\left(\mathrm{PuO}_{2}-\mathrm{UO}_{2}\right)$ Irradiations, Interim Report, Steady-State Irradiations, September 1965, (GEAP-4819).

4. Hanson, J. E., and Field, J. H., Experimental Studies of Transient Effects in Fast Reactor Fuels, Series III, Pre-Irradiated Mixed Oxide $\left(\mathrm{PuO}_{2}-\mathrm{UO}_{2}\right)$ Irradiations, Final Report, Transient Irradiations, July 1967, (GEAP-4469).

5. Thomas, G. R., and Field, J. H., Transient Overpower Irradiation of Axially Restrained, Zero-Burnup, Fast Reactor Fuel Specimens, September 1969, (GEAP-13562).

6. Hikido, T., and Field, J. H., Molten Fuel Movement in Transient Overpower Tests of Irradiated Oxide Fuel, September 1969, (GEAP-13543).

7. Freund, G. A., et al., Design Summary Report on the Transient Reactor Test Facility (TREAT), July 1960, ANL-6034.

8. O'Neill, G. L., et al., Experimental Studies of Sodium Logging in Fast Ceramic Reactor Fuels, September 1963 (GEAP-4283).

9. Field, J. H., et al., An Evaluation of the Effect of Design and Operating Variables on SEFOR Fuel and Cladding, December 1967, (GEAP-5304).

10. Sodium-Cooled Reactors - Fast Ceramic Reactor Development Program. Thirty-Fourth Quarterly Report, February 1970-April 1970, General Electric Company, GEAP-10028-34.

11. Skirvin, S. C., User's Manual for the Standard THTD Computer Program on GE-600 Series Computers, General Electric Research and Development Center, May 1969, (69-C-205).

12. Golden, G. H., et al., Thermophysical Properties of Sodium-Recommended Values, Reactor and Fuel-Processing Technology, Vol. 11, No. 1, Winter 1967-1968. 


\section{APPENDIX A \\ EQUIPMENT DESCRIPTION}

\section{A.1 FUEL SPECIMEN AND CAPSULE DETAILS}

\section{A.1.1 Design Criteria}

The design of the test capsule was based on the following criteria:

- An external capsule configuration that would permit installation in the TREAT reactor core by substitution for a TREAT fuel element.

- Sufficient heat capacity to absorb all the heat generated by the fuel specimen during transient irradiations in TREAT.

- Calorimeter-type construction so that the heat generated by the fuel specimen during transient irradiation may be obtained from temperature measurements.

- Sufficient strength and integrity to sustain internal pressures and provide containment for fuel and other capsule materials.

\section{A.1.2 Fuel Element}

The fuel specimens (Figure $\mathrm{A} .1$ and $\mathrm{A} .2)$ were composed of $10 \% \mathrm{U} 235$ enriched $\mathrm{UO}_{2}(\mathrm{O} / \mathrm{M}=2.000)$ pellets and powder. Since fuel melt volume was the failure criteria for these tests, the composition $\left(\mathrm{UO}_{2} \mathrm{vs} \mathrm{UO}_{2}-\mathrm{PuO}_{2}\right)$ was not a major factor. Also, the use of slightly enriched fuel alleviated any flux depression effects. The pellets were pressed and sintered to approximately $89 \%$ of theoretical density (corresponds to a smeared density of approximately $83.0 \%$ ). The powder was vibratory compacted to a density of approximately $82.0 \%$. The parameters are summarized in Table A.1. The fuel was contained in a 0.250 -inch (nominal) o.d. tube, 0.015 -inch wall thickness, Type-316 stainless steel with a total fuel length of 24 inches. A 15 -inch long natural $\mathrm{UO}_{2}$ blanket was located between the top end of the fuel and the fission gas plenum. A 2 -inch $\mathrm{UO}_{2}$ insulator was located below the fuel. The blankets and insulators were composed of pellets in all cases.

\section{A.1.3 Test Capsules}

The test capsule assembly shown in Figure A.3 was designed to be dimensionally compatible with a TREAT fuel element. The significant feature of this capsule assembly was the placement of three inner capsules side-by-side in a triangular array. This arrangement provided a way to compare directly the performance of sodium-filled pins to a reference gas-bonded pellet pin. Since the $\pm 20 \%$ uncertainty in repeatability of TREAT transients was effectively eliminated, the formulation of definitive conclusions on comparative studies was greatly facilitated. The combination of low fuel enrichment (minimize flux depression) and relatively wide inner capsule spacing minimized interaction between pins. In addition, the small solid angles subtended by each pin did not cast neutronic "shadows" on adjacent pins.

Instrumentation of each inner capsule consisted of chromel-alumel thermocouples (TC) and were located as follows (see also Figure A.3):

1. Three TCs in the sodium-filled annulus between the heat sink and the capsule wall.

2. Four TCs in the sodium-filled annulus between the heat sink and fuel pin cladding.

Prior to transient operation, the test specimens were electrically heated to approximately $400^{\circ} \mathrm{F}$ to simulate coolant temperature conditions in an FCR. The heater element for this purpose was wrapped around the exterior surface of the inner capsules. A layer of insulation was placed between the inner capsule and outer shell (pressure vessel) to minimize the loss of heat while approaching equilibrium temperature.

\section{A.2 SODIUM FILL SYSTEM}

The requirement to sodium fill larger length (24-inch) fuel specimens and powder fuel pins necessitated the design and fabrication of a high pressure sodium fill system. A schematic of the system is shown in Figure A.4. The installed system is shown in Figure A.5.

The system was designed to accommodate fuel pins up to five feet long (overall length) and sodium fill pins at pressures up to $500 \mathrm{psig}$ and at temperatures up to $750^{\circ} \mathrm{F}$. The high pressure capability was required for the powder fuel specimens. The volume of sodium transferred to each fuel pin was monitored primarily by checking the sodium level in the level or fill tube. The fuel pin was also checked to determine whether the sodium level was as specified. Table A.2 summarizes fill system operating parameters and estimated sodium volumes for the Series 6 fuel specimens. 
Table A.1

SERIES VI FUEL PIN PARAMETERS

\begin{tabular}{|c|c|c|c|c|c|c|c|c|}
\hline \multirow[b]{2}{*}{ Specimen * } & \multirow[b]{2}{*}{$\begin{array}{c}\text { Fuel } \\
\text { Composition }\end{array}$} & \multirow[b]{2}{*}{$\%$ U.235 } & \multirow[b]{2}{*}{ Fuel Type } & \multirow{2}{*}{$\begin{array}{c}\text { Diametral } \\
\text { Gap (in) } \\
\text { (min) } \\
\text { (max) }\end{array}$} & \multicolumn{2}{|c|}{ Density and } & \multirow{2}{*}{$\begin{array}{l}\text { Cladding } \\
\text { I.D. (in) } \\
\text { (min) } \\
(\max )\end{array}$} & \multirow{2}{*}{$\begin{array}{c}\text { Fuel Pellet } \\
\text { Diameter (in) } \\
\text { (min) } \\
\text { (max) }\end{array}$} \\
\hline & & & & & $\begin{array}{l}\text { Pellet } \\
(\min ) \\
(\max )\end{array}$ & $\begin{array}{c}\text { Smeared } \\
(\min ) \\
(\max )\end{array}$ & & \\
\hline C6A-1 & $100 \% \mathrm{UO}_{2}$ & 10.011 & Pellet & $\begin{array}{l}0.0076 \\
0.0084\end{array}$ & $\begin{array}{l}88.3 \\
89.7\end{array}$ & $83.0 t$ & $\begin{array}{l}0.2201 \\
0.2205\end{array}$ & $\begin{array}{l}0.2121 \\
0.2125\end{array}$ \\
\hline C6A.2 & $100 \% \mathrm{UO}_{2}$ & 9.946 & Powder & - & - & 81.9 & $\begin{array}{l}0.2201 \\
0.2204\end{array}$ & - \\
\hline C6A-3 & $100 \% \mathrm{UO}_{2}$ & 10.011 & Pellet & $\begin{array}{l}0.0076 \\
0.0085\end{array}$ & $\begin{array}{l}88.0 \\
89.7\end{array}$ & $82.6 t$ & $\begin{array}{l}0.2200 \\
0.2206\end{array}$ & $\begin{array}{l}0.2121 \\
0.2124\end{array}$ \\
\hline $\mathrm{C} 6 \mathrm{~B}-1$ & $100 \% \cup_{2}$ & 10.011 & Pellet & $\begin{array}{l}0.0078 \\
0.0084\end{array}$ & $\begin{array}{l}87.5 \\
89.7\end{array}$ & $83.0 t$ & $\begin{array}{l}0.2201 \\
0.2205\end{array}$ & $\begin{array}{l}0.2121 \\
0.2123\end{array}$ \\
\hline $\mathrm{C} 6 \mathrm{~B}-2$ & $100 \% \mathrm{UO}_{2}$ & 9.946 & Powder & - & $\cdot$ & 82.0 & $\begin{array}{l}0.2201 \\
0.2205\end{array}$ & - \\
\hline C6B-3 & $100 \% \mathrm{UO}_{2}$ & 10.011 & Pellet & $\begin{array}{l}0.0078 \\
0.0084\end{array}$ & $\begin{array}{l}88.3 \\
89.7\end{array}$ & $82.5 t$ & $\begin{array}{l}0.2202 \\
0.2205\end{array}$ & $\begin{array}{l}0.2121 \\
0.2124\end{array}$ \\
\hline
\end{tabular}

* -1 and -2 are sodium-filled specimens, -3 is gas-bonded pellet specimen

$\dagger$ (average)

Table A.2

FILL SYSTEM OPERATING PARAMETERS AND SODIUM VOLUMES

$\begin{array}{lccc}\begin{array}{c}\text { Fuel } \\ \text { Specimen }\end{array} & \begin{array}{c}\text { Fill } \\ \text { Pressure } \\ \text { (psig) }\end{array} & \begin{array}{c}\text { Fill } \\ \text { Temperature } \\ \text { ( }\end{array} & \begin{array}{c}\text { Estimated } \\ \text { Volume } \\ \text { (cc) }\end{array} \\ \text { C6B-1 (Pellet) } & 50 & 400 & 4.02 \\ \text { C6B-2 (Powder } & 230 & 400 & 4.05 \\ \text { C6A-1 (Pellet) } & 10 & 400 & 4.28 \\ \text { C6A-2 (Powder) } & 230 & 400 & 3.90\end{array}$




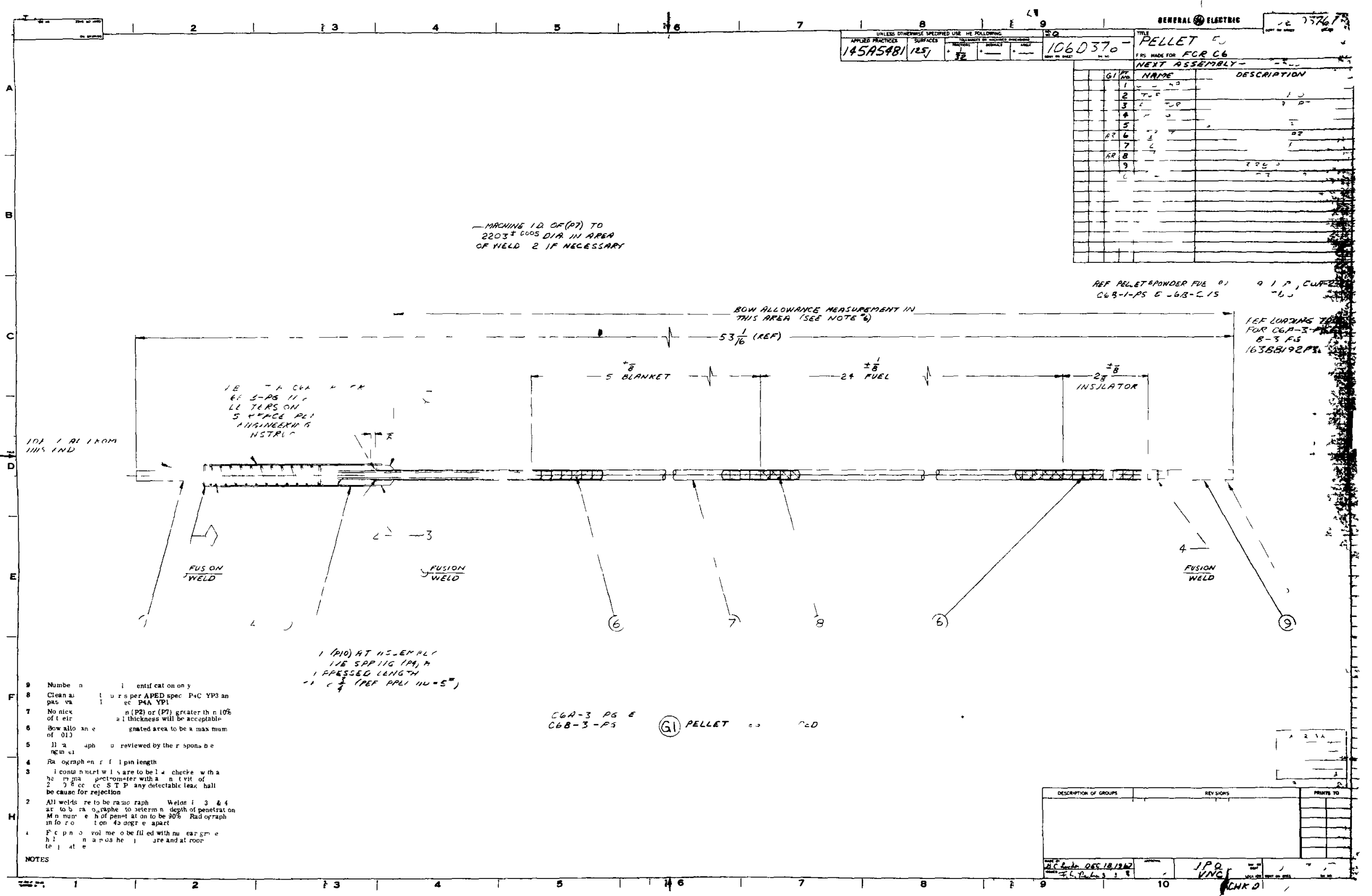

Figure A.2 Series 6 Fuel Pin Assembly, Gas-Bonded Specimens 


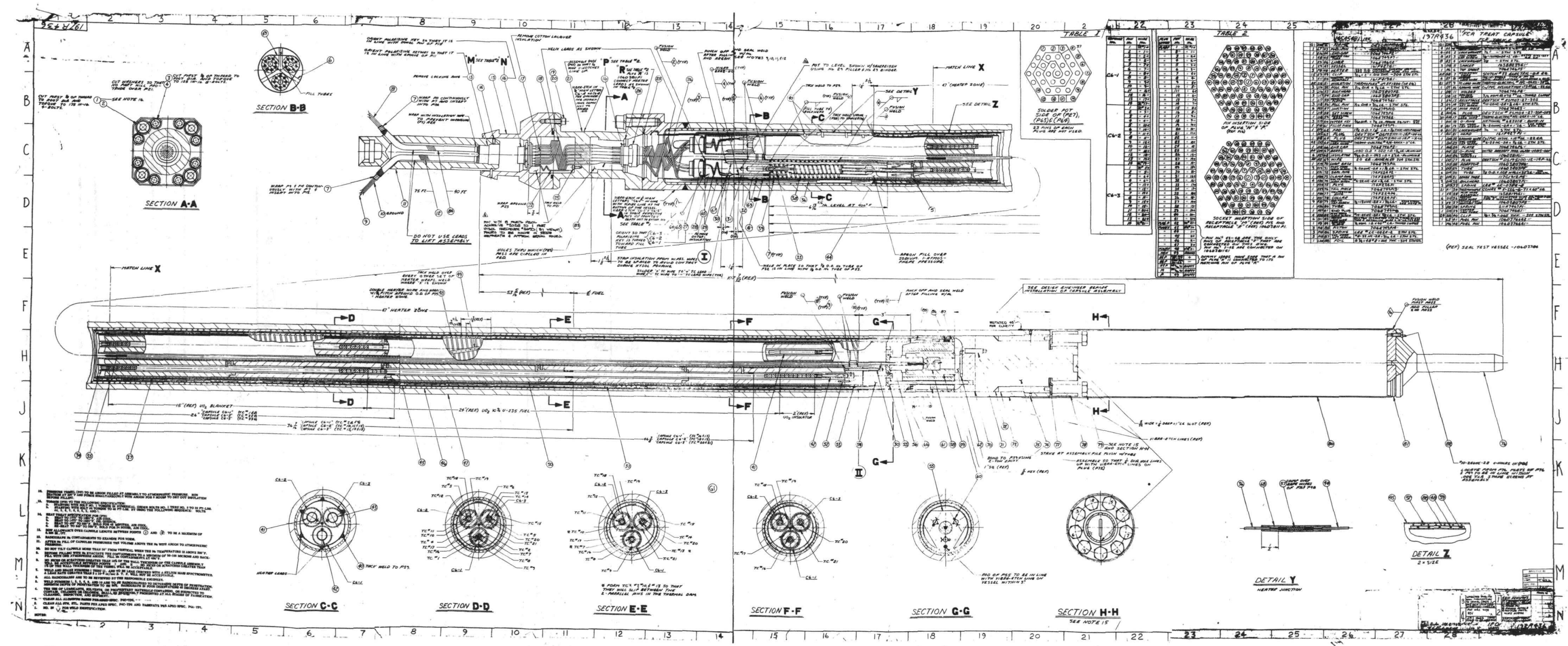




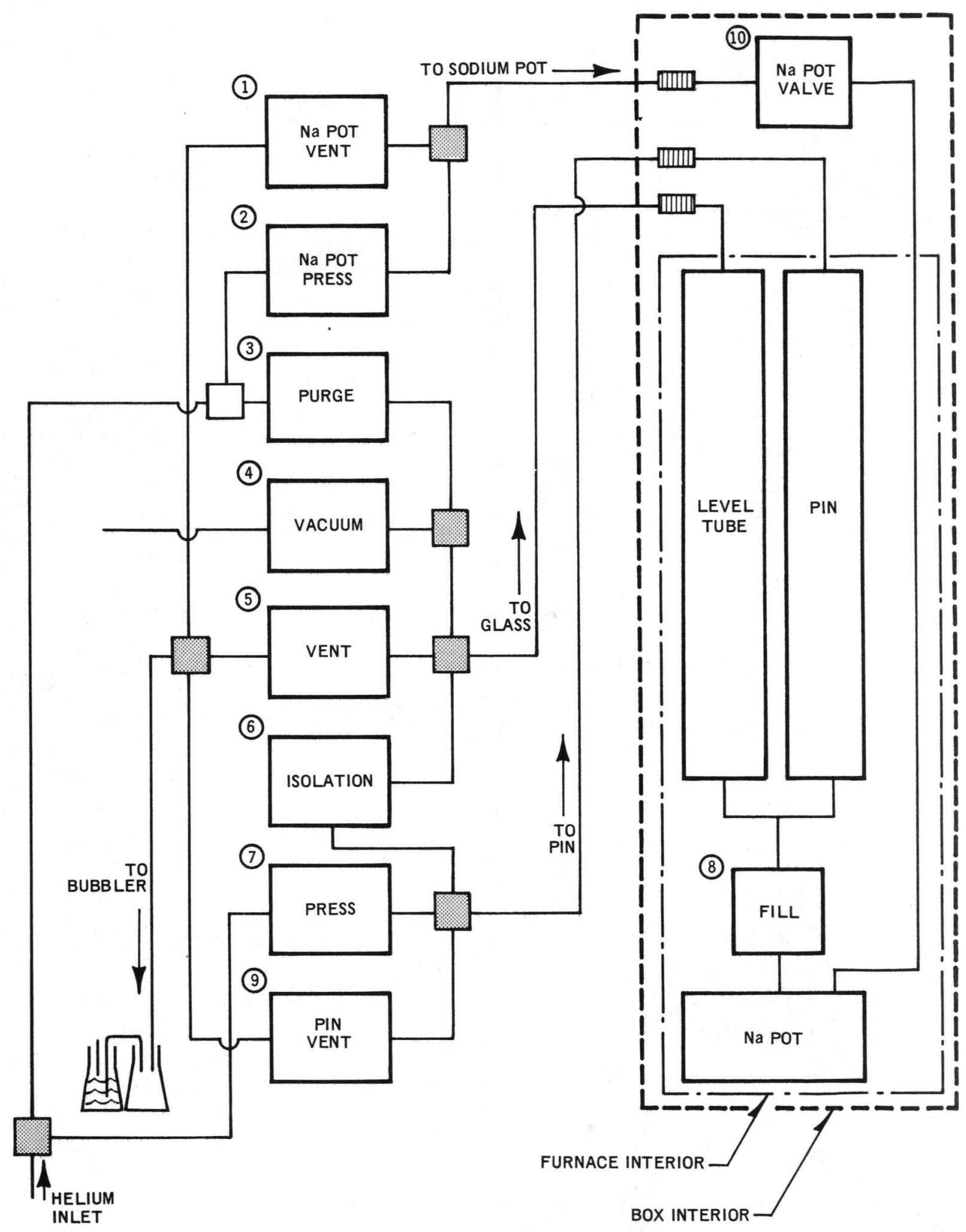

Figure A.4 High Pressure Sodium Filling System, Schematic 

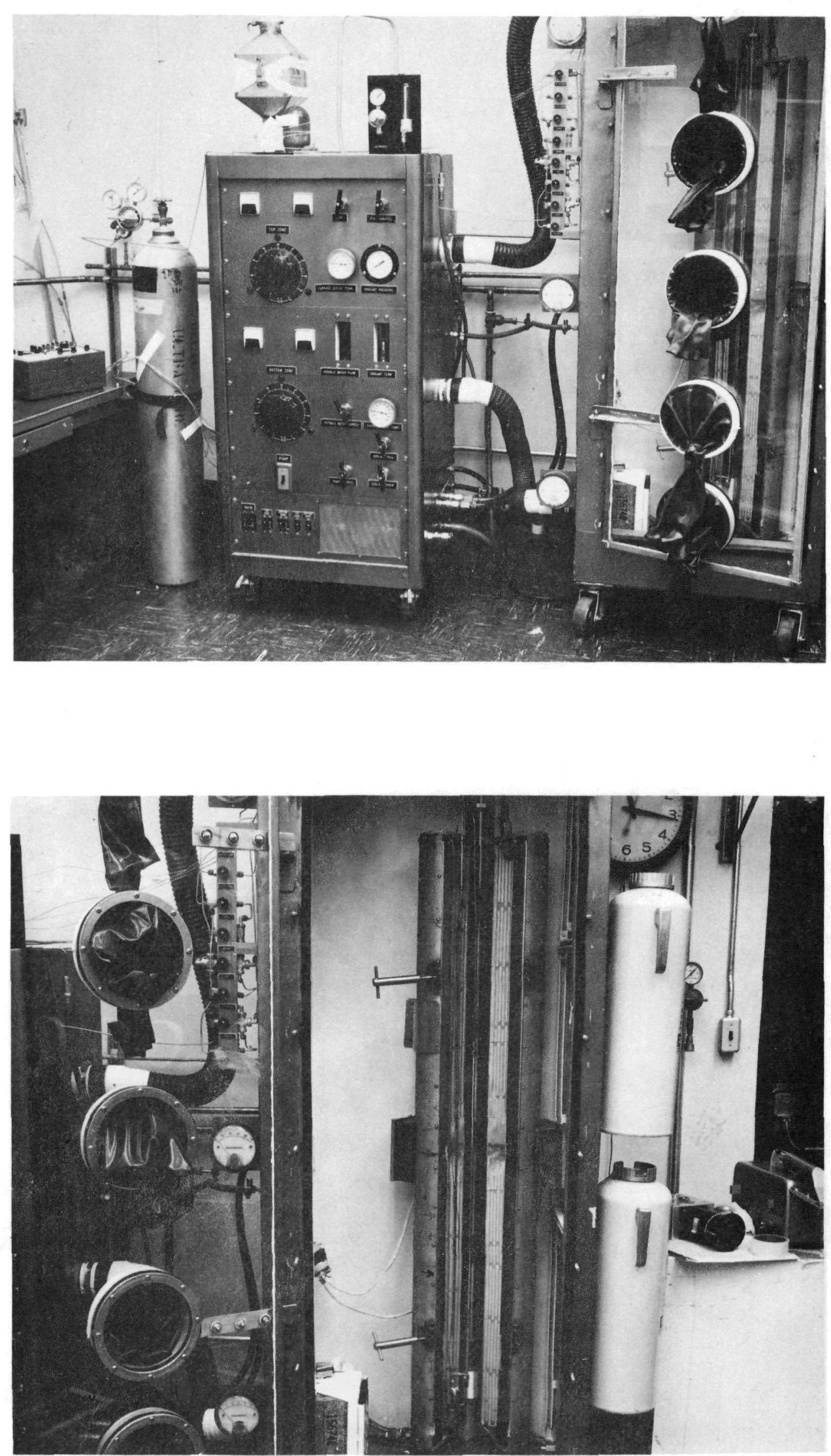

Figure A.5 System For Filling Fuel Pins With Sodium 
-

$r$

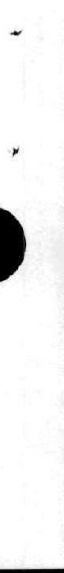




\section{APPENDIX B}

\section{SERIES 6 HEAT TRANSFER ANALYSIS MODEL}

The basic model (THTD heat transfer code ${ }^{11}$ ) utilized for the analysis and design of the Series 6 test transients is shown in Figure B.1. The basic model was used for all three cases (sodium-filled pellet and powder, and gas-bonded pellet), varying only the fuel physical properties. The effect of the sodium was simulated in the model by employing (1) a large gap conductivity coefficient $\left(10,000 \mathrm{Btu} / \mathrm{h}-\mathrm{ft}^{2}{ }^{\circ} \mathrm{F}\right)$ and $(2)$ an effective fuel conductivity greater than the fuel itself. A gap coefficient of 1000 to $2000 \mathrm{Btu} / \mathrm{h}-\mathrm{ft}^{2} .^{\circ} \mathrm{F}$ was used for the gas-bonded specimens.

For the sodium-filled powder fuel pins, it was assumed that sodium was evenly distributed within the fuel section. The fuel-sodium "mixture" would then have an effective fuel conductivity greater than the fuel itself. Conductivity values were arbitrarily increased until reasonable correlation with thermocouple data was achieved. Since the fuel melt (if any) radius for these pins could not be determined, the thermocouple data correlation was the only criterion considered.

The sodium-filled pellet fuel pins were analyzed initially assuming the sodium was confined primarily to the fuel-cladding gap (gas-bonded fuel conductivity combined with large gap coefficient). The large gap coefficient was not sufficient to achieve a reasonable correlation with thermocouple data. Subsequent calculations assumed either one or both of the outer two nodes (95 and 105) were saturated with sodium. The conductivity of these two nodes were then arbitrarily increased (gas-bonded fuel conductivity values increased by a factor of 10) until measured and calculated temperature data and melt radii were in substantial agreement. Each specimen was analyzed independently. The spacing and fuel composition (see Appendix A) was such that interaction (flux skewing) between pins was assumed to be negligible. Examination of test data and fuel microstructures verified the validity of this assumption.

Although interaction between pins was negligible, the effects of flux depression in the individual pins themselves were evident in the calculated fuel temperature-time histories within each pin. The fuel center temperatures initially lagged slightly behind temperatures nearer the fuel surface. Consequently, portions of the fuel toward the surface reached the melting point before the fuel center. This is shown graphically in Figures B.2 through B.5. The integrated and instantaneous power curves for the two test transients, TT 1308 and TT 1312, are shown to establish a time reference for the graphs.

The development of the fuel temperature history (TT 1308) for the gas-bonded pellet specimen, C6B-3, is partially shown in Figure B.3 (see also Figure B.1). At time $t=2.0$ seconds, nodes 5 through 75 have reached the melting temperature of $5150^{\circ} \mathrm{F}$ and have partially progressed through the heat of fusion. Note that the outer nodes have slightly higher melt fractions. At $t=2.25$ seconds, nodes 5 through 65 are completely molten with fuel temperatures still reflecting the effects of flux depression. In subsequent time steps, the temperature profile gradually becomes parabolic. The melt fractions of the outer nodes gradually decrease as seen in node 75 from $t=2.0$ seconds to $t=2.25$ seconds. Based on these calculations, the fuel melt radius would be greater than 0.070 inch. Converting the melt fraction of node 75 to a radial distance would indicate an equivalent melt radius of $\cong 0.076$ inch or a calculated melt radius in the range of 0.070 to 0.076 inch. This compares very well with the estimated (from fuel microstructure) melt radius of 0.070 to 0.075 inch.

The trends shown in Figure B.4 for the other gas-bonded pellet specimen (C6A-3, TT 1312) are similar to that calculated for C6B-3. The melt radius would be in the range of 0.080 to 0.083 inch, which again compares well with the estimated melt radius of 0.082 to 0.085 inch.

Shown for comparison in Figure B.5 are calculated results for the sodium-filled pellet specimen, C6A-1. The sodium had a decided effect on the fuel temperature profile and melt radius when compared to the gas-bonded case. The calculated melt radius would be in the range of 0.050 to 0.058 inch compared to the estimated melt radius of 0.053 to 0.058 inch. 

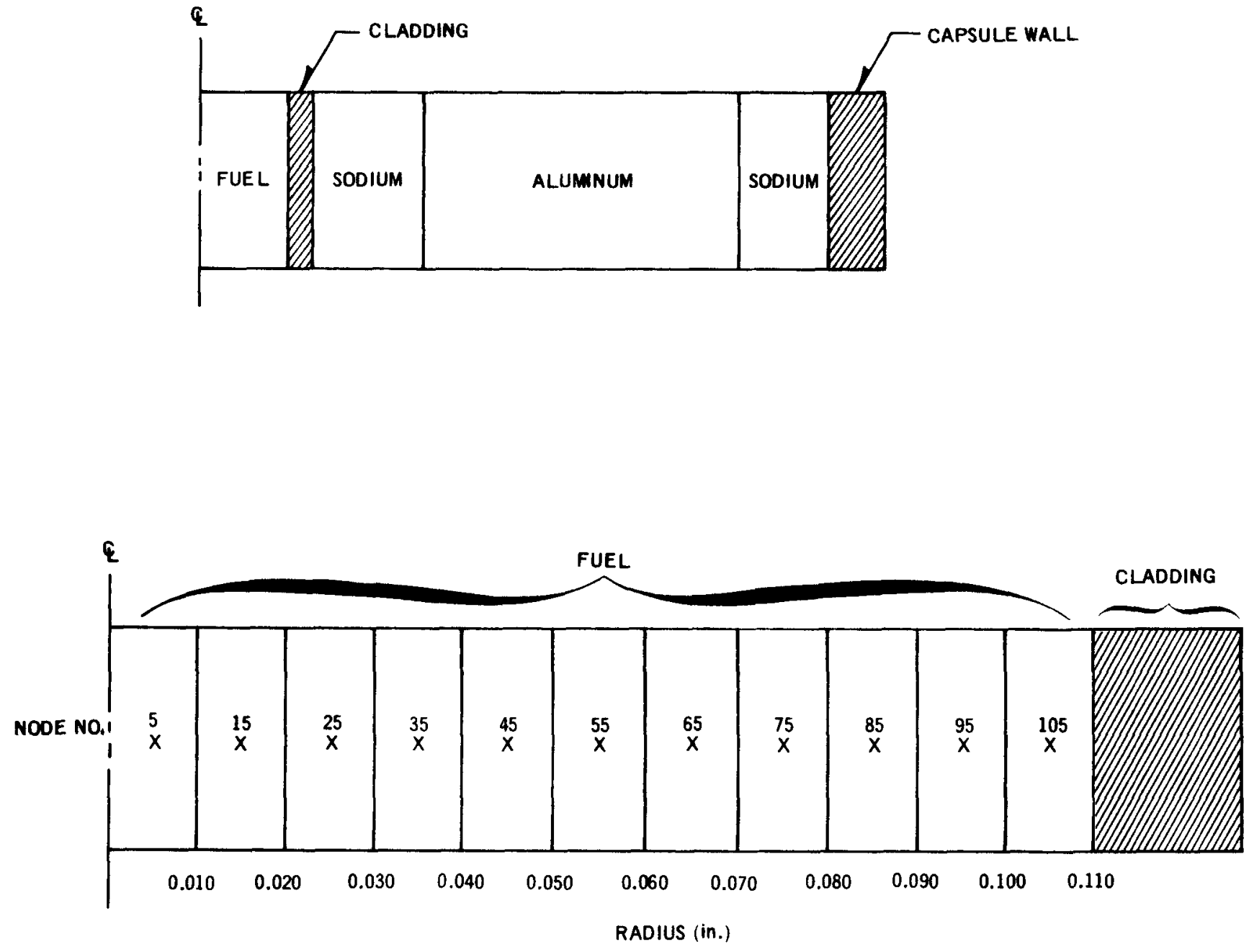

Figure B.1 Series 6 Heat Transfer Analysis Model Schematic 

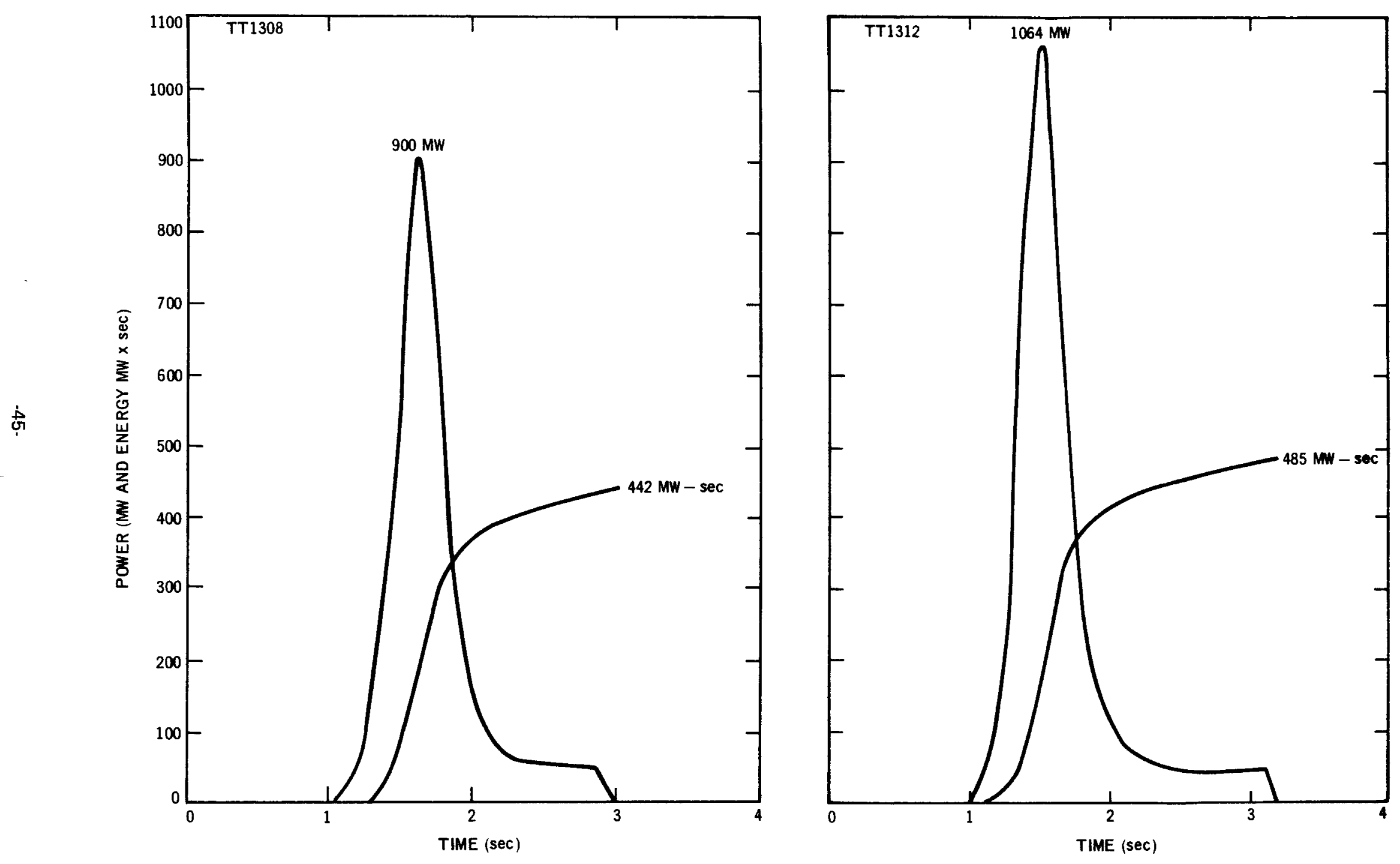

Figure B.2 Instantaneous and Integrated Power Versus Time for TT 1308 and TT 1312 

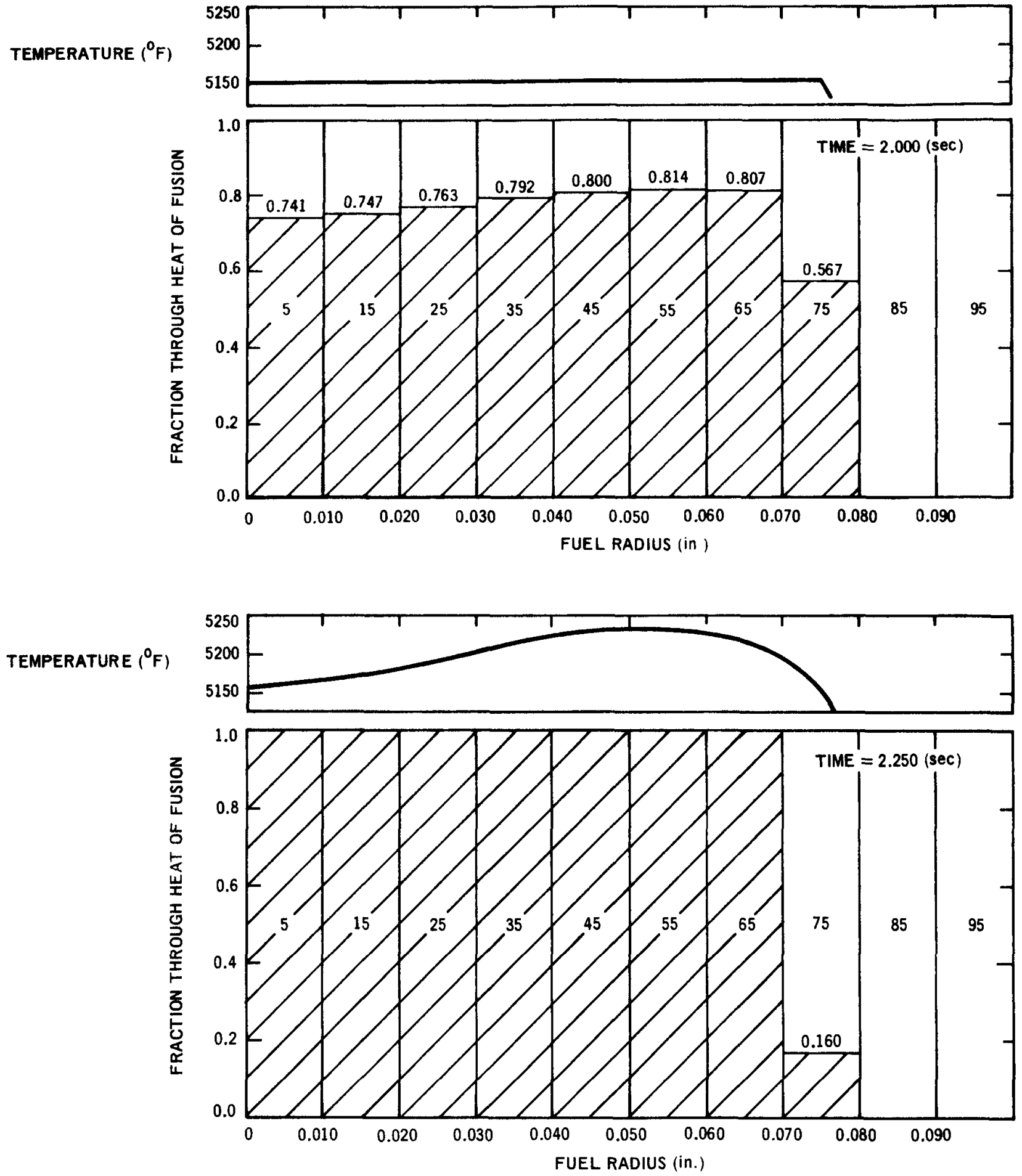

Figure B.3 Calculated Fuel Melt Radius, Fuel Melt Fraction, and Fuel Temperature Versus Time, C6B-3 (Gas-Bonded Pellet), TT 1308-442 MW-sec 

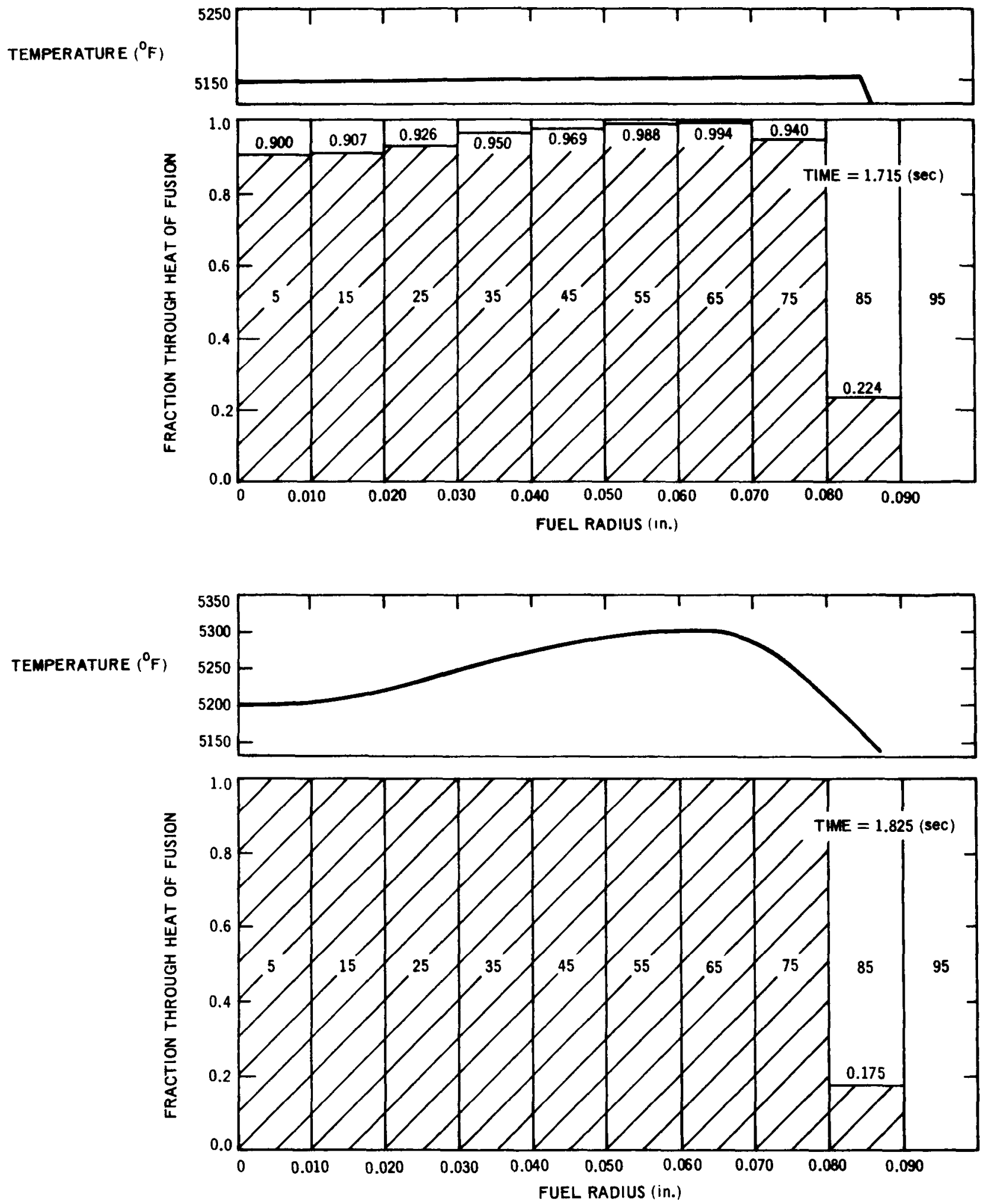

Figure B.4 Calculated Fuel Melt Radius, Fuel Melt Fraction, and Fuel Temperature Versus Time, C6A-3 /Gas-Bonded Pellet), TT 1312-485 MW-sec 

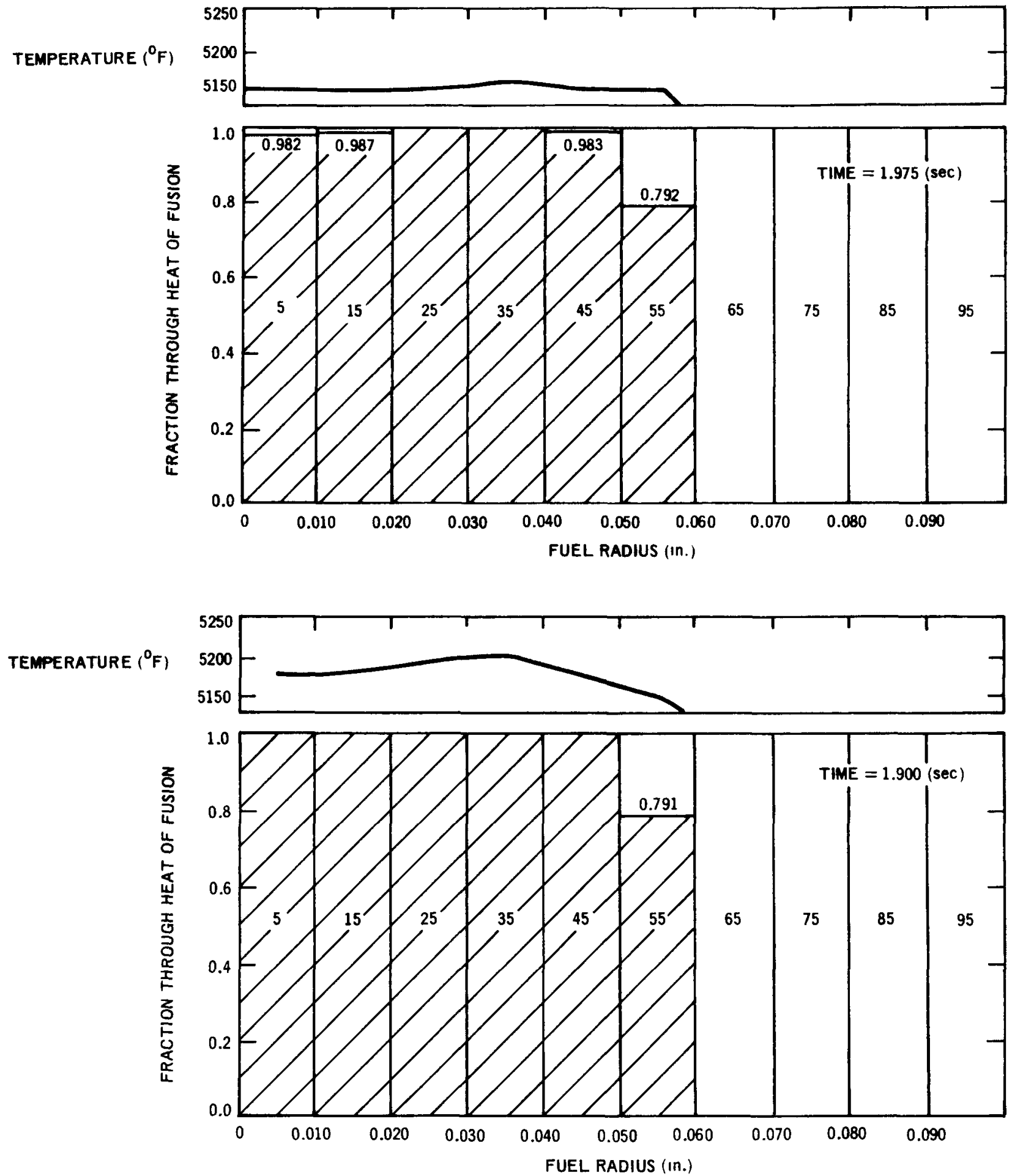

Figure B.5 Calculated Fuel Melt Radius, Fuel Melt Fraction, and Fuel Temperature Versus Time, C6A-1 (Sodium-Filled Pellet), TT 1312-485 MW-sec 


\section{APPENDIX C SODIUM VAPOR FORMATION AND EXPANSION CALCULATIONS}

The presence of sodium in the fuel section during transient overpower conditions offers a potential for generation of extreme pressures as a result of sodium vapor formation and expansion. Such potential conditions existed for the sodium-filled powder fuel specimen (C6A-2) but gross cladding failure did not occur, although cladding deformation of 0.0025 to 0.004 inch was measured. Calculations were performed to estimate the volume of sodium vaporized and the pressure generated to cause the observed deformation.

Based on test observations and consideration of possible alternatives, a closed system analogy was felt to be the most realistic approach for this analysis. The "closed system" in this case was assumed to be the fuel section enclosed by cladding, upper blanket, and lower insulator. Previous experiments $1,2,4,5$ have shown there is virtually no communication to the gas plenum during a transient. In a closed system, some vaporization could occur but would be limited to the void volume available. Self pressurization would occur until the vapor volume was less than the available void volume. The limiting pressure in the system would therefore be the sodium saturation pressure equivalent to zero sodium vapor generation. The maximum sodium temperature was assumed to be equal to the calculated maximum fuel volume average temperature of $3800^{\circ} \mathrm{F}$. From reference 12 , the saturated sodium vapor pressure is estimated to be $\cong 2900 \mathrm{psi}$. This is well below the calculated burst pressure of the cladding $\cong 6500 \mathrm{psi} @ 1350^{\circ} \mathrm{F}$ ).

The pressure to cause the observed cladding deformation can be calculated from:

$$
P=\frac{\sigma t}{R\left(1-\frac{v}{2}\right)}
$$

Where

$$
\begin{aligned}
\mathrm{t} & =\text { wall thickness }=0.015 \text { inch } \\
\mathrm{R} & =\text { Radius }=0.127 \text { inch }(4 \mathrm{mil} \text { diametral, deformation }) \\
\nu & =\text { Poisson's ratio }=0.26 \\
\sigma & =\text { Effective stress }=22,200 \mathrm{psi} \\
\mathrm{P} & =\frac{(22,200)(0.015)}{(0.127)\left(1-\frac{0.26}{2}\right)} \\
& =3020 \mathrm{psi}
\end{aligned}
$$

The maximum capsule cover gas pressure external to the pin (assumed to be at the same peak temperature as cladding) was calculated to be approximately 50 psi. The total internal pressure then was:

$$
\begin{aligned}
P & =3020+50 \\
& =3070 \mathrm{psi}
\end{aligned}
$$

The estimated pressure of 3070 psi to cause the observed cladding deformation is seen to be approximately equal to the saturated sodium vapor pressure of $\cong 2900$ psi, lending credence to the "closed system" approach.

For the estimated pressure, the necessary volume of sodium vaporized can be calculated. Sodium boiling temperature of $1745^{\circ} \mathrm{F}\left(2205^{\circ} \mathrm{R}\right)$ corresponds to capsule pre-heat conditions of $435^{\circ} \mathrm{F}$ and cover gas pressure of 1.7 atm. The available void is estimated from the initial fuel void volume plus the additional volume resulting from extension of the fuel column and cladding deformation minus the initial sodium volume in the fuel pin. 


$$
\begin{aligned}
& P \quad 3070 \mathrm{psi}=209 \mathrm{~atm}=1.7 \mathrm{~atm} \frac{\text { Vapor Volume }}{1.85 \mathrm{cc}} \frac{4260^{\circ} \mathrm{F}}{2205^{\circ} \mathrm{R}} \\
& \text { Vapor volume }=\frac{(209)(1.85)(2205)}{(1.7)(4260)} \\
& \approx 118 \mathrm{cc}
\end{aligned}
$$

The weight of sodium liquid would be:

$$
\begin{aligned}
\text { Vapor volume } & =118 \mathrm{cc}=\frac{\text { wt. liquid }}{0.0005 \mathrm{gm} / \mathrm{cc}} \\
\text { Wt. liquid } & =(118 \mathrm{cc})(0.0005 \mathrm{gm} / \mathrm{cc}) \\
& =0.059 \mathrm{gm}
\end{aligned}
$$

The volume of sodium liquid represented would be:

$$
\begin{aligned}
\text { Wt. liquid } & =0.059 \mathrm{gm}=(0.72 \mathrm{gm} / \mathrm{cc}) \text { Vol. liquid } \\
\text { Vol. liquid } & =\frac{0.059 \mathrm{gm}}{0.72 \mathrm{gm} / \mathrm{cc}} \\
& \approx 0.08 \mathrm{cc}
\end{aligned}
$$

This volume of liquid constitutes less than $3 \%$ of the total volume of sodium initially in the fuel pin.

Fuel column extension occurred in both sodium-filled powder fuel specimens (C6B-2, C6A-2) possibly as a result of sodium expansion. In order to demonstrate the potential for fuel column extension resulting from liquid sodium expansion, the following analysis is presented.

Assuming the sodium remains a liquid (i.e., does not vaporize), the volume expansion can be estimated and then converted to an equivalent length. Sodium conditions assumed in the preceding vaporization and expansion calculations for specimen C6A-2 were again employed.

$$
\begin{aligned}
& \text { (Volume sodium) hot }=\left(\text { Volume sodium) initial }\left(\frac{\text { density, cold }}{\text { density, hot }}\right)\right. \\
& \begin{aligned}
V & =2.7 \mathrm{cc} \frac{0.896 \mathrm{gm} / \mathrm{cc} 435^{\circ} \mathrm{F}}{0.454 \mathrm{gm} / \mathrm{cc} @ 3800^{\circ} \mathrm{F}} \\
& =5.32 \mathrm{cc} \\
\Delta V & =5.32 \mathrm{cc}-2.7 \mathrm{cc} \\
& =2.62 \mathrm{cc}
\end{aligned}
\end{aligned}
$$

An equivalent length can now be estimated from the sodium volume increase and the cladding volume (including deformation) per unit length.

$$
\begin{aligned}
L, \text { equivalent } & =\frac{2.62 \mathrm{cc}}{0.645 \mathrm{cc} / \mathrm{in}} \\
& \approx 4.1 \text { inches }
\end{aligned}
$$

The increase in length is seen to be much greater than the $\cong 2$ inches measured from neutron radiographs. The calculations show that thermal expansion alone would have been sufficient to cause the observed fuel column extension. This simplistic analysis does not consider other contributing factors such as friction, partial vaporization and condensation, sodium distribution, etc.; and was intended only to indicate the potential effect of thermal expansion of the liquid sodium. 


\section{ACKNOWLEDGMENTS}

This experimental work was a joint effort of several working groups and many individuals of the Breeder Reactor Development Operation, Vallecitos Atomic Laboratory (Irradiation Processing Operation), and the staff of the TREAT facility at NRTS.

The work was performed within the Fast Ceramic Reactor Development Program, Task C-1, Safety Experimentation, under the guidance of W. E. Baily, PA-10 Project Engineer, and J. H. Field, Task C-1 Leader.

Major contributions to the program were made by:

Program Management at IPO

R. H. Eymann, F. J. Lamphere, and M. E. Carino

Design Engineering at IPO

G. L. Stimmell, G. C. Linder, and N. C. Shirley

Fuel Fabrication

M. L. Thompson and T. E. Lannin

Irradiation in TREAT

J. F. Boland and Staff

Post-Irradiation Examinations

D. L. Zimmerman, R. E. Smith, and S. M. Lukezic

\section{Computer Calculations}

R. C. Thompson and J. L. Scofield 
